\title{
THE DETERRENT EFFECT OF THE DEATH PENALTY: EVIDENCE FROM BRITISH COMMUTATIONS DURING WORLD WAR I
}

\section{DANIEL L. ChEN}

Abstract During World War I, the British military sentenced over 3,000 soldiers to death, but only executed $12 \%$ of them; the others received commuted sentences, unbeknownst to soldiers at the time. I verify that variation in commutations and executions is consistent with a random process. Using this result, I identify the effect of executions on subsequent desertions. There is limited evidence that executing deserters deterred absences, while executing Irish soldiers, regardless of the crime, spurred absences, particularly Irish absences. These results are consistent with legitimacy of authority affecting why people obey the law.

Keywords: Compliance, Legitimacy, Deterrence

JEL codes: N44, K14, K42, P48

\footnotetext{
*Daniel L. Chen, daniel.chen@iast.fr, Toulouse School of Economics, Institute for Advanced Study in Toulouse, University of Toulouse Capitole, Toulouse, France. I would like to thank assistance and comments from Julian Putkowski, the British National Archives, Gerard Oram, Sonya Hymer, Markus Loecher, and many colleagues. Work on this project was conducted while I received financial support from the European Research Council (Grant No. 614708), the Ewing Marion Kauffman Foundation, the Institute for Humane Studies, Agence Nationale de la Recherche, the John M. Olin Foundation, PetrieFlom Center, the Swiss National Science Foundation (Grant Nos. 100018-152678 and 106014-150820), and the Templeton Foundation (Grant No. 22420).
} 
The deterrent effect of the death penalty is a classic legal and economic question that remains unanswered (Nagin and Pepper, eds 2012; Ehrlich 1975, Donohue and Wolfers 2005). What makes causal estimates challenging is that locations that allow the death penalty differ from those without it in ways that independently affect levels of crime, and executions are frequently delayed and hidden from the public (Katz et al. 2003). Yet, as one economist stated, "if I was allowed 1,000 executions and 1,000 exonerations, and I was allowed to do it in a random, focused way ... I could probably give you an answer" to the question of whether the death penalty deters crime $1^{1}$ Such a scenario is thankfully unlikely to occur, but the use of the death penalty in the British Army during World War I provides a close approximation. This paper uses the quasi-random application of the death penalty in the British Army during WWI to test whether executions deterred desertion.

Section 1 provides historical background on the use of the death penalty by the British Army during WWI. British Army executions for desertion during WWI were designed for maximum deterrence. They were immediate, brutal, and often carried out by fellow soldiers from the deserter's battalion. Convinced of the deterrent power of the death penalty Oram 2003, pp. 39, 69; Putkowski and Sykes 2007, p. 11; Babington 1983 p. 19), British military officers sentenced over 3,300 soldiers to death, but only about $12 \%$ of them were executed (Figure 1). Commanders were reluctant to execute soldiers who might still make some contribution (Oram 2003, pp. 2, 4; Moore 1975, p. 70) and were wary of popular anger at home among the British public. Historians assess the death penalty to have been a pitiless lottery $2^{2}$ Soldiers whose sentences were commuted, typically to prison terms or hard labor after the war, returned to the trenches (Oram 2003, p. 69). Soldiers were unaware of death sentences unless executions were carried out Graham-Harrison, ed 1907, p. 318-9).

Section 2 presents the eleven data sources that I digitize and link together. The British kept detailed administrative records, which survived WWII. Court martial records were not released for 75 years, but since their release historians have pieced together (1) a general account of death sentences, executions, and commutations (Oram 2003). I link this data to absentee lists collated after roll call every morning and circulated among the military police searching for deserters. Lists are preserved in the British National Archives in (2) surviving war diaries, (3) Police Gazettes, and (4) handwritten trial registries of deserters. I link these data by military unit and date using the (5) Order of Battle $\left\lfloor^{3}\right.$ which

\footnotetext{
1"Does Death Penalty Save Lives? A New Debate," The New York Times, Nov. 18, 2007. The quote is from Justin Wolfers.

${ }^{2}$ Email on December 24, 2007 from Gerard Oram.

${ }^{3}$ Order of Battle. The Long, Long Trail (Baker 1996). Retrieved from http://www.1914-1918.net/oob.htm.
} 


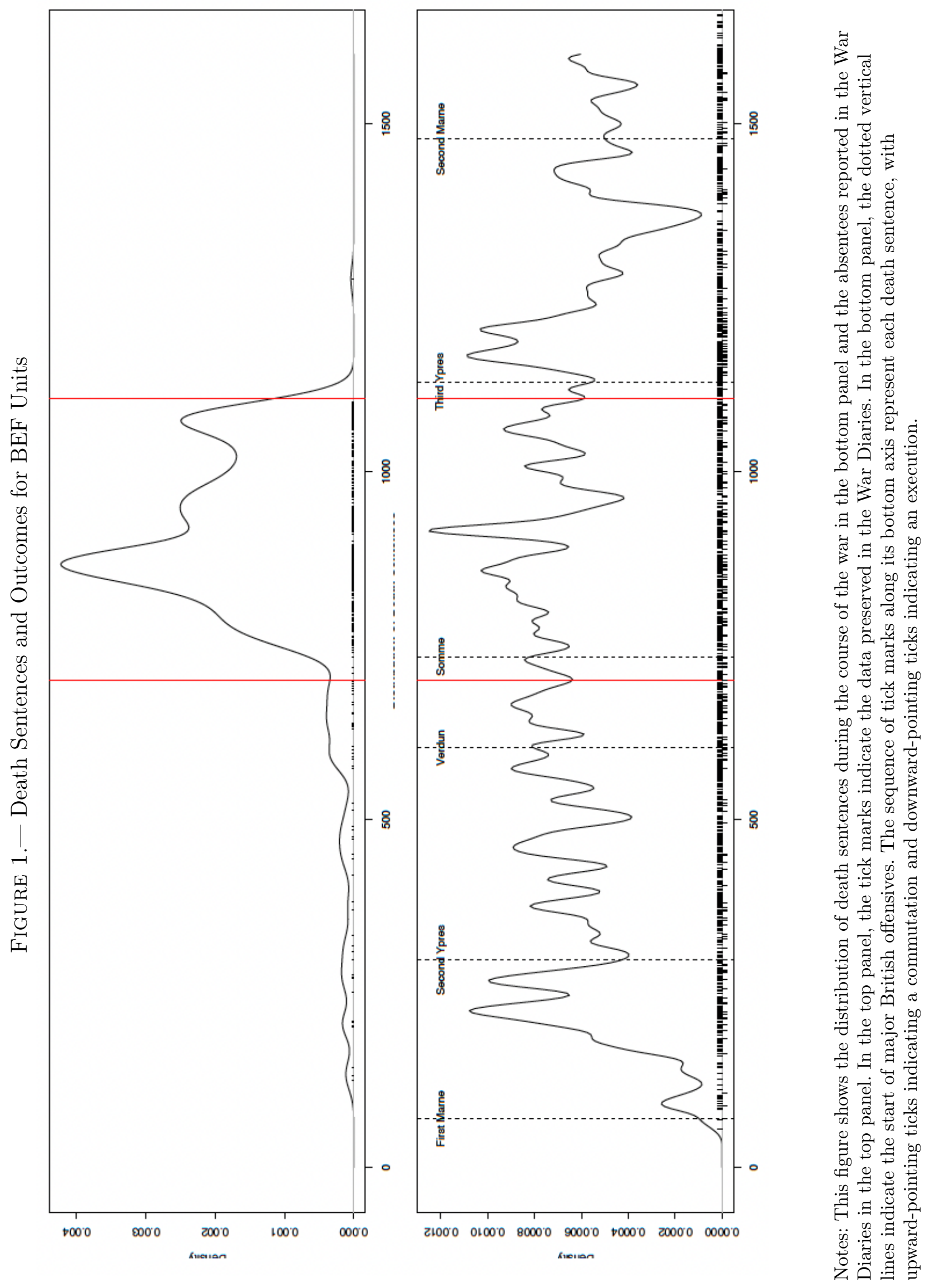


I digitize to obtain troop movements, both physical and organizational (e.g., battalions moving to another division). I employ the (6) Soldiers Died in the Great War database of all casualties to measure point-in-time unit combat danger. The Order of Battle of Divisions provides (7) commanding officers at each unit level and date and (8) lists of battles for each division, which I use to point-in-time geolocate each military unit. Additional covariates, such as soldiers' birthdates, enlistment dates, enlistment location, and birthplace, are preserved in (9) surviving portions of the Service and Pension Records, which I link by soldier's name to the other datasets. I use (10) a dictionary of Irish surnames to identify soldiers of probable Irish ethnicity. A fuller account of the assessment of probable Irish ethnicity can be found in Appendix C. Finally, I use the (11) Medal Rolls Index, which contains virtually all soldiers who served, to validate the use of the surname dictionary vis-à-vis official statistics regarding Irish enlistment. $\mathrm{f}^{4}$

Section 3 quantitatively assesses execution randomness. Some historians believe in strong randomization, but others argue that Irish soldiers, non-commissioned officers, and those seen as physically weak or undesirable were more likely to be executed (Oram 2003 , pp. 9, 56, 61, 74). Others surmise that certain units were targeted due to a perceived lack of discipline (Babington 1983, Putkowski and Sykes 2007, p. 17; Putkowski and Dunning 2012, p. 212). I show that execution decisions are uncorrelated with Irish ethnicity, rank, and age. They are also uncorrelated with unit-level casualties, desertion, execution rates, commanding officers' fixed effects and ethnicities, timing with respect to major battles, distance to the coast or to Germany, seasonality, and army type. I show the sequence of execution decisions within a unit is statistically indistinguishable from a random string of $1 \mathrm{~s}$ and 0s. In doing so, I consider metrics of the Commander-in-Chief, who made the final decision on every case, targeting perceived indiscipline (long runs of executions), feeling that certain units were "due" for an execution (negative autocorrelation), and addressing "groups of bad apples" (positive autocorrelation). Irish execution decisions are also consistent with randomization. My analysis sample includes 466 Irish and 1,942 non-Irish death sentences.

Section 4 adopts the language of potential outcomes. I observe what happened in a particular Army division following an execution - I would like to know what would have happened if that same unit had instead experienced a commutation (Rubin 1974). However, the within-unit design means that each division is essentially serving as its own control. This method is problematic if past events in a unit's history continue to affect

\footnotetext{
${ }^{4}$ Some government sources quote national statistics that refer to Irish birthplace, while others refer to Irish regiments. Secondary references are not always clear, so I follow the historical citations to the original source.
} 
FIGURE 2.- Local Execution Rate by Division (War Diaries)

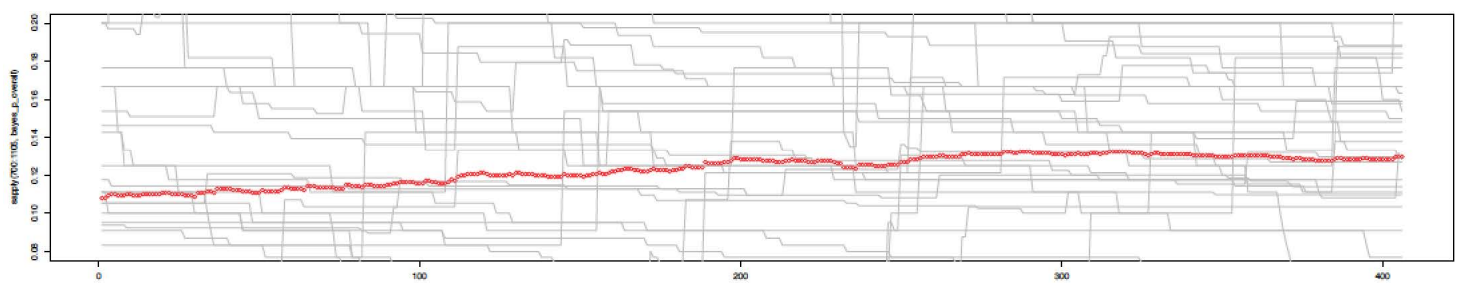

Notes: This figure shows the execution rate of each division in grey and the global execution rate in red.

outcomes in later time periods. I thus develop three sets of analyses. The first set of analyses assumes a strong form of SUTVA (stable unit treatment value assumption) where only the most recent event matters. This is a reasonable assumption based on theoretical models of rational inattention (Sims 2003, Caplin and Dean 2015) and experimental research indicating that recent events are more salient (Kahneman 2011; Hertwig et al. 2004). The second set of analyses assumes a weak form of SUTVA and parametrically models the effects of previous events. I explore whether or not the results are robust to the inclusion of prior events in the model specification. The third set of analyses uses a day-by-day maximum likelihood model of absence, where each unit has some probability of experiencing absence on any particular day. I model how this probability depends on all previous death sentences, their outcomes, and distance in time. This combines the effects of salience and the execution rate. Notably, the distribution of past events identifies exogenous shifts in the local execution rate in different divisions (Figure 2), which can be used to separately estimate the impact of the execution rate across many events from the impact of execution salience from the most recent event. To put this in context, random variation in the sequence of executions creates exogenous temporal variation in how strictly the death penalty is applied, which is similar to existing studies using variation in execution rates (but summarized critically by Donohue and Wolfers (2005)).

Section 5 presents results. There is mixed evidence of deterrence. If there is deterrence, it is the execution rate that deters, not the execution salience of the most recent event. Executing Irish soldiers spurred absences. After Irish executions, 19\% of the immediately following absences were Irish whereas after a British execution, $11 \%$ of the following absences were Irish. After commutations of either ethnicity, $13 \%$ of the next absences were Irish, consistent with randomization and ignorance of commutations. Irish executions increased the hazard of absence by 2-3 fold out of a median time of 2 weeks to the next absence. The day-by-day framework also finds that Irish executions spurred Irish desertions. 
The differences between this study and contemporary criminal justice scenarios are vast, so a more nuanced understanding of the differences is warranted for rigorous policy lessons. One way to interpret the British experience during WWI is that it provides a low-bar test for the death penalty. Finding a deterrence effect would not be a strong argument, leaving aside moral issues, that the death penalty is good policy. Yet a negative result showing limited deterrent effect might have more policy salience since executions took place almost immediately in order to maximize their deterrent effect. Desertion is also certainly not analogous to murder, and criminals weighing potential homicide are certainly different from soldiers weighing military desertion. However, all else being equal, more executions should deter absences, and if we find this not to be the case, then we may doubt a behavioral response to the death penalty, which is still in place for over $60 \%$ of the world's population, despite a lack of empirical evidence regarding the deterrent effect of the death penalty. I provide evidence of a mechanism for legal compliance beyond deterrence that has received less attention in the formal literature, and that state-imposed sanctions can undermine state legitimacy.

\section{Historical Background}

Most British military officers from the WWI-era viewed the death penalty as essential to military discipline. Senior officers were, seemingly without exception, death penalty advocates, viewing it as their only recourse for maintaining discipline after corporal punishment, such as branding and public flogging, was outlawed as inhumane in the preceding half-century (Oram 2003, p. 38). Sir Neville Macready, a former B.E.F. (British Expeditionary Force) Adjutant-General, stated "if you abolish the death penalty you might as well abolish the army" (Jahr 1998, p. 314). General Horace Smith-Dorrien wrote, "There is a serious prevalence of desertion to avoid duty in the trenches...and I am sure that the only way to stop it is to carry out some death sentences" Oram 2003, p. 69; Babington 1983 , p. 19). Courts martial records also indicate many instances where military officers claimed that "the state of discipline" of a particular unit "requires an example" (Department of Foreign Affairs 2004, p. 38). In order to deter desertion, the military made the death penalty common knowledge among soldiers. "It is well known ... to all soldiers that desertion in the face of the enemy is liable to be punished by death" (Under-Secretary of State for War Harold Tennant, quoted in The Western Gazette, 28 January 1916). When recruits joined the army, they were informed that the death penalty could be inflicted upon anyone who deserted while on active service (Moore 1975, p. 50).

Importantly, soldiers were not informed of impending offenses.5 Infantry soldiers would typically have only 12-24 hours advance notice, even if they were in the front line or reserve

\footnotetext{
${ }^{5}$ Email from Putkowski on October 8, 2008.
} 
trenches. Furthermore, when it came to a major offensive, they could not have anticipated anything about the scale of preparations until the artillery barrage commenced, at which point there would no doubt about what was going to happen ${ }^{6}$ Casualty totals were kept strictly secret (Ferguson 2008). There was relatively little opportunity for a solier to desert on the front, as they would be immediately shot. Moving soldiers was like "squeezing toothpaste" and the battle police were always close behind. $]^{7}$ Barriers prevented men from leaving the front line and collected stragglers for redistribution to their unit's forward position (Sheffield 1996, p. 76). Deserters who were shot immediately would not be in the lists of absentees collated after morning roll calls in my data, which were more likely to include the soldiers who deserted overnight.

Battalions generally rotated 10 days in the front, 10 days in reserve, and 10 days at rest every month ${ }^{8}$ Because soldiers were moved at night 9 the best opportunity to desert was during rotation. Although some soldiers fled during battle and were later convicted of desertion (Babington 1983), desertion can be considered relatively cool-headed in contrast with another capital crime, cowardice in the face of the enemy (Peaty 1999, p. 199).10 The fact that desertions often took place far from the front line has led some historians to conclude that desertions cannot be deemed the result of shell shock (Peaty 1999, pp. 200, 201, 206). A soldier who went missing during battle would generally be categorized as a straggler and not as a deserter 11

Practically all absentees were caught and arrested within two weeks. ${ }^{12} \mid \mathrm{Jahr}(1998,2014)$ confirms this conclusion by analyzing the infantry records of seven divisions. He finds that many soldiers' absences ended after 1 or 2 weeks, but a few soldiers were not caught for at least four weeks. The prevalence of British and French military police in forward areas, and French civilians' general unwillingness to risk helping a deserter, rendered a deserter's apprehension a virtual certainty. ${ }^{13}$ The high rate of apprehension is consistent

\footnotetext{
${ }^{6}$ Email from Putkowski on October 8, 2008.

${ }^{7}$ Conversations with Putkowski, November 24-26, 2011.

${ }^{8}$ Conversations with Putkowski during November 24-26, 2011. The same 1:1:1 ratio ("4 days in the front line, then 4 days in close reserve and finally 4 at rest") is found in The Long, Long Trail (In the trenches. (n.d.). LLT. Retrieved from http://www.1914-1918.net/intrenches.htm), although this varied enormously depending on conditions (e.g., weather and availability of adequate reserve troops). Front line action can be subdivided further. Of the 120 days of front line action a year, "perhaps only 5-10 days were in intensive action [while] 60-100 days involved front-line trench activities without being in action" (The infantry battalion. (n.d.). LLT. Retrieved from http://www.1914-1918.net/whatbatt.htm). ${ }^{9}$ Conversations with Putkowski during November 24-26, 2011.

${ }^{10}$ For a list of definitions, see Graham-Harrison, ed 1907, p. 267, Retrieved from http://archive.org/stream/manualofmilitary00greauoft\#page/267/mode/1up (with free login).

${ }^{11}$ Email with Putkowski on January 26, 2008.

${ }^{12}$ Email with Putkowski on January 3, 2008.

${ }^{13}$ Most British soldiers only had a rudimentary knowledge of French, and civilians would rarely risk knowingly helping a deserter because it was an offense for which they could be jailed or severely
} 
with available statistics, which indicate that the number of absentees and deserters is close to the number of trials for absentees and deserters. The desertion rate at home and abroad was 10.26 per 1,000 men, ${ }^{14}$ entailing that in an army of 5.4 million serving in France and Flanders, there were roughly 55,400 deserters.15 The estimated number of deserters may be too high, since the fog of war would make it very hard to pin down the true number. In addition, officers were required to report absences to the Police Gazette "as soon as it is known that a soldier has absented himself," 16 which may further increase overcount. Historians are doubtful that officers would conceal absences, because doing so would lay them open to being charged with an offense of violating routine orders. If a deserter was captured far from his unit (e.g., by military police or an officer from another unit), a report would be sent to the commander of the division, and the resulting publicity would require the lower level commander to "acknowledge publicly his soldiers' crimes or to make an example" (Corns and Hughes-Wilson 2007, p. 89).17 Thus if there was overcount of

punished. Deserters were viewed as being, if not dangerous, a nuisance because they were compelled to live off the country, scavenging and stealing food, money, or clothing. Of those deserters who evaded detection for an extended period of time, most either enjoyed assistance from civilians or holed up in one of the larger Army bases. This latter strategy, however, was only successful at the beginning of the war when bases suffered from greater disorganization. Email with Putkowski on January 3, 2008.

14"Post-war statistics show that the overall desertion rate between 1914 and 1918 was 10.26 per 1,000 men - so that in an army of 1 million men, there were over 10,000 absentees ... The size of the problem was already becoming apparent by mid 1915, when instructions were issued by the War Office, drawing attention to the fact that there had been 1,251 desertions from the Expeditionary Force and over 20,000 desertions from the new army, reserve and other regular units." Corns and Hughes-Wilson 2007, p. 216. Since 146,730 members of the army were struck off as deserters from Aug 1914-March 1920 at home and abroad (https://archive.org/stream/statisticsofmili00grea\#page/82/mode/2up. Free login available.), I infer that Corns and Hughes-Wilson (2007) refers to deserters at home and abroad.

${ }^{15}$ This number may be higher if desertion rates were higher in France and Flanders than in the UK or other theatres of war (e.g., Mesopotamia, Egypt and Palestine, Salonika, Italy, and Gaillipoli).

16"When there is good ground for supposing an absentee to have deserted, the report should be rendered within 24 hours after the absence has been discovered, but in no case should it be delayed beyond 5 days." The King's Regulations and Orders for the Army (1914). London: His Majesty's Stationary Office, Para. 514, p. 117. After 21 days, an absentee was presumed to be a deserter and a court of inquiry called regarding "the illegal absence of a soldier." King's Regulations (1914), Para. 673, p. 149.

${ }^{17}$ Apprehension may be even higher due to prosecutorial discretion. There is no direct evidence of officers actively concealing absences, though there is evidence that whenever possible, commanding officers did not report minor infractions outside their regiments (Corns and Hughes-Wilson 2007, pp. 88-90; van Emden 2010, p. 4259 of Kindle e-book). The commanding officer of a unit had wide discretion in any matter of discipline. Under Section 46 of the Army Act, the commanding officer could often deal with a case summarily by selecting a charge that was within his powers to punish (such as "Conduct to the Prejudice of Good Order and Military Discipline", Graham-Harrison, ed 1907, pp. 298-299 (Army Act Section 40), retrieved from http://archive.org/stream/manualofmilitary00greauoft\#page/298/mode/1up. ), and imposing up to 28 days detention, field punishment, or forfeiture of pay, rather than escalating the matter to a court martial. Selective prosecution, whether due to officer whim (Sheffield 1996. Burrage 1930, Turner and Haigh 1969) or limited bandwidth during a major battle, have led some to describe military discipline as "negotiable" (Rubin 2013). However, commander discretion was limited to trivial violations such as a late return back from a pass, drunken behavior, a dirty rifle, or being unshaven on parade. Email with Putkowski on February 20, 2015. 
absences, the true number of absentees and deserters (nominally 55,400) would be closer to the number of trials $(44,395)$ and consistent with deserters being invariably caught. Official records indicate 44,395 courts martial for absentees or deserters, of which 7,361 were for desertion and 37,074 were for absence (The War Office 1922, p. 667), which suggests that at least $80 \%$ were caught. 18

Most desertions in France and Flanders were handled by Field General Courts Martial (FGCM), which were less formal and easier to convene than a full General Court Martial (GCM). The GCM was generally reserved for officers, while the vast majority of deserters were not officers. The FGCM was comprised of at least three officers, the president holding the rank of major or above. The court could only pass a death sentence if all members agreed (Department of Foreign Affairs 2004, p. 7). Prosecution was handled by the accused soldier's adjutant and defense handled by a junior regimental officer. Trials were private (Babington 1983, p. 13), so the typical soldier had little news about death sentences or about deserters until an execution was promulgated. They would therefore be unaware of randomization. Soldiers who deserted in the UK while their unit was based in France and Flanders would be returned to their unit and tried by the FGCM. Typically, these soldiers had failed to return to the front after furlough or after convalescence in the UK.19

The usual defense for desertion was a plea of extenuating circumstances GrahamHarrison, ed 1907). Convicting a soldier for desertion required establishing intent (Corns and Hughes-Wilson 2007, pp. 44-5; Oram 2003, Department of Foreign Affairs 2004, p. 7). Intent to desert would be presumed if there was evidence to indicate intent of not returning (e.g., wearing civilian clothes or failing to report for a key deployment) or if the soldier had been absent for at least 21 days.20 However, "in any case of doubt as to whether [desertion or absence without leave] has been committed, the court should find

\footnotetext{
${ }^{18}$ To put this in historical perspective, only $40 \%$ of deserters during the U.S. Civil War were caught, and deserters faced a negligible risk of death if arrested (Costa and Kahn 2003). 14\% of Union army soldiers deserted during the American Civil War, compared to 1\% for the British Army during World War I. In addition, British Army deserters were not subject to the death penalty during World War II, and the desertion rate was high enough that the Army wanted to reintroduce the death penalty in 1942 but politically could not do so (Bond et al. 2010, p. 213).

${ }^{19}$ There was also the District Court Martial (DCM), which handled UK desertions and absence without leave for draft dodgers after conscription began and those who deserted while their unit was based in the UK. Including these, the total number of soldiers and officers tried for desertion or absence at home or abroad was 126,818 from August 4, 1914 to March 31, 1920 (The War Office 1922, pp. 83-89). The 31,390 desertion and 51,249 absence DCM trials are not my subject. The DCM could only impose a maximum sentence of two years of imprisonment. Historical discussions of sentences for desertion often do not distinguish between DCM and FGCM, and make ambiguous statements, e.g., $46 \%$ of desertion trials in July 1915 resulted in sentences of less than three months (Corns and Hughes-Wilson 2007, p. 216). Citations to War Office statistics may not distinguish between DCM and FGCM trials.

${ }^{20}$ Someone missing for 21 days was presumed to be a deserter (Putkowski and Sykes 2007, pp. 13-14; King's Regulations and Orders for the Army, 1914, Para. 673, p. 149, Para. 514, p. 117).
} 
the accused guilty of the less[er] offense. ${ }^{21}$ The offense of absence did not typically receive the death penalty.

Historians were previously unsure whether soldiers convicted for desertion were invariably sentenced to death in FGCM trials. ${ }^{22}$ Only Jahr (1998)'s statistical analysis of 7 divisions (analyzing a subset of the data source that I digitize) found that all FGCM trials for desertion resulted in conviction, but not every trial resulted in a death sentence.23 My analysis of all 144,609 FGCM trials, of which 13,309 are for desertion, is consistent with Jahr - all but $3 \%$ of soldiers tried for desertion were convicted, but only a small fraction $(13 \%)$ received a death sentence. If the true conviction rate is somewhere near $100 \%$, then the official statistics of 7,361 desertion trials and 2,004 desertion death sentences, suggests a death sentencing rate near $27 \% .24$ Regardless of the reason for issuing a death sentence, what is important for causal identification is whether executions, conditional on death sentences, are quasi-random. To put it another way, commutations serve as a control for factors associated with a death sentence when I examine the impact of executions.

Neither soldiers at the time nor British military historians knew about the low rate of death sentences for convicted deserters. It was policy that convictions for desertion were promulgated: "In a trial of a member of His Majesty's Forces, in which a conviction results, the result is always made public by means of the promulgation of the finding and sentence. 25 However, military regulations stated that informing the offender and no one else of the charge, finding, sentence, and confirmation will be sufficient promulgation to satisfy this rule (Army Act s. 53, note). Moreover, it is unlikely that the 130,936 FGCM convictions were circulated to the entire army - over 90 convictions a day would be unlikely to be remembered if circulated across the entire B.E.F. Widely circulating a large number of convictions that did not lead to death sentences would be inconsistent with repeated admonishments that "on active service the usual penalty is death" for leaving one's post, cowardice, sleeping on one's post, and violence to inhabitants, among other offenses (GRO signed by Smith-Dorrien, Commander of $2^{\text {nd }}$ Army B.E.F. France and Flanders, February 11, 1915 WO 95/646). I have not come across any primary or secondary source mentioning public knowledge of low rate of death sentences for convicted deserters, which would have

${ }^{21}$ Retrieved from http://archive.org/stream/manualofmilitary00greauoft\#page/19/mode/1up. GrahamHarrison, ed 1907 III.20, p. 19. A free login is necessary for viewing.

${ }^{22}$ Email with Putkowski on February 20, 2015, stating the difficulty in knowing what happened to convicted deserters who were not sentenced to death as no one knows and it is otherwise speculation.

${ }^{23}$ By the end of 1917, sentences of over 5 years of imprisonment constituted an increasing share, while death sentences constitute a decreasing share of sentences for desertion.

${ }^{24}$ Since FGCM trial registrars were handwritten and hand-entered, my FGCM numbers may not match the official statistics.

${ }^{25}$ Undersecretary of State for War Military Harold Tennant, Hansard HC Deb. vol. 82 col. 2911,1 June 1916. Retrieved from http://hansard.millbanksystems.com/commons/1916/jun/01/courts-martial-1. 
been incredibly demoralizing if widely known. ${ }^{26}$ Therefore, it seems safe to conclude that soldiers had no way to know that executions were random, while understanding that deserters were executed.

Soldiers convicted of desertion were typically detained while awaiting their final sentence (Babington 1983) ${ }^{27}$ The final decision occurred within two weeks. Commuted sentences were suspended and served after the war, and the soldier was sent back to the trenches.28 Military authorities were always very anxious to ensure that either a spell in jail or detention was not viewed by soldiers as a way of avoiding front line service. Commuted sentences seem to have been unknown to the soldiers.29 Men were not immediately informed of their sentence, just that they had been found guilty. This is supposedly because the sentence only became legal when it was confirmed by the Commander-in-Chief. The judges serving on a court martial had to swear "not to divulge the sentence of the court until it is duly confirmed.' 30 A commutation is not an acquittal. According to the Army Act, s. 54(3) ${ }^{31}$ acquittals were to be read out in open court. However, if convicted a soldier would not know the nature of the conviction or sentence until the night before promulgation (Babington 1983, pp. 15, 17).

Officers would likely not have wanted to publicize commutations for fear of subsequent indiscipline in their unit and concerns over their own career and advancement. If soldiers knew about their own commutation, they would not want others to know, because deserters would face social censure or worse. Official statistics on death sentences, commutations, and executions were not made public until April 1920 Corns and Hughes-Wilson 2007 , p. 407) ${ }^{32}$ Compared to the plentiful primary sources in diaries, letters, and memoirs indicating that executions were known, there is scarce evidence that commutations were known. The two exceptions to the rule are first-hand accounts from the Western

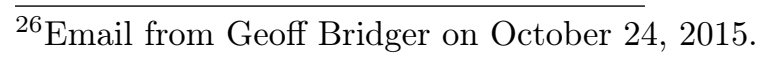

${ }^{27}$ Major Christopher Lowther (Assistant Provost Marshall 1917-1919, Member of Parliament for North Cumberland 1918-1922), Hansard HC Deb. vol. 127, pp. 1603-4, 13 April 1920. Retrieved from http://hansard.millbanksystems.com/commons/1920/apr/13/new-clause-deathsentences-appeal\#column_1603. In some cases, they were immediately thrown back into the trenches (Oram 2003) with the information that the sentence was being reviewed.

${ }^{28}$ Through good conduct, soldiers with sentences to be served after the war could reduce or completely eliminate their sentence. Undersecretary of State for War Military Harold Tennant, Hansard HC Deb. vol. 70, pp. 1212-3, 8 March 1915 (available at http://hansard.millbanksystems.com/commons/1915/mar/08/army-suspension-of-sentences-bill).

${ }^{29}$ Email on December 24, 2007 from Gerard Oram.

30 Graham-Harrison, ed 1907, pp. 318-9, Retrieved from http://archive.org/stream/ manualofmilitary00greauoft\#page/319/mode/1up. A free login is necessary for viewing. 31 Graham-Harrison, ed 1907, p. 322, Retrieved from http://archive.org/stream/ manualofmilitary00greauoft\#page/322/mode/1up. A free login is necessary for viewing.

${ }^{32}$ The Darling Report in Nov. 1919 revealed 89\% of death sentences were commuted but not the numbers.
} 
Front of announcements of commutations of death sentences (Carrington 1965, p. 128; Arthur 2002, p. 173). However, historians are doubtful regarding these accounts ${ }^{33}$ The first memoir is not correct in the recollection of crimes and dates 34 The second account is written in a first-hand perspective but without any primary sources or interviews. A second-hand source attests that a convicted soldier would know about their death sentence before the execution or commutation decision: he would receive a secret envelope with the death sentence along with the information that the sentence was liable to revision by higher authority. ${ }^{35}$ This would likely have only occurred after April 17, 1918 when the Under Secretary for War, Macpherson, announced that those sentenced to death would be informed of the sentence prior to confirmation, rather than after confirmation, as had been the previous policy (Peaty 1999, pp. 208-209).

I have not found any general routine order that mentioned a commutation, or a lesser sentence, for a convicted deserter in primary or secondary sources. There is nothing written of public outrage over commuted death sentences. Executions were likely the only news about death sentences communicated to the typical soldier. The fact that there are no dates of commutations preserved in news circulars provides further evidence consistent with there being no public announcement of commutations of death sentences, and that soldiers had little or no awareness of randomization. ${ }^{36}$ In addition, some soldiers did not believe executions took place at all (Johnson 2015, p. 110), so their beliefs would be updated from a null prior.

After a death sentence was issued, each of that soldier's commanding officers (in the battalion, brigade, division, corps, and army) had to submit his opinion to confirm or commute the sentence based on three factors: 1) a soldier's fighting character and general behavior, 2) general discipline within his unit, and 3) whether the crime had been intentional. Once the paperwork was complete, the Commander-in-Chief made the ultimate decision, which some historians characterize as a "pitiless lottery" (Babington 1983).

Executions typically occurred within a few days after confirmation of the sentence and

\footnotetext{
${ }^{33}$ Email from Putkowski on July 10, 2013.

${ }^{34}$ Carrington reports 3 deserters sentenced to death whose penalties were commuted to 3 months field punishment. But in Carrington's unit, 3 death sentences were given out on June 11, 1916, all for Quitting-not deserting-and all commuted to 2 years hard labor. Three death sentences in other battalions in his regiment were commuted to 3 months field punishment, but the death penalties were handed down on February 7, 1915, before Carrington's unit arrived in France on March 22, 1915.

${ }^{35}$ Christopher Lowther (Assistant Provost Marshall 1917-1919, Member of Parliament for North Cumberland 1918-1922), Hansard HC Deb. vol. 127, pp. 1603-4, 13 April 1920.

${ }^{36}$ The government kept death sentences quiet, and records were not public for 75 years. There are only soldiers' speculations that soldiers who would otherwise have been executed were instead compelled to take part in the forefront of the first available raid or assault on the enemy.
} 
the soldier was informed the following morning. ${ }^{37}$ After confirmation of a death sentence, there would be a special parade of the sentenced man's unit on the evening before the soldier's execution, during which officers from the unit read extracts from the evidence at his trial, the findings and sentence of the court, and the order of confirmation by the Commander-in-Chief. Promulgation was to take place in front of as many men as could be made available (Babington 1983). Often, promulgation involved the entire battalion, sometimes other battalions in the brigade, but probably not the entire division, whose encampment could stretch for 15 miles. Executions were usually carried out by a squad from the victim's battalion, often witnessed by the entire battalion or whatever companies were at hand. ${ }^{38}$ Hearsay, rumor, and newspapers (Sellers 2003) spread the word, once the shocked members of a firing squad shared their feelings with comrades Corns and HughesWilson 2007). The number of references to executions in diaries, letters and memoirs testifies to their impact. 39

\section{Data}

\subsection{Court Martial Death Sentences and Commutation Data My data includes}

all 3,342 death sentences, complete with name, unit, offense, sentencing date, rank, and outcome (execution with date or commutation), reference number in the national archives, age (if the soldier was executed), and theater of war, from August 1914 to September 1923 Oram 2003). Original data sources include War Office (WO) records of the trials of soldiers who were executed (WO 71), registers of field general courts martial (FGCM) trials (WO 213/2-26), and general court martial (GCM) trials (WO 90). In my data, the date refers to the date of the death sentence, which is usually the trial date. It invariably differs from date of execution, which is listed separately. The categories of offenses with the highest number of sentences are: desertion (2,005), sleeping at post (449), cowardice (213), disobedience (120), and murder (118) 40

\footnotetext{
${ }^{37}$ Email from Putkowski on February 4, 2008.

${ }^{38}$ Email from Putkowski on December 24, 2007.

${ }^{39}$ For many soldiers, the experience of witnessing an execution and the fear generated by the rumors circulating in the trenches were a profound part of the wartime experience (Oram 2003). One soldier wrote about shooting his comrades, "It's the only thing I look back on in my military career with shame." A witness to another execution wrote, "I witnessed a shooting. ... It shook me a bit" (Sellers 2003). Another wrote, "The discipline out here is very severe. Men found absent or drunk or found out of bounds are tried by Court Martial and several men have been shot for straying away from camp. One was shot this morning" (Adamson 1997). "The Corporal was shot in Happy Valley. For discipline's sake his whole Battalion was paraded to witness the proceeding. Other Battalions of the Brigade were close by. The Battalion was called to attention, and the firing party were ordered to fire" (Dalton 1986). Sometimes eyewitnesses felt sorry for the firing squad, likely not what the army intended.

${ }^{40}$ The other offenses are: Irish rebellion, quitting post (leaving guard duty), striking a senior officer, mutiny (which could involve absence but was more related to collective action or conspiracy), offense against inhabitant (i.e., rape), espionage, treason, hostile acts, violence, insubordination, absence, sedition, aiding the enemy, casting away arms, possessing firearms, armed robbery, plundering, drunkenness,
} 
Figure 3.- Distribution of Crimes and Death Sentences

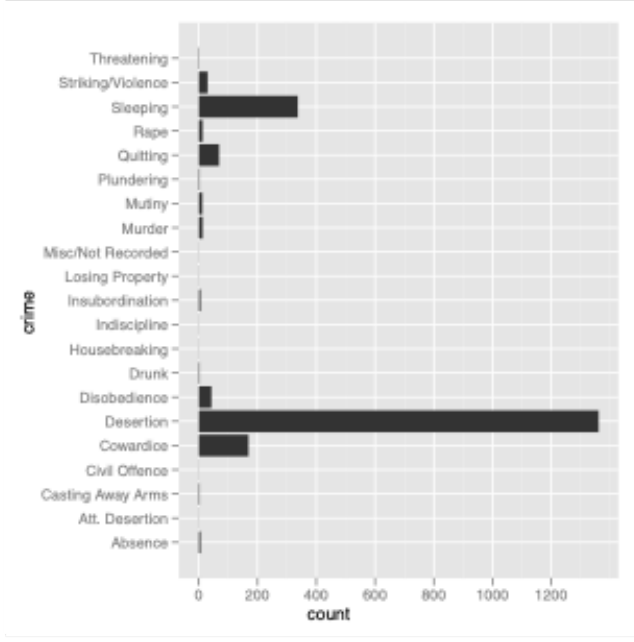

Notes: This figure shows a tabulation of crimes and death sentences.

Final sentences in the dataset are those punishments (if any) ultimately confirmed by the Commander-in-Chief. Of the 3,342 sentences, 2,724 are from the B.E.F., the remainder coming from other countries such as Canada, New Zealand, etc. If the soldier's original death sentence was not confirmed, then the soldier was either given a reduced sentence (hard labor, penal servitude, imprisonment, tied to a fixed object, or reduced in rank) or the sentence was sometimes "quashed" (i.e., vacated). Figure 3 plots the distribution of crimes for those sentenced to death and Figure 4 plots the distribution of crimes for commuted and confirmed death sentences.

2.2 War Diaries Data Absentee lists are partially preserved in monthly war diaries of the Assistant Provost Marshal (APM) for the four-year period from 1914 to 1918. They come from the National Archive Files: a) WO 154/112: Monthly War Diary APM, September 1915 - May 1917; b) WO 154/114: Monthly War Diary APM, August 1914 - November 1916; c) WO 154/8: Monthly War Diary APM 9th Army Corps, December 1916 - May 1918. Lists and descriptions of absentees were printed and circulated with ID Number, Rank, Name, Unit (Battalion Number, Battalion, and Regiment), Date of Absence, Reported by, and Description (usually including age and height, and sometimes also hair color, build, lips, complexion, eyes, teeth, facial hair, and accent; see Figure 5 for a sample image). The War Diaries span four years, but the bulk of what was preserved

threatening a senior officer, offense against martial law, conspiracy, robbery, theft, attempted assassination, attempted murder, attempted desertion, housebreaking, losing army property, pillaging, aiding the enemy while POW, and unspecified/other. In total there are over 30 types of offenses. 
Figure 4.- Distribution of Crimes and Commuted and Confirmed Death Sentences

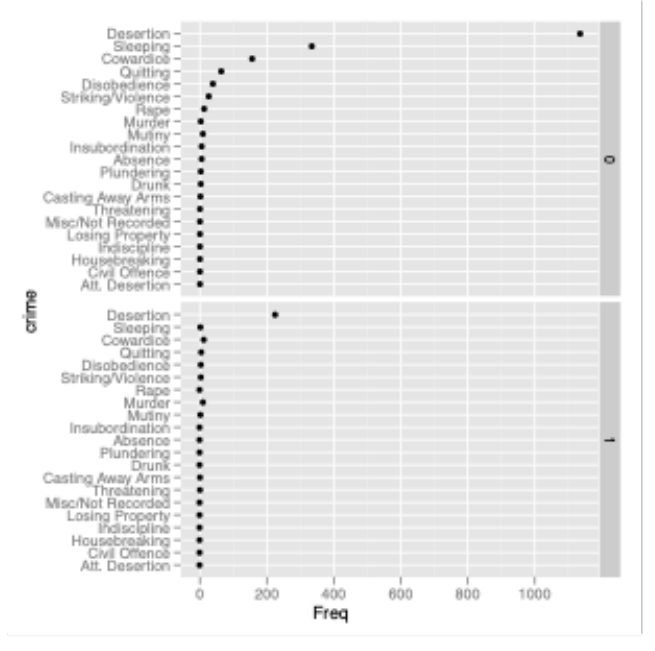

Notes: This figure shows a tabulation of crimes and commuted (top panel) and confirmed (bottom panel) death sentences.

in absentee lists is from July 1916-June 1917.

The absentee list was generated in the following manner 41 The APM was responsible for the military police and the oversight of general military discipline and order. They maintained war dairies and sent reports to the Provost-Marshall at General Headquarters in France. Among his duties for the area of his particular jurisdiction, the APM noted the number of absentees from regiments broadly on a weekly basis. Military units took roll call and attendance every morning (or more frequently). Those not present had to be categorized: killed in action, wounded, missing (prisoner-of-war or wounded), sick or straggler (lost or awaiting return from a "stragglers post" or "battle stop," where they had been gathered up by either regimental or Military Police). After a month, the names of those who were still absent and not accounted for were forwarded to the Provost Marshall at headquarters where the information was collated with other APM reports. The Provost Marshall would aggregate the material and circulate a printed, updated list of the names of men absent for a month by unit for the armies at the front. The APM could then match names and descriptions to any soldier arrested. On occasion, three-month lists seemed to have appeared. These lists revised known absentees making earlier lists redundant.

2.3 Police Gazettes Data A separate absentee list is preserved in the Deserters and Absentees (D\&A) supplement to the weekly Police Gazette from 1914 to 1918. This

\footnotetext{
${ }^{41}$ Conversations with Putkowski and the British National Archives.
} 
FiguRe 5.- War Diaries

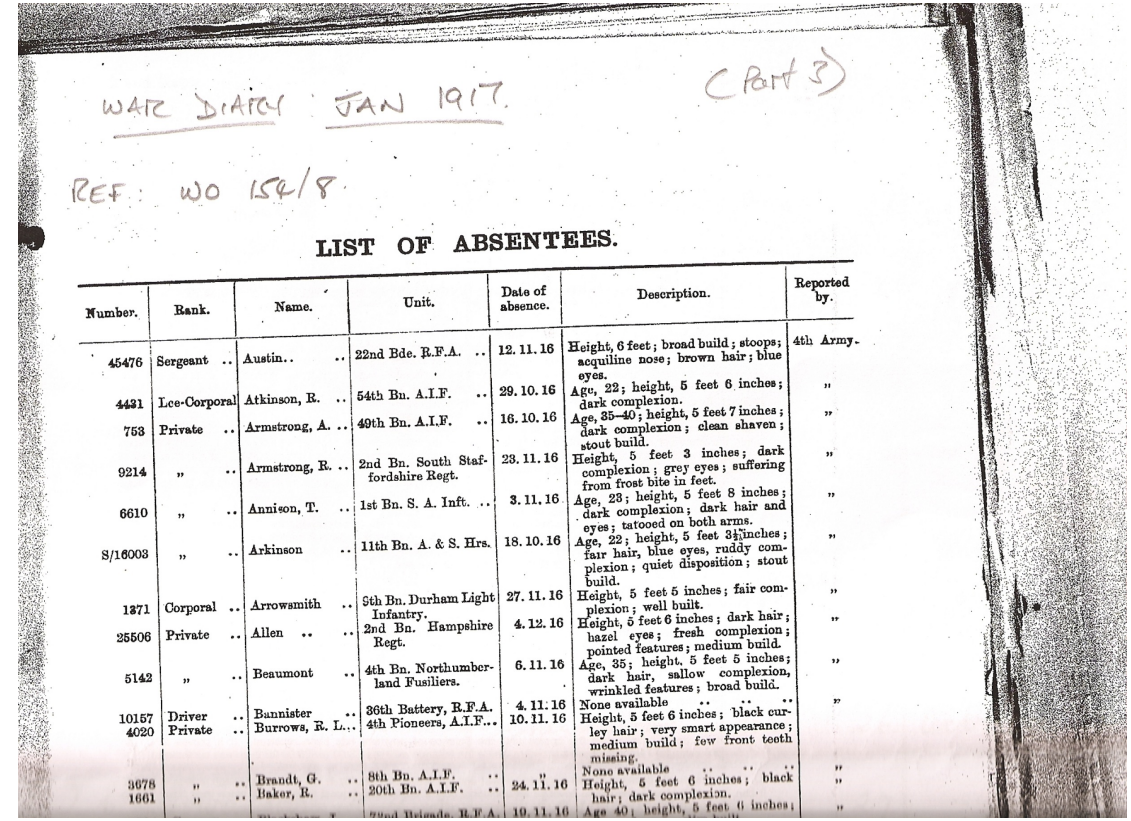

Notes: This figure shows a sample of the War Diaries data.

data includes: Office Number, Name, Rank, Regiment Number, Corps (Battalion Number, Battalion, and Regiment), Age, Height, Complexion, Hair, Eye Color, Trade (civilian occupation), Enlistment Date, Enlistment Place, Birth Place (Parish and County), Desertion Date, Desertion Place, Marks and Remarks (see Figure 6). Additional biographical characteristics were merged in from soldiers' attestation papers completed upon joining the Army.

Compared to the War Diaries, the D\&A supplement records are much more complete. However, they include absentees both at home (where it was much easier to desert) and abroad (in the notes, e.g., "from B.E.F."; for an example, see the "Marks and Remarks" column in Figure 6). To provide a sense of data quality, Figure 7 shows the plot of all 126,818 absences at home and abroad. The sharp spike in 1914 is the day after the assassination of Archduke Ferdinand, which suggests that quite a few soldiers were reluctant to go to war. In 1916 and 1917, spikes are observed around Christmas, when soldiers are likely reminded of family. Another spike is observed at the end of the war in November 1918, consistent with exhaustion or a belief that there was no death penalty for desertion during peacetime. Although this paper digitizes the entire database, absences at home are not subject to the death penalty, so I gleaned 3,009 B.E.F. desertions from this data source by searching for the terms "en route" or "from B.E.F." in the notes field. Figure 


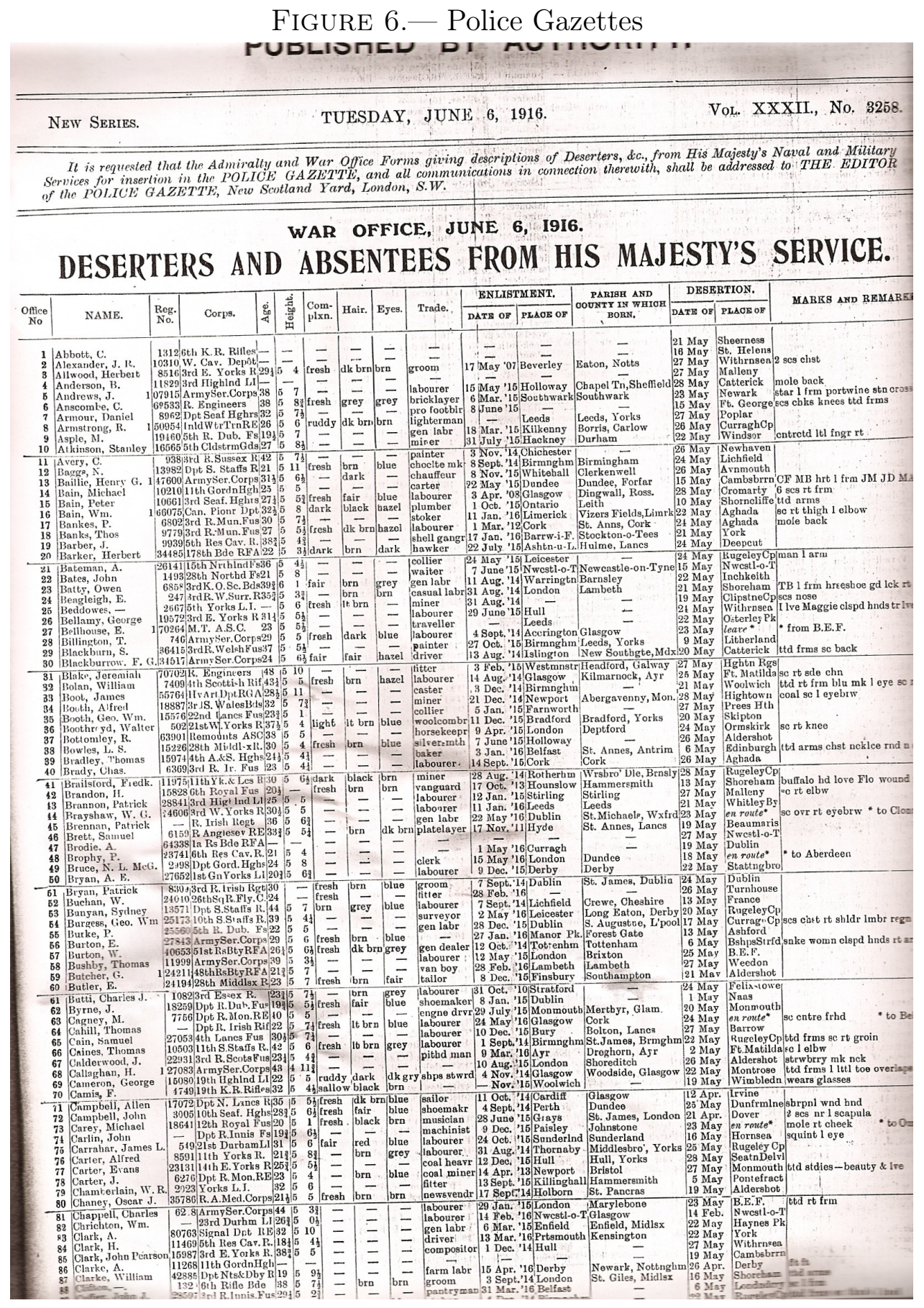

Notes: This figure shows a sample of the Police Gazettes data. 
Figure 7.- All absences reported in Police Gazettes

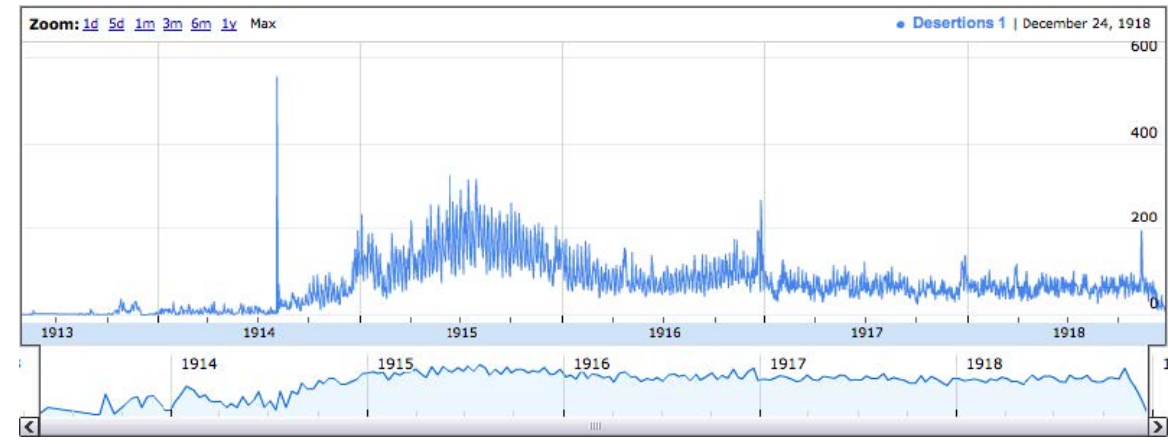

Notes: This figure shows the density of all 126,818 absences at home and abroad reported in the Police Gazettes.

Figure 8.- B.E.F. desertions in Police Gazettes

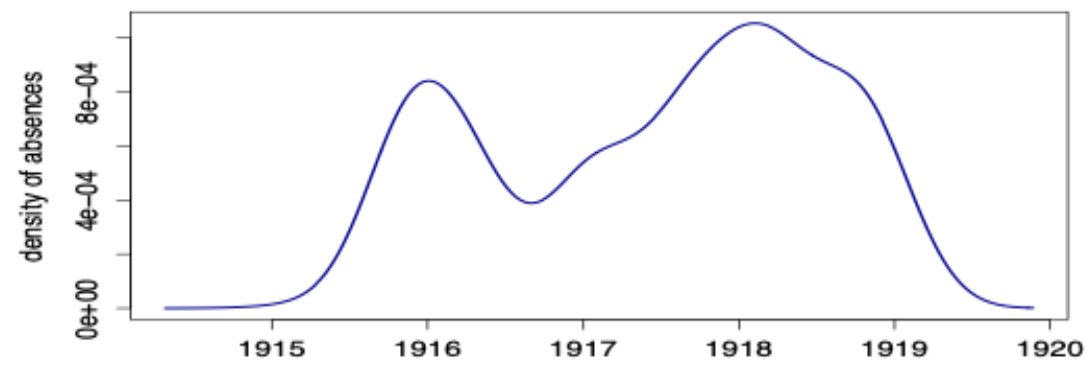

Notes: This figure shows the density of absences denoted as "en route" or "from B.E.F." in the Police Gazettes data.

8 shows that these B.E.F. desertions occur throughout the war. The majority of these absentees were likely en route from B.E.F. to the UK ${ }^{22}$

2.4 Trial Records A third source of absentees is preserved in handwritten FGCM registers (WO 213/2-26), dating from January 1914 to November 1919, recording roughly 144,609 trials. The data includes: Date the Record was received, Rank, Name, Battalion Number, Regiment, Place of Trial, Date of Trial, Nature of Charge, Nature (and length) of Sentence, Acquittal (or Not Guilty), Remittance (i.e., commutation to a different sentence or sentence length), and Remarks (e.g., Suspended to serve after the war). The charges include: Offense to Inhabitants, Mutiny, Cowardice, Absence (including absence from parade or Breaking out from barracks or camp), Striking or violence to a superior

\footnotetext{
${ }^{42}$ Email from Putkowski on November 4, 2012.
} 
officer (and during superior officer's execution of office), Insubordinate or threatening language to a superior officer, Disobeying lawful command of superior officer, Leaving post (sentry or picquet) or asleep on sentry, Drunkenness (and while on duty), Injury and receiving (stolen) property, Losing equipment (and clothing, necessaries, etc.), Stealing and theft, Indecency, Resisting or escaping escort, Escaping confinement, and Other offenses. The range of sentences includes: Death, Penal servitude, Imprisonment, Detention, Field punishment, Ignominy, Reduction in Rank and Seniority, Fine, Reduction (of pay), and Stoppages (of leave or other privileges). Sometimes another field, Appeal from Summary Award of C.O., is present. In the data, only $0.5 \%$ of desertion trials and $3 \%$ of absence trials come from an appeal. I do not make a different calculation of dates of absence for trials that come from an appeal since both the initial judgment and the soldier's exercise of his right to demand a trial instead of summary judgment were likely to have been immediate.

There are 28,754 trials for absence and 13,309 trials for desertion. The number of death sentences across all crimes was 2,858. The number of death sentences for desertion was 1,730. 449 of the accused deserters were not guilty, but the remaining received some kind of sentence. Some of the difference from the official statistics may be attributed to data entry errors as handwriting is difficult to transcribe. For all crime variables, I interpret any mark in the column in the affirmative. Note that these data are registers (see Figure 9) and not the trial proceedings themselves, most of which no longer exist. The trial proceedings that survive are primarily of those where the accused was executed, and these have already been previously analyzed by historians.

All three absentee records represent different samplings of the true desertion rate. When I compare post-execution outcomes to post-commutation outcomes within a particular unit, I minimize the potential bias that results from error in measuring outcomes. For example, if desertion and absentee lists are under-inclusive because of poor preservation or if they are over-inclusive because they include those who were killed, were prisoner of war by accident, or were stragglers, these measurement errors would affect both treatment and control groups equally. Or, since only the trial date is recorded, the time delay between desertion and apprehension should be similar in both treatment and control. I merge the FGCM data into the Order of Battle assuming that the absence occurred one month earlier and analyze the data accordingly.

2.5 Casualties Data I utilize the Soldiers Died in the Great War database containing 658,555 casualties to proxy for point-in-time danger by unit and by date. Casualties predict desertion (Costa and Kahn 2003). This data includes: regiment, battalion, surname, first (and middle) name, birthplace town and county, enlistment town and county, regimental 
Figure 9.- FGCM Trial Registry

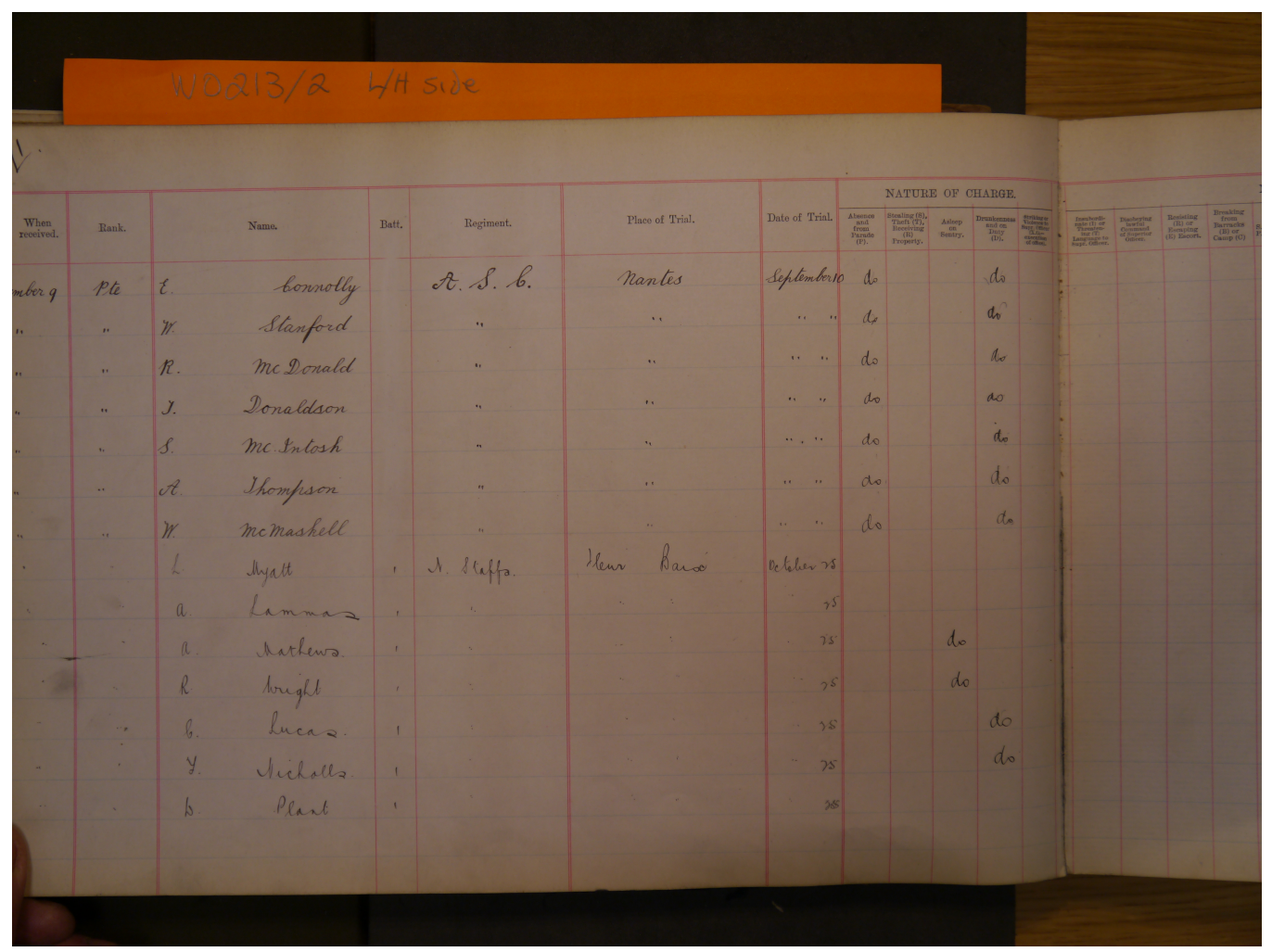

Notes: This figure shows a sample from the FGCM Trial records. 
number, rank, killed in action, died of wounds, died, theatre of war of death, date of death and supplementary notes. Thus, I can match this data to desertion dates by military unit to control for high frequency changes in perceived danger.

An interactive version of this data can be viewed at this link 43 B.E.F. casualties over the course of the war are displayed in the top panel and France-Flanders casualties in the bottom panel. The estimated casualties (in thousands) are expressed as number pairs in the format (German/Allies) in red and blue. Red indicates casualties from battles initiated by Germany. Another interactive version allows comparing casualties with the execution rate and is available at this link. France-Flanders casualties are displayed in the top panel and death sentences in the format (execution/sentences) in the bottom panels. Figure 10 presents a screenshot. Casualties and casualty rates are positively related since officers tried to fill in the divisions in a manner such that the divisions were roughly constant in size.

2.6 Irish Surnames A list of 426 Irish surnames identifies soldiers of probable Irish ethnicity ${ }^{44}$ The use of this data is subject to the caveats of potential measurement error. Differences between Irish and British soldiers would be underestimated to the extent soldiers are sometimes miscategorized. Any measurement error on "true Irishness" would tend to bias towards zero the difference in the effects of executing British vs. Irish soldiers. As shorthand, I use "Irish soldiers," "soldiers with Irish surnames," and "soldiers with male Irish ancestry" interchangeably. I also use "British" interchangeably with "non-Irish," but it just means soldiers who lacked Irish surnames.

2.7 Service and Pension Records The Service and Pension Records were obtained from Ancestry.com, which digitized the original records held at the British National Archives (WO 363 and WO 364). The Service and Pension Records generally include name, age of enlistment, birth parish, birth county, residence address, regimental number, and date of attestation. The Service Records (WO 363) comprise roughly 2 million nonunique records. Of the original 6.5 million Service Records, only $40 \%$ survived a German bombing raid on London during World War II. These records are also known as the "Burnt Documents" or "Burnt Records" due to charring and water damage in the records that survived 45

\footnotetext{
${ }^{43}$ For all interactive figures, Safari or Internet Explorer works best for viewing, and loading of scripts and Flash may need to be manually toggled.

${ }^{44}$ Surnames of Irish Origin. (2009) Last Name Meanings Dictionary. Retrieved from http://www.lastnames.net/origincat.asp?origincat $=$ Irish.

${ }^{45}$ These records are for soldiers who were discharged, demobilized at the end of the war, who died between 1914 and 1920 and who were not eligible for an Army pension. Some soldiers who were in the regular army before the outbreak of war in August 1914 may, however, be included in this class of records. The Service Records do not include soldiers who continued to serve in the military after 1920. Their records
} 
Figure 10.-Casualties, Executions, and Battles

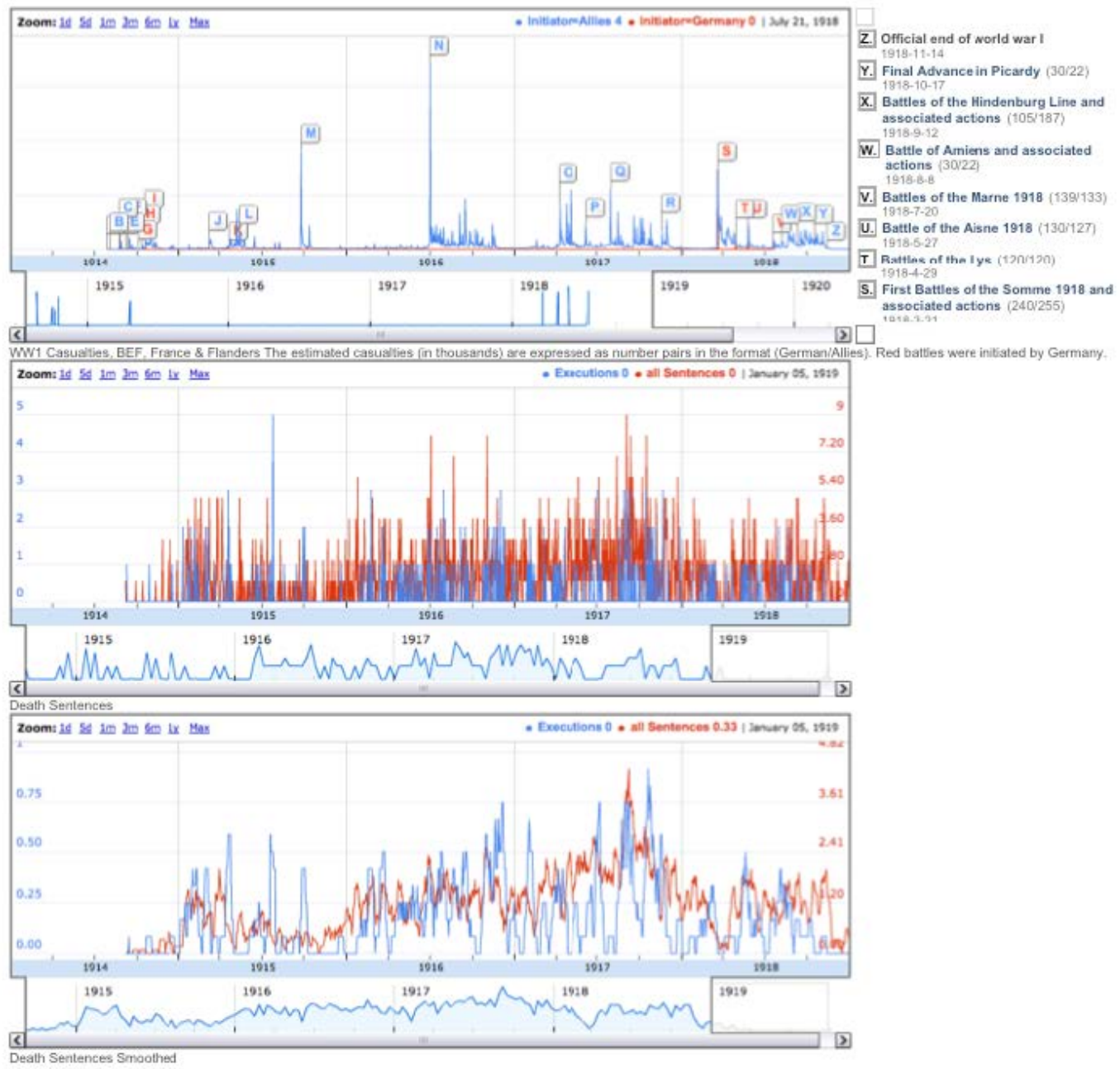

Notes: This figure shows a snapshot of a data explorer for casualties, executions, and battles. 
In addition to the 2 million or so "Burnt Documents", there are the Pension Records (WO 364), also known as known as the "Unburnt Documents", comprising roughly 1 million non-unique records, which contain information on soldiers who were discharged from the Army and claimed disability pensions, so some records also include date and place of injury ${ }^{46}$

I match the Service and Pension Records by name, where possible, to the death sentences dataset. This provides additional covariates for checks of random assignment. Together, they provide 2.7 million unique records identified by name, regiment, and residence. Even though the data is incomplete, age is useful to merge in because age is only recorded in the capital sentences data for soldiers who were executed, but age is recorded in the Service and Pension Records for non-executed soldiers. Therefore, the combined data can serve to check for correlation between the execution decision and soldier's age. In this kind of analysis, missing data is dummied out and an indicator for whether age is missing is included. The Service and Pension Records are also useful to examine the Irish surname database.

2.8 Unit of Analysis It is necessary to choose a unit of analysis for the study. Military organizations are obviously hierarchical and there is a great deal of discretion in choice of unit-size. The casualty data and absence data are at the battalion level, so I could in principle choose any unit from this level up to the Corps. While there are exceptions, in general, the sequence of military units listed from lowest to highest was: Battalion $\rightarrow$ Regiment $\rightarrow$ Brigade $\rightarrow$ Division $\rightarrow$ Corps $\rightarrow$ Army $\rightarrow$ Army Group. Each higher level of organization contains three or four subordinate units plus headquarters and higher-level assets. A battalion consisted of 1,000 men, with 3 to 4 battalions per brigade and 3 to 4 brigades per division. With the addition of support, a division consisted of between 18,000 and 19,000 men and would occupy up to 15 miles of road while moving (Corns and Hughes-Wilson 2007, p. 108). According to historical accounts, the division commander was the highest-level commander whose commutation recommendation was ignored Oram 2003, p.129; Babington 1983, pp. 78-79, 103). I do not know anything about ignored execution recommendations, because the records of the commuted cases were destroyed. If higher-level commanders did target certain soldiers based on discipline

are not available for public access.

${ }^{46}$ These records are for soldiers who were discharged for medical reasons (illness or wounds). These records also include soldiers who were in the British Army before August 1914 and who were eligible for an Army pension because their term of service came to an end in or before 1920. These records are unlikely to contain information on three non-exclusive groups of individuals: 1) those who did not claim a pension, 2) those who were discharged from demobilization at the end of the war (since they were generally not eligible for a pension), and 3) those who were killed in action and had no dependents (as there would have been no one to claim a pension). 
or show discretion, then the division is the highest level appropriate for analysis.

The thinness of the outcome data also compels a fairly high level of organization, even though the salience of an execution and hence its deterrence effect (if any) would be strongest at lower levels of organization. To be included in the analysis, units must contain at least 1 execution, 1 commutation, and 1 absence. From the War Diaries data, I identify 676 usable matches preserved mostly from July 1916 to June 1917, that is, roughly onethird of the war. The upper panel of Figure 1 plots the distribution of matches from 700 to 1100 days after the assassination of Archduke Ferdinand on June 28, 1914. World War I officially began one month later on July 28. The median time between trial and next recorded desertion at the division level is about two weeks. From the Police Gazettes, I identify 3,009 B.E.F. deserters for all four years of the War; 1,319 of these are merge-able with the Order of Battle. From the trial data, I identify 45,824 usable matches for all four years; 4,365 of these matches are desertion trials.

2.9 Order of Battle and Merging To conduct the analysis, each event (death sentence, desertion, or casualty) must be assigned a particular division. But most of the sources list the battalion of a soldier, not the division. To determine the division, I developed a table of division assignments for each battalion. Complicating this effort was the fact that battalions changed divisions throughout the war in response to particular strategic goals or needs of the divisions. The Order of Battle dataset provides the means to determine which division was commanding for a given battalion on a given date. To develop this dataset, I relied primarily on the Long, Long Trail (LLT) website. The website, available at http://www.1914-1918.net, is based on James (1978). A sample appears in Figure 11. This website gives, in mostly paragraph form, a time history of each battle unit and, in particular, the movement among divisions and brigades. Appendix $\mathrm{C}$ documents how the Order of Battle was entered. The website gives this data in two main forms. The first form focuses on the battalion (or other unit), and describes in chronological order the movements of that unit. The second form focuses on the division, and describes the movement of units into and out of the division. Combining these two data sources and focusing on the mergeable units (some units like Army Service Corps are impossible to merge) yields over 7,800 associations between battalion to brigade to division. Appendix $\mathrm{B}$ describes the process of merging and additional challenges, such as different spellings or abbreviations. I also track higher-level unit transfers (e.g., transfers from divisions to corps to army), constituting an additional 770 associations between the divisions to corps to army. The two data sources are LLT and Edmonds (1922).

With the exception of Service and Pension Records, I do not merge by soldier name across datasets. All datasets were scanned digitally and then checked, with the remaining 
Figure 11.- Order of Battle Sample

\title{
The West Yorkshire Regiment Battalions of the Regular Army
}

\author{
1st Battalion \\ August 1914 : in Lichfield. Part of 18 th Brigade in 6th Division. Moved on 7 August to Dunfermline then six days later to Cambridge. \\ Landed St Nazaire (France) on 10 September 1914. \\ 2nd Battalion \\ August 1914 : in Malta. \\ Returned to England and landed at Southampton on 25 September 1914. \\ 25 September 1914 : came under orders of 23rd Brigade, 8th Division, forming up at Hursley Park near Winchester. \\ Landed at Le Havre 5 November 1914. \\ 3rd (Reserve) Battalion \\ August 1914 : in York. A training unit, it remained in UK throughout the war. Moved in August 1914 to Whitley Bay and played a part as \\ Tyne Garrison. \\ 4th (Extra Reserve) Battalion \\ August 1914 : in York. A training unit, it remained in UK throughout the war. Moved in August 1914 to Falmouth, going on in December \\ 1915 to Redcar and in April 1916 to West Hartlepool, where it played a part as Tees Garrison.
}

\section{Battalions of the Territorial Force}

\section{1/5th Battalion}

August 1914 : in York. Part of West Riding Brigade, West Riding Division. Moved on 10 August to Selby, end of the month to Strenshall and late October to York. In March 1915 moved to Gainsborough.

15 April 1915 : landed at Boulogne.

15 May 1915 : formation became 146th Brigade, 49th (West Riding) Division.

1/6th Battalion

August 1914 : in Bradford. Part of West Riding Brigade, West Riding Division. Moved on 10 August to Selby, end of the month to

Strenshall and late October to York. In March 1915 moved to Gainsborough.

Record sarne as $1 / 5$ th Bn.

1/7th (Leeds Rifles) Battalion

Carlton Barracks, Leeds. Part of West Riding Brigade, West Riding Division. Moved on 10 August to Selby, end of the month to

Strenshall and late October to York. In March 1915 moved to Gainsborough.

Record same as $1 / 5$ th Bn.

1/8th (Leeds Rifles) Battalion

Carlton Barracks, Leeds. Part of West Riding Brigade, West Riding Division. Moved on 10 August to Selby, end of the month to

Strenshall and late October to York. In March 1915 moved to Gainsborough.

Record same as $1 / 5$ th Bn.

30 January 1918 : transferred to 185th Brigade, 62nd (2nd West Riding) Division, absorbing 2/8th Bn and renamed 8th Bn.

Notes: This figure shows a sample of the Order of Battles data. 
unscannable entries entered by hand. The trial registers were written in cursive handwriting. The lack of computerized records from this time period makes prohibitively difficult the linking of absentees by name to their trial and to their death sentence date, if any. Absentee lists are only a sample of the universe of absentees. So any conclusion about the deserters being invariably caught (thus potentially appearing in the trial registers) rests on historians' statements and on the inferences rendered from the aggregate data. The inability to merge by name also precludes extensive balancing checks based on demographic data stored in datasets other than the lists of executions and commutations.

2.10 Medal Rolls The inability to match by name precluded the use of the Medal Rolls Index (WO 372), which I obtained in digital form from the British National Archives. Virtually all soldiers who served received at least the British War Medal for "entering a theatre of war or rendering approved service overseas" and there are 5,424,254 unique soldiers and a total of 7.8 million records (some soldiers received multiple medals). This data provides the name, rank, regiment, regimental number, medal entitlement, first theater of war and date of entry, information on soldiers who forfeited their medal entitlement because of disciplinary infringement, and additional remarks (e.g., date of death or discharge). Merging by the Medal Rolls Index would regularize the spelling of the military unit for ease of merging into the Order of Battle, but merging the absentee, casualty, and trial data directly into the Order of Battle proved more effective. I use this data to make assessments about the Irish surname dictionary by comparing against the official statistics regarding Irish enlistment, which I am able to do since the Medal Rolls Index contains roughly the universe of all enlisted soldiers.

2.11 Officers I digitize a dataset of the 2,992 commanding officers and general staff officers for division, corps, army, and general headquarters and the dates of their assignments and reassignments throughout the war (Becke 1935-1944). Officer data enables additional checks of whether the decision to execute or commute was correlated to officer identity and ethnicity and whether the soldier's decision to desert is correlated with his officer's identity and his officer's ethnicity inferred using the surname dictionary. These data are merged into the Order of Battle.

2.12 Geographic Location The Order of Battle also contains major battles and the divisions associated with each battle. The great majority of battles are named after the town or city in which, or near which, they took place. The towns can be entered into Google Maps, which provides geographic coordinates. I make the assumption that divisions travel linearly and incrementally from one battle to the next to interpolate the rough location of each division on any date. Finally, these coordinates yield calculations of distances between divisions, distance to the English Channel, and distance to Berlin, 
which serve as additional controls. This data allows estimating the approximate location of each soldier on the day of his absence. I also use Google Maps to geolocate the enlistment towns, birthplaces, and residences of soldiers for analysis in Appendix D, where I make five assessments: 1) assess how closely Irish surname and Irish birthplace align, 2) assess the relative loyalty of Irish and non-Irish by birthplace, 3) assess differences between being born in Ireland or Britain vs. being enlisted in Ireland or Britain vs. having Irish vs. non-Irish surname, 4) assess the quality of geolocation, and 5) assess population representativeness of casualties. Differences in distance-in-time to Irish roots can be related to differences between having male Irish ancestry vs. having an Irish birthplace. Those born and raised in Britain with Irish male ancestry may be more loyal than those born and raised in Ireland, but those having male Irish ancestry may be less loyal than those without male Irish ancestry even among soldiers born and raised in Britain. I compare my statistics with the prior historical knowledge.

\section{Assessment of Randomness}

\subsection{Are Decisions Correlated With Observable Characteristics? Table 1 shows} the results of several regressions of observable characteristics for death sentences. ${ }^{47}$ No specification reveals a relationship between Irish ethnicity and probability of execution. Figure 12 illustrates that Irish soldiers were not disproportionately executed, conditional on the death sentence. Moreover, the first column of Figure 12 shows that the Irish were not disproportionately sentenced to death relative to the proportion of Irish absences. The first bar shows the relative share of Irish soldiers in the War Diaries' absentee lists. Figure 13 shows there were no time periods when Irish capital sentences were disproportionately confirmed, for example, after the Easter Rising in 1916. This result is confirmed in the set of interactions between year and Irish soldiers displayed in Table 1 in Column 5.

Column 2 shows that Privates were not disproportionately executed, and in fact, they were somewhat less likely to be executed than officers. Column 3 shows that age does not predict the execution decision. Column 4 shows that year fixed effects are jointly significant. There appears to be a decline in execution rates over time, which is consistent with Figure 14. Year fixed effects will be included in the analyses in Section 6. As for other time dimensions like seasonality and day of week, Columns 6 and 7 report that neither month fixed effects nor day of week fixed effects are jointly significant. Column 8 shows that division fixed effects are jointly significant - division fixed effects will also be included in the Section 6 analyses. Column 9 shows that the type of army-Regular, New, or Territorial, with Regular being the baseline category - do not predict execution rates. Column 10 shows that the log of casualties does not predict execution rates. All log

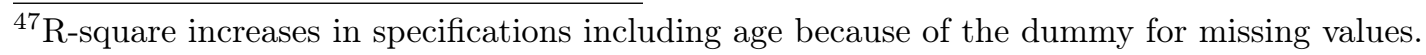




\section{FIGURE 12.- Irish and non-Irish Executions}

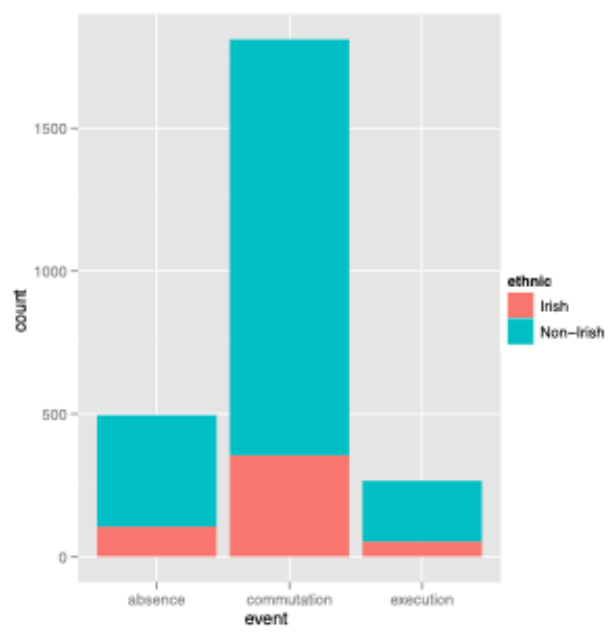

Notes: This figure shows a tabulation of Irish and non-Irish absences, commutations, and executions.

FiguRE 13.- Irish and non-Irish Executions Over Time

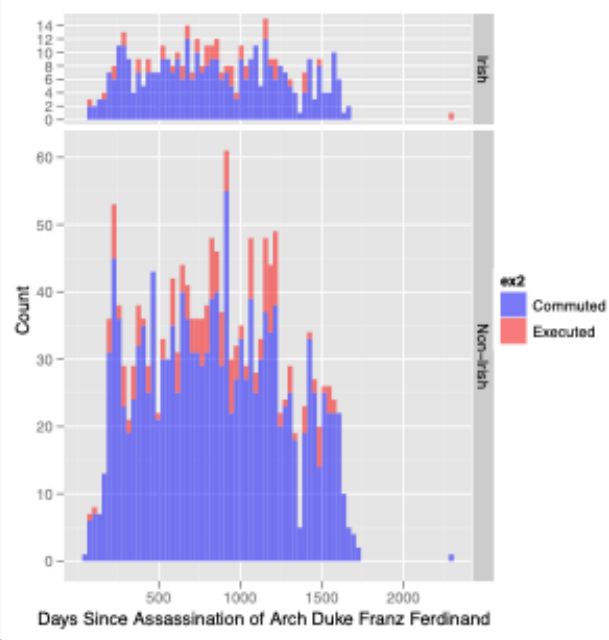

Notes: This figure shows a tabulation of Irish and non-Irish commutations and executions over time. 


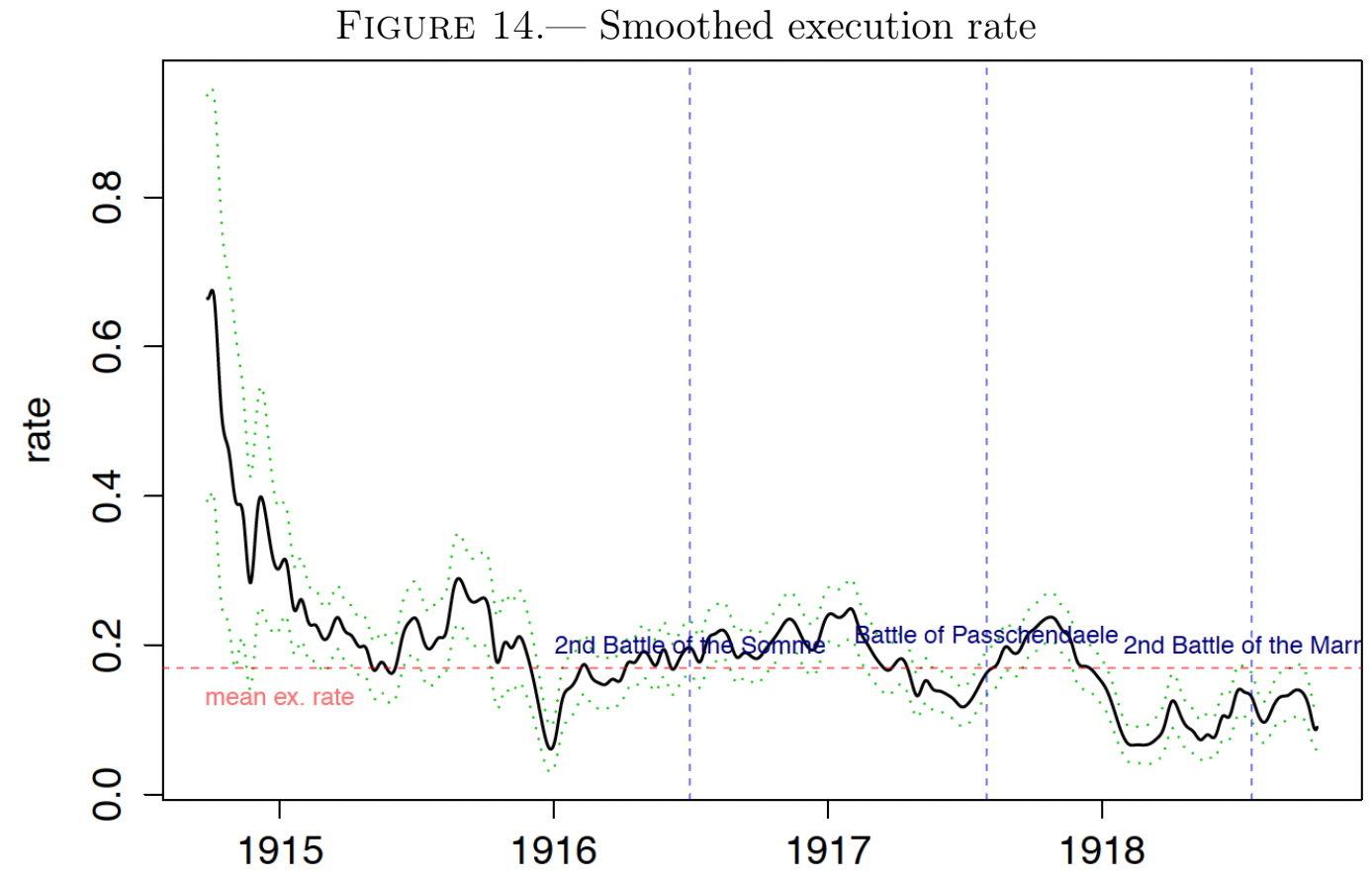

Notes: This figure shows the execution rate over time across the war.

values are calculated as $1+$ the underlying variable. Casualties do not predict execution rates regardless of whether it is measured in levels (e.g., measured 1-29, 30-59, or 60-89 days ago or 1-29 days in the future relative to the trial date) or in first-differences to address potential serial correlation in casualties. Column 11 shows that distance to coast and distance to Berlin also do not jointly predict execution rates. All regression analyses are restricted to death sentences occurring in France and Flanders before the end of the war. Death sentences recorded from the Labour Corps were also removed. Sample size varies for army and distance specifications because not all divisions were assigned to an army, and distance data is unavailable before the first battle and after the last battle.

Table 2 Panel A shows the results of several regressions of unit-level factors such as officer identity and recent military indiscipline (i.e., number of military trials, death sentences, or executions). Panel A shows that fixed effects for Brigade unit, Corp unit, and Army unit are not jointly statistically significant. Fixed effect for officers-General Officer Commanding (GOC) for Brigade, Division, Corps, Army, and General Headquarters, and First General Staff Officer (GSO) of Division, Corp, Army, and General Headquarters - are also not jointly statistically significant with the exception of division commanding officer which is significant at the $5 \%$ level. One or more significant effects may be expected given the large number of tests reported. Officers and units that appear with less than 10 
frequency were categorized in a separate "other" category.

Joint significance tests of fixed effects for whether the officer is Irish and the soldier is Irish do not reveal systematic differential execution probability of Irish soldiers when their officers are British. The latter result is not due to the lack of Irish officers ${ }^{48}$ Lagged measures (30 and 60 days ago) of log of military trials, log of death sentences, and execution rates also do not reveal significant relationships with the current execution decision. All regressions include fixed effects for division, year, and Irish surname.

Table 2 Panel B examines autocorrelation in execution decisions. The string of events within each unit are stacked and the first event within each unit was excluded as a dependent variable. If more than one event occurred on a day within a unit, the average outcome was calculated. All regression models include year fixed effects and the leave-one-out (i.e. excluding the current decision) mean execution rate of the unit 49 Separate ordinary least squares stacked autocorrelation regressions with different levels of aggregation (division, brigade, corp, army, army type, and global) do not show significant autocorrelation.

Table 3 repeats the exercise for all capital sentences regardless of crime. An exception to the randomization hypothesis is that murderers were more likely to be executed relative to other capital sentences, while privates were less likely to be executed. The lower panel of Figure 4 shows that the overwhelming majority of executions were for deserters. Table 4 repeats the specifications from Table 2 and two sets of fixed effects are jointly significant at the $10 \%$ level out of 16 tests. Analyses of Tables 1-4 in logit or probit specifications yield similar inferences. Finally, I report the same exercises for Irish capital sentences in Appendix Tables 15 and 16.50 Appendix D conducts additional randomization checks.

3.2 Stable Unit Treatment Value Assumption Even if treatment assignment is ignorable, valid causal inference is not necessarily possible: I have to be certain that the outcome in one unit is not affected by the treatment assignment in another unit, i.e., that SUTVA is satisfied. The within-unit design helps with ignorability but creates a SUTVA problem because each unit is essentially serving as its own control.

For the problem of past events affecting the effect of future events, one possibility is to include only those events between which there is sufficient elapsed time. Unfortunately, requiring a greater amount of time between events helps SUTVA but hurts the ignorability

\footnotetext{
${ }^{48}$ The proportions of Irish commanding officers for soldiers who deserted or had trials are $9 \%$ for Brigade, $12 \%$ for Division GOC, $11 \%$ for Division First GSO, $7 \%$ for Corps GOC, $15 \%$ for Corps GSO, $15 \%$ for Army GSO, 19\% for General Headquarters GSO, and 0\% for Army GOC and Commanders-in-Chief.

${ }^{49}$ Including division fixed effects would bias the estimated relationship between the current and previous decisions because the fixed effect is controlling for the mean (which includes the dependent variable), inducing negative autocorrelation between any two decisions (Chen et al. 2016).

${ }^{50}$ Besides murderers being more likely to be executed, another two tests have $p<0.05$ and four tests have $p<0.1$ out of 28 individual tests and 29 joint tests of significance.
} 
of treatment since treatment assignment is most likely to be ignorable when comparing capital cases that appeared before the commander at roughly similar times. The approach taken is to make a strong assumption, which is that past events are irrelevant. I then weaken this assumption by assuming a parametric model for deterrence and condition out the past effects of previous events. With this approach, the effect of past treatment assignments on future outcomes is modeled explicitly rather than assumed to be zero.

\section{Empirical Strategy}

4.1 Duration Analysis My first modeling approach is to assume that the elapsed time from the most recent deterrence event to the next absence in a particular unit is a random variable drawn from some distribution parameterized by unit and time characteristics (i.e., $y$ is drawn from a distribution with a pdf $f$ ). For exposition's sake I use an exponential distribution, though other parametric distributions are possible. I assume that the likelihood of observing an elapsed time of $y$ from a given deterrence event to the next absence is given by $f(y)=\lambda \exp (-\lambda y)$.

The hazard rate, $\lambda$, depends upon the characteristics of that particular deterrence event. $\lambda=\beta_{0}+\beta_{e x} e x_{i j}+\beta_{e x d} e x_{i j} \cdot d e s_{i j}+\beta_{d e s} \cdot d e s_{i j}+\gamma^{C} \operatorname{cas}_{i t}+\gamma_{j}^{U}+\gamma_{\text {year }(j)=T}^{T}$. Military units are indexed by $i$, observations by $j$. ex is an indicator for an execution, des is an indicator that the trial was for desertion, cas is the casualty rate and $\gamma^{\mathbf{U}}$ and $\gamma^{\mathbf{T}}$ are unit and year fixed-effects, respectively. Collectively, I refer to these parameters as a vector $\theta$. The specification can also be interpreted as follows: cas controls for the cost of staying and ex captures exogenous variation in perceptions of costs.

It is possible, however, that an execution or commutation occurs at the end of the data frame, in which case the elapsed time $y$ is no longer a realization of the time until an absence, but rather a censored value. I assume that without the intervention I would have eventually observed an absence. In these censored cases, which I indicate with $d=0$, the likelihood is not $f(y \mid \theta)$, but rather $1-F(y \mid \theta)$. The log-likelihood function consistent with this censoring is given by: $L(\theta)=\sum_{j=1}^{N} d_{j} \log \left(f\left(y_{j} \mid \lambda(\theta)\right)+\left(1-d_{j}\right)\left(1-F\left(y_{j} \mid \lambda(\theta)\right)\right.\right.$.

When analyzing the impact of the most recent event, the calculations treat desertions and capital sentences that occurred in pairs or groups as one observation since the decisions to execute or commute these soldiers were not independent: almost without exception, they were determined simultaneously and with identical outcomes. The time until the next absence is calculated beginning on the following day. Absences that occurred on the day of an event are considered as having occured the previous night, so they do not count as the first absence after an event. Multiple absences or events on the same day from different ethnicities are considered as British as they constitute the typical soldier.51

\footnotetext{
${ }^{51} \mathrm{~A}$ date with an Irish execution (absence) means that only Irish were executed (absent).
} 


\section{The Weak-SUTVA Approach}

I assume that past events matter, but that they fade out exponentially, according to some parameter $k$. I test values of $k$ such that $k=-\frac{\log \frac{1}{2}}{\Delta t}$ where $\Delta t$ takes values of 7, 14, 30, 60 and 90, corresponding to deterrence-effect half-lives of one week, two weeks, one month, two months, and three months. In the weak-SUTVA approach, I define two sets: $E_{e x}\left(t^{*}\right) \equiv$ times of all executions in the unit prior to $t^{*}$ and $E_{c m}\left(t^{*}\right) \equiv$ times of all commutions in the unit prior to $t^{*}$.

These two terms measure the cumulative effects of past events, one for executions and one for commutations. They also measure idiosyncratic variation in execution rates over time within divisions, since the sequence is also exogenous. Differences in the effects of these two terms characterize the effect of exogenous variation in the application of the death penalty. Neither term by itself has a causal interpretation because the number of death sentences could be endogenous. To be consistent with the strong-SUTVA parameter, multiple events on the same day and division are still treated as one event. $D_{e x}(k)=$ $\sum_{t \in E_{e x}\left(t^{*}\right)} e^{-k\left(t^{*}-t\right)}$ and $D_{c m}(k)=\sum_{t \in E_{c m}\left(t^{*}\right)} e^{-k\left(t^{*}-t\right)}$. The hazard is the original hazard plus two terms for past executions and commutations: $\lambda^{\prime}(k)=\lambda+\alpha_{e x} D_{e x}+\alpha_{c m} D_{c m}$.

Results of the hazard model are presented in the main tables with standard errors clustered at the division level because the weak-SUTVA parameters are serially correlated within division. The appendix tables present two checks - one set of results without clustering (to see if the statistical significance is similar), and another set of results where time is run backwards and I calculate the time until the previous absence before a treatment event (to see if there is a null result). In the specification check with time run backwards, to minimize leakage, where the absence event that led to the death sentence is included by chance as an outcome, the clock begins 90 days into the past.

\subsection{Day-by-Day Probability, Maximum Likelihood Approach One difficulty} of treating each death sentence as an observation, with an indicator for executions as the primary independent variable and absences as an outcome (either a count of absences or duration until the next absence) is that each unit experiences a whole sequence of executions and commutations. These past deterrent effects presumably affect the probability of future absences within that unit, and hence it is hard to see why they can be ignored. My response is to use a framework where the effects of past events are explicitly modeled. I assume that each unit had some probability of experiencing absence on any particular day, and that this probability depends upon military unit and year fixed effects, all past death sentences, including the nature of the crime and the outcome, and their distance in time from the present day and the instantaneous casualty rate.

Military Units: $i=1 \ldots I$ 
Time: $t=1 \ldots T \quad$ Measured from day 0, July 28th, 1914 .

Absences: $a_{i}(t)$ is an indicator for whether there was an absence in unit $i$ on day $t$.

Preceding Events: $K_{i}(t)$ is the set of past deterrence event dates in a unit $i$ (executions or commutations) before time $t ;\left|K_{i}(t)\right|$ is the number of events in the set.

Day: $t_{k}$ is the day on which the $k^{\text {th }}$ element of $K$ occurred.

Execution or Commutation: $x_{k}$ is an indicator for execution or commutation.

Crime Type: $d_{k}$ is an indicator for desertion or some other crime.

I use the logit as my link function, so the probability of an absence in unit $i$ on day $t$ is: $p_{i}(t)=\frac{1}{1+e^{-z(i, t ; \theta)}}$, where $z(i, t ; \theta)$ is $z(i, t ; \theta)=\left(\sum_{k=1}^{\left|K_{i}(t)\right|} e^{-\lambda\left(t-t_{k}\right)} D(k)\right)+X(t) \gamma, D(k)=$ $\beta \cdot \mathbf{E}(\mathbf{k})=\left(\begin{array}{llll}\beta_{\text {exd }} & \beta_{\text {exo }} & \beta_{s d} & \beta_{s o}\end{array}\right) \cdot\left(\begin{array}{c}x_{k} d_{k} \\ x_{k} \\ d_{k} \\ 1\end{array}\right)$, and $X(t) \gamma=\gamma^{0}+\gamma^{C} \operatorname{cas}_{i t}+\gamma_{i}^{U}+\gamma_{\text {year }(t)}^{T}$. $\beta_{\text {exd }} \equiv$ effect of executing a deserter, $\beta_{\text {exo }} \equiv$ effect of executing for any crime, $\beta_{s d} \equiv$ effect of a desertion death sentence, and $\beta_{\text {so }} \equiv$ effect of a death sentence for any crime.

I define a vector of parameters: $\theta=\left(\lambda, \beta_{\text {exd }}, \beta_{\text {exo }}, \beta_{c d}, \beta_{c o} ; \gamma^{0}, \gamma^{C}, \gamma^{\mathbf{U}}, \gamma^{\mathbf{T}}\right) . X(t)$ is a collection of covariates, such as the instantaneous, unit-specific danger rate (computed from casualties) and a unit fixed effect. The effects of past events fade as time progresses. There is one $\lambda$ for both executions and commutations, i.e., events are "forgotten" at the same rate since commutations serve as control for executions. ${ }^{52} F$ is the link-function whose range is [0, 1]. The log-likelihood is thus: $L=\sum_{i=1}^{I} \sum_{t=1}^{T} a_{i}(t) \log p_{i}(t)+\left[1-a_{i}(t)\right] \log \left(1-p_{i}(t)\right)$. $\beta_{\text {exd }}$ and $\beta_{\text {exo }}$ have causal interpretation. I also introduce terms for Irish executions and Irish death sentences. Results are presented only with standard errors clustered at the division level since the treatment variable is serially correlated within the division. The appendix tables present a specification check for null results where time is run backwards.

All analyses with the War Diaries data as outcome restrict the sample from day 670 to day 1085, when the vast majority of absence data is recorded (Figure 1). Figure 15 visually summarizes the duration model and Figure 16 visualizes the day-by-day approach.

\section{Results}

I begin by presenting the results graphically without controls. Figures 17, 18, and 19 present for each of the three datasets a univariate analysis of the duration model - KaplanMeier survival rates (assuming an exponential hazard). The first of each pair of figures presents the effect of Irish executions and the second of each pair presents the effect of British executions. What is immediately apparent is the dispersion between the pairs of

\footnotetext{
${ }^{52} \mathrm{An}$ attempt to infer $\lambda$ from the data did not converge, so I present estimates using different values of $\lambda$ instead.
} 
FiguRE 15.- Illustration of Duration Model

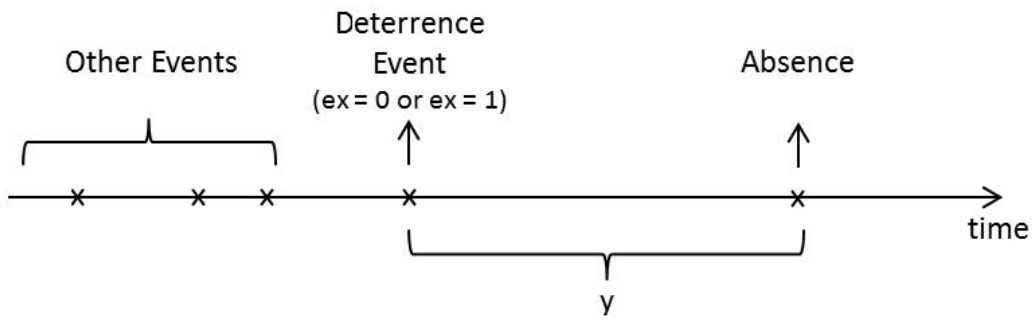

$y \equiv$ time from event (either execution of commutation) to absence

Notes: This figure visually summarizes the duration model.

FiguRE 16.- Illustration of Day-by-Day Model

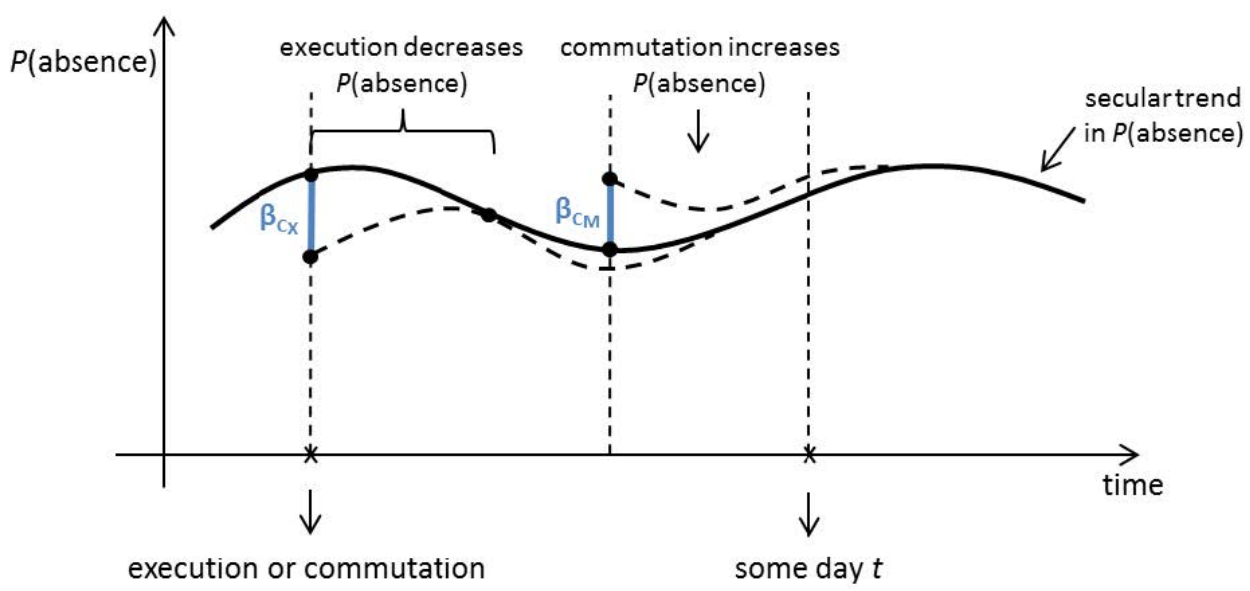

Past events influence current probability, but this influence wanes over time.

Notes: This figure visually summarizes the day-by-day model. 
FIGURE 17.- Non-Parametric Survival Distributions (War Diaries)
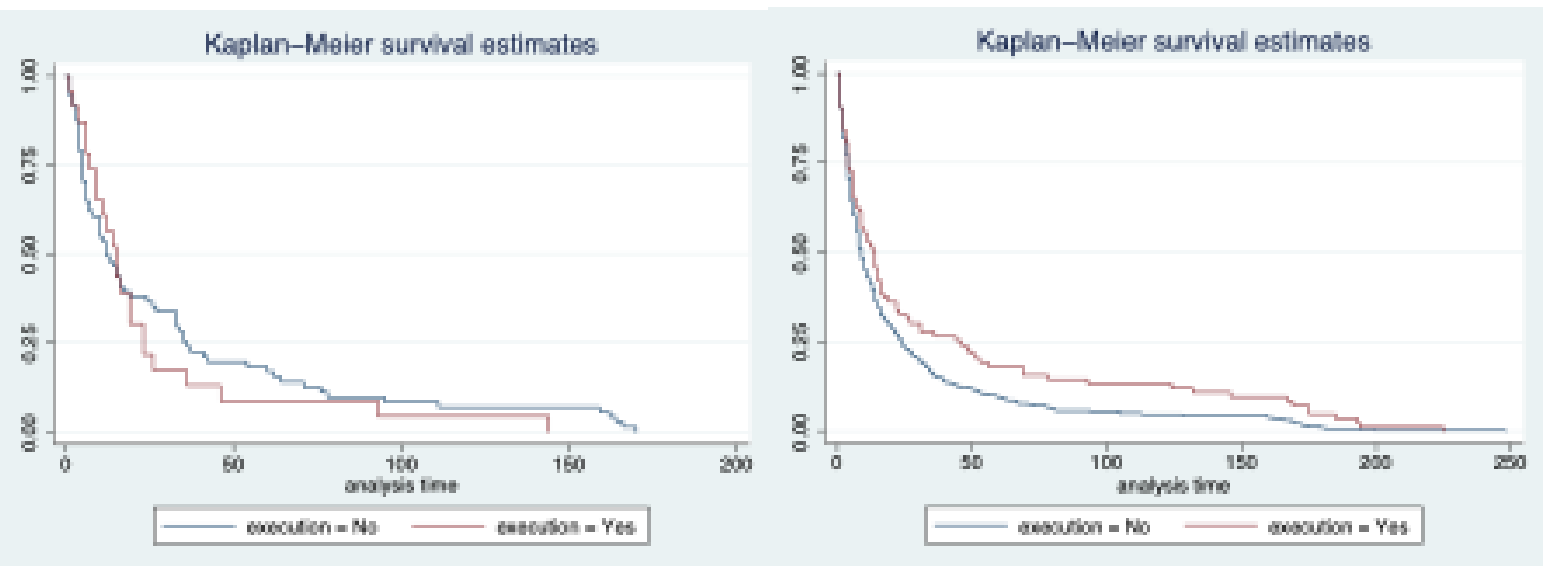

Notes: This figure shows the impact of Irish (left) and British (right) executions on time until next absence in the War Diaries dataset.

hazards in each figure, especially in the War Diaries data (Figure 17). The hazard rate of absences after executions - displayed in the red - is generally pulled inwards to the origin, relative to the hazard rate of absences after commutations - displayed in blue. The results suggest that Irish executions spurred absences and British executions deterred.

5.1 Duration Framework-Strong SUTVA I use three different hazard models: exponential distribution, Weibull, and Cox. I make three different imputations of commutation dates, and I employ three different datasets. Across tables, I gradually add controls ${ }^{53}$ A negative coefficient implies a positive effect on time until next absence - i.e., a negative coefficient suggests deterrence, while a positive coefficient suggests spurring of desertion 54

Table 5 finds limited evidence of a deterrence effect. Consistent across specifications is a "spurring" due to casualties (whether or not this has a causal interpretation is not my purpose). In most specifications, the increase in casualties (both contemporaneous $\triangle \log$ casualties and $\triangle \log$ casualties 30 days ago) is strongly correlated with a spurring effect on time until next absence, significant at the $5 \%$ or $1 \%$ level. While Table 5 finds limited evidence that executing deserters deters absence, Table 6 finds that executions of Irish soldiers spur absence relative to British executions, as visualized in Figures 17, 18, and 19 . I add several interaction terms: whether the death sentence was for desertion, whether the

\footnotetext{
${ }^{53}$ Many models are presented with recognition of model uncertainty (Leamer 1978 , Sala-i Martin, Doppelhofer and Miller 2004 Hansen 2007: Cohen-Cole, Durlauf, Fagan and Nagin 2009).

${ }^{54}$ In the exponential distribution, the mean duration is $\frac{1}{\lambda}$, and the marginal effect of a coefficient $\hat{\beta}$ is $-\frac{\beta}{\hat{\lambda}^{2}}$, where $\hat{\lambda}$ is the average duration.
} 
Figure 18.- Non-Parametric Survival Distributions (Police Gazettes)
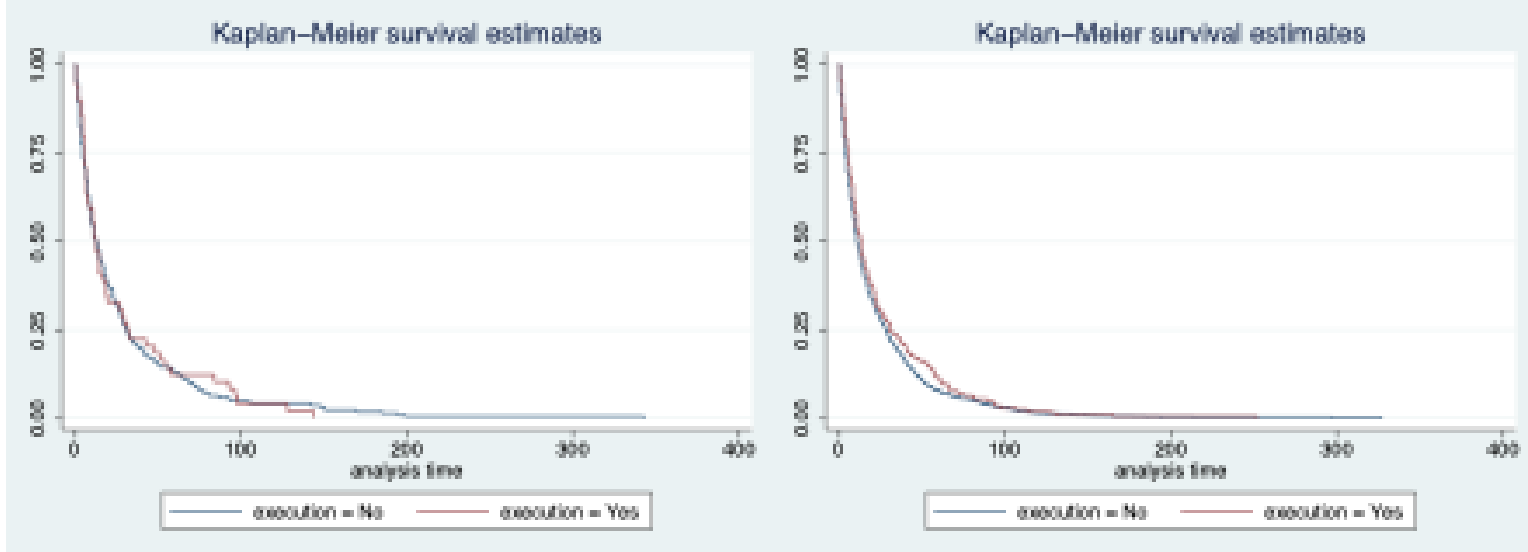

Notes: This figure shows the impact of Irish (left) and British (right) executions on time until next absence in the Police Gazettes dataset.

Figure 19.- Non-Parametric Survival Distributions (FGCM Trial Registries)

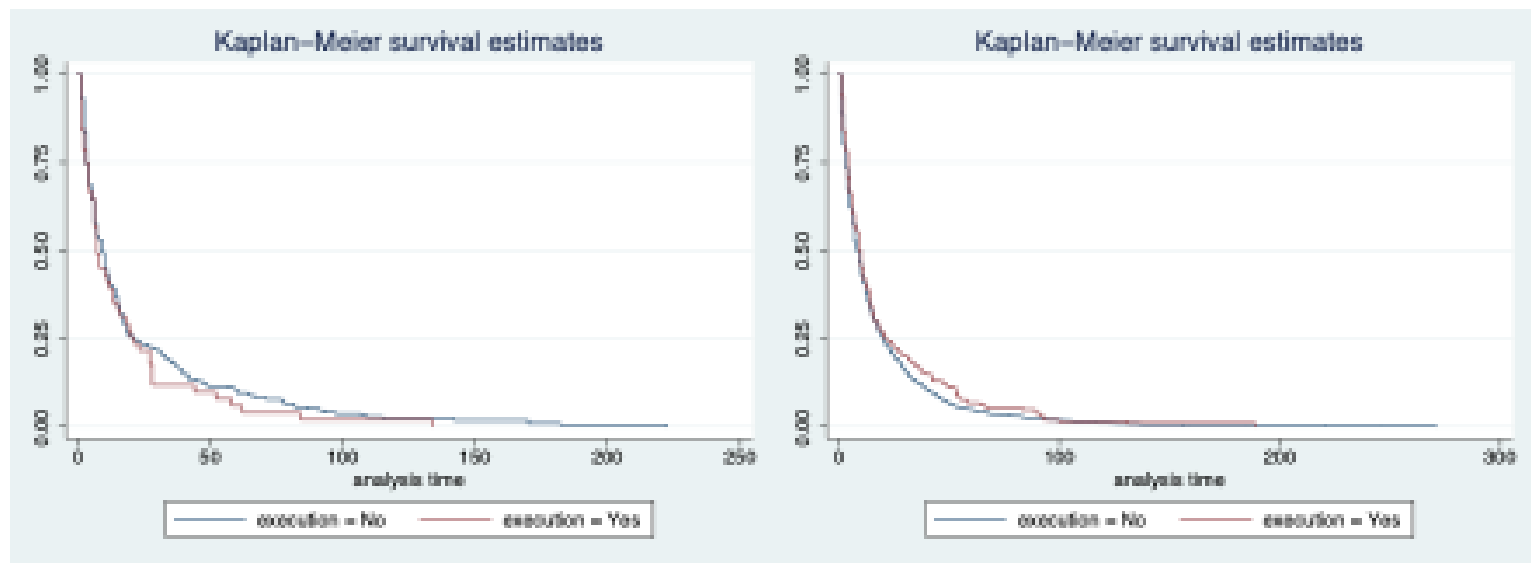

Notes: This figure shows the impact of Irish (left) and British (right) executions on time until next absence in the FGCM Trial Registries dataset. 
deserter was executed, whether the death sentence was for an Irish soldier, and whether the Irish soldier was executed. The hazard interpretation-presented in Appendix Table 11 column 1 (7 and 13), which corresponds to Table 6 column 1 Panel A (B and C) - is that an Irish execution triples the hazard for the War Diaries (and increases by 50\% or 100\% for the Police Gazettes and trial registries respectively). This means that relative to the median time-to-next absence, which is about two weeks, an Irish execution cuts the time by about $66 \%$ in the War Diaries (less in the other two datasets). In some specifications, executing deserters significantly deterred absences relative to execution of non-deserters (Table 6 Panel A Columns 7-9) 55

5.2 Duration Framework-Weak SUTVA Table 7 includes aggregate past effects in two separate terms, one for prior executions and one for prior commutations. It presents across separate columns the results from assuming five different half-lives for an effect (7 days, 14 days, 30 days, 60 days, 90 days) 56 Due to the randomness of executions, the effect of the most recent event is invariant to inclusion of previous events. The robustness is not surprising since the executions are randomly ordered; to put it another way, the decision to execute is uncorrelated with the sequence of executions within the military unit, so, including the prior events should not affect the estimates of the effect of the most recent execution (which was defined as execution salience earlier). Thus, relaxing the strong-SUTVA assumption that events prior to the most recent death sentence are irrelevant turns out to not matter. The effect of executing Irish on spurring absences is robust. The difference between the execution and commutation measure of previous events represents the effect of the execution rate. The execution rate has a deterrence effect, and it is observed in models that assume a longer half-life. In terms of magnitudes, an execution instead of a commutation - evaluated on the day of the event-leads to a 10-15\% decrease in hazard rate in the time to next absence (Appendix Table 11).

\subsection{Ethnic Identity of the Subsequent Deserter I analyze the ethnic identity} of the deserter subsequent to Irish and British executions and commutations. Examining the commutations separately assesses whether commutations were unknown to soldiers. I find that Irish executions double the likelihood that the next absentee is Irish. Using numbers reflecting the 466 Irish and 1,942 non-Irish death sentences in the analysis sample, the doubling of the Irish proportion yields a Fisher's exact test that is statistically

\footnotetext{
${ }^{55}$ The significant negative coefficients on Irish death sentences suggests that they occur when desertions are less frequent, though they do not have a causal interpretation. The negative correlation could bias effects of Irish executions to be one of deterrence, so true spurring effects may be larger.

${ }^{56}$ I focus on commutation imputation of 14 days and an exponential distribution.
} 
significant at the 5\% level. ${ }^{57}$ After Irish and British commutations, the immediately following absences are unaffected, consistent with unnoticed commutations. After Irish and British commutations, $13 \%$ of immediately following absences are Irish (Table 8). This is consistent with commutations serving as an adequate control for executions unnoticed by soldiers. Appendix D discusses results under different commutation imputations and datasets 58

5.4 Robustness Checks Appendix D reports further checks. I explore whether results may be spuriously significant by using specifications run backwards in time. I report analyses without clustering of standard errors. These analyses temper a strong inference that execution rates deter. I also include more controls (officers, location, etc.). I explore whether the effects of execution differ depending on the current casualty rate, distance to coast or Berlin, officer status of the executed soldier, age of the executed solder, days since the war began, and army type. Only one analysis is statistically significant in each of the three absentee datasets: executions appear to deter desertions in the New Army. Since the New Army saw less battle than the Regular Army, the effectively lower $c$ implies a greater deterrence effect 59 I conclude that the soldiers' response to executing Irish soldiers is special, since the other interactions are not robustly significant. I pool all three absentee datasets, but treat a death sentence that occurs before another absence as censoring rather than as an absence. Executing Irish soldiers still spurs absences.

5.5 Day-by-Day Framework I now combine the effect of the salience of the most recent event with the delayed effects of all previous events using a day-by-day approach. Based on the previous robustness checks, I use the execution date and impute the commutation date of 14 days after the trial date. Table 9 uses as outcome variable an indicator for whether any absence occurred 60 When aggregating Irish and non-Irish absences together, I usually cannot detect a deterrent or spurring effect ${ }^{61}$ Table 10 shows robust patterns of Irish (but not British) executions spurring rather than deterring Irish desertions. The dependent variable in Table 10 takes the value of 1 if only Irish absences occurred on that day in that division, -1 if only British absences occurred, and 0 if neither or both occurred. An event that may spur the desertion of Irish soldiers may not affect British, or even deter British desertions. Note that unlike the duration model, positive coefficients indicate spurring and negative coefficients deterrence. The effect is observed across all

\footnotetext{
${ }^{57}$ To be sure, the time frame of the War Diaries dataset makes necessary an analysis of a subset, whose sample size does not allow strong conclusions. This question is revisited with the day-by-day framework. ${ }^{58}$ Using the trial date introduces noise, so I use the 14-day imputation in the day-by-day framework.

${ }^{59}$ However, the prediction that higher casualties generally reduce the deterrence effect is not born out.

${ }^{60}$ Group desertions are not independent events, and it may be easier to desert in pairs or groups.

${ }^{61}$ In Panel B reporting on the Police Gazettes, some of the coefficients suggest a deterrence.
} 
half-life specifications in the War Diaries and Police Gazettes. In terms of magnitudes, an execution of an Irish soldier (relative to execution of a British soldier) on the day of an execution would cause an increase of around 2 percentage points in the probability of an Irish absence relative to a British absence. Appendix D explores whether results may be spuriously significant.

\section{Conclusion}

Many countries struggle with non-compliance to state laws, and sanctions are sometimes ineffective in international law (Goldsmith and Posner 1999: Posner 2003). The prevailing strategy for addressing non-compliance is the imposition of harsher sanctions, and for $60 \%$ of the world's population this includes the death penalty. This is despite a lack of empirical evidence regarding the effects of the death penalty. Moral issues aside, analysis of whether British executions during World War I deterred military desertions provides a novel test for the death penalty. One prerequisite for a death penalty policy is whether individuals respond to increasing subjective risk of criminal sanction (Nagin and Pepper, eds 2012). A negative finding showing limited deterrent effect on military desertions would suggest that, even in a context where the death penalty was designed for maximum deterrence (immediate executions, public, and wide promulgation), the death penalty is not as strong a disincentive as we might imagine.

Historians believe that the decision to execute or commute was basically a random process, which I statistically corroborate. Using this result and archival data on desertions, I employ three modeling approaches to estimate the deterrent effect of the death penalty: strong SUTVA, where only the most recent event matters and I study the time from an execution or commutation until next absence; weak STUVA, where I also control for the effects of more distant events; and a day-by-day non-parametric approach, where I estimate the probability of absence as it depends on the cumulation of past executions and commutations, but impose assumptions about the half-life of these events. I find limited evidence that executing deserters deterred absences. Deterrence is observed primarily in models that cumulate the effects of all previous events with an assumption that the effect of events have half-lives of one month or more. Executing Irish soldiers spurred absences, especially Irish absences. Executing an Irish soldier increased the hazard rate of absences by 2-3 fold out of a median time of 2 weeks to the next absence, doubled the chance of Irish being the next absence, and led to a $2 \%$ higher chance of Irish absence relative to British absence.

The research design presented in this paper brings causal evidence related to issues such as the role of legitimacy in courts, organizations, and nation-states. In order to investigate the relationship between legitimacy and crime, one would need a scenario where 
essentially identical crimes led to very different punishments for arbitrary reasons with individuals observing the punishment and tracked before and after the event. Thus, this paper suggests that sometimes state-imposed sanctions can undermine state legitimacy and provides evidence of another mechanism for legal compliance beyond deterrence that has received less attention in the formal literature.

Higher rates of crime among disadvantaged groups have been attributed to mistrust of legal institutions (Tyler and Huo 2002). Disadvantaged groups in the U.S. are disproportionately sentenced to death (Donohue 2013, Alesina and La Ferrara 2014). Disparate treatment and ideological bias permeate many parts of the judicial system. More generally, questions of endogenous justice and how the normative commitments of different groups evolve onto separate paths is an interesting area of future research. One of the reasons why we regard "lawbreakers" such as Nelson Mandela and Rosa Parks as heroes is that their apprehension and treatment by authorities contributed to the collective view of the unjustness of the legal authorities they resisted. Persecuted or disadvantaged minorities may not view the law as particularly legitimate. As a result, a rational punisher must consider this reaction when setting his decision-rules, and deterrence becomes intimately tied to beliefs about how rules are applied and how knowledge and beliefs evolve over time. Assessing legitimacy of authority is essential to determining the deterrent effect of sanctions like the death penalty. 


\section{References}

Adamson, Agar, Letters of Agar Adamson, 1914 to 1919: Lieutenant Colonel, Princess Patricia's Canadian Light Infantry, first ed., CEF Books, 1997.

Alesina, Alberto and Eliana La Ferrara, "A test of racial bias in capital sentencing," The American Economic Review, 2014, 104 (11), 3397-3433.

Arthur, Max, Forgotten Voices Of The Great War, first ed., Ebury Press, 2002.

Babington, Anthony, For the Sake of Example: Capital Courts-martial, 1914-1920, Secker \& Warburg, 1983.

Baker, Chris, "The British order of battle of 1914-1918," The Long, Long Trail 1996. Retrieved from http://www.1914-1918.net/oob.htm.

_ " "In the trenches," The Long, Long Trail 1996. Retrieved from http://www.19141918.net/intrenches.htm.

_ "The infantry battalion," The Long, Long Trail 1996. Retrieved from http://www.19141918.net/whatbatt.htm.

_ , "The Long, Long Trail," http://www.1914-1918.net 1996.

Becke, Archibald Frank, Order of battle of divisions, London: His Majesty's Stationery Office, 19351944.

Bond, Steve, Asli Leblebicioglu, and Fabio Schiantarelli, "Capital Accumulation and Growth: A New Look at the Empirical Evidence," Journal of Applied Econometrics, November 2010, 25 (7), 1073-1099.

Burrage, Alfred McLelland, War is War, first ed., London: Victor Gollanczictor Gollancz, 1930.

Caplin, Andrew and Mark Dean, "Revealed preference, rational inattention, and costly information acquisition," The American Economic Review, 2015, 105 (7), 2183-2203.

Carrington, Charles, Soldier from the Wars Returning, first ed., Hutchinson \& Co Ltd, 1965.

Chen, Daniel L., Tobias J. Moskowitz, and Kelly Shue, "Decision-Making Under the Gambler's Fallacy: Evidence from Asylum Judges, Loan Officers, and Baseball Umpires," Quarterly Journal of Economics, 2016.

Cohen-Cole, Ethan, Steven Durlauf, Jeffrey Fagan, and Daniel S. Nagin, "Model Uncertainty and the Deterrent Effect of Capital Punishment," American Law and Economics Review, 2009, 11 (2), $335-369$.

Corns, Cathryn and John Hughes-Wilson, Blindfold and Alone: British Military Executions in the Great War Cassell Military Paperbacks Series, Orion Publishing Group, Limited, 1 April 2007.

Costa, Dora L. and Matthew E. Kahn, "Cowards and Heroes: Group Loyalty in the American Civil War," The Quarterly Journal of Economics, May 2003, 118 (2), 519-548.

Dalton, Hugh, The political diary of Hugh Dalton, 1918-1940, 1945-1960, London: Cape in association with the London School of Economics and Political Science, 1986.

Department of Foreign Affairs, "Shot at Dawn: Report into the Courts-Martial and Execution of Twenty Six Irish Soldiers by the British Army during World War I," 2004.

Donohue, John J., "Capital Punishment in Connecticut, 1973-2007: A Comprehensive Evaluation from 4686 Murdes to One Execution," 2013.

_ and Justin Wolfers, "Uses and Abuses of Empirical Evidence in the Death Penalty Debate," Stanford Law Review, 2005, 58 (3), 791-845.

Edmonds, James Edward, History of the Great War: Military Operations, France and Belgium, London: MacMillan and Co., Limited, 1922.

Ehrlich, Isaac, "The Deterrent Effect of Capital Punishment: A Question of Life and Death," The American Economic Review, June 1975, 65 (3), 397-417.

Ferguson, Niall, The pity of war: Explaining world war I, Basic Books, 2008.

Fitzpatrick, David, "Militarism in Ireland, 1900-1922," in Thomas Bartlett and Keith Jeffery, eds., A military history of Ireland, Cambridge University Press, 1996, chapter 17, pp. 379-406.

Goldsmith, Jack L and Eric A Posner, "A theory of customary international law," The University of Chicago Law Review, 1999, pp. 1113-1177.

Graham-Harrison, W. M., ed., Manual of Military Law, 5th ed., London: His Majesty's Stationery Office, November 1907. Great Britain War Office.

Great Britian War Office, The King's Regulations $\&$ Orders for the Army, first ed., London: His 
Majesty's Stationary Office, 1914.

Hansard, "House of Commons Debates," $1915 . \quad$ Retrieved from http://hansard.millbanksystems.com/commons/1915/jul/01/courts-martial-death-sentences.

Hansen, Bruce E, "Least squares model averaging," Econometrica, 2007, 75 (4), 1175-1189.

Hertwig, Ralph, Greg Barron, Elke U. Weber, and Ido Erev, "Decisions From Experience and the Effect of Rare Events in Risky Choice," Psychological Science, 2004, 15 (8), 534-539.

i Martin, Xavier Sala, Gernot Doppelhofer, and Ronald I. Miller, "Determinants of Long-Term Growth: A Bayesian Averaging of Classical Estimates (BACE) Approach," The American Economic Review, 2004, 94 (4), 813-835.

Jahr, Christoph, Gewöhnliche Soldaten: Desertion und Deserteure im deutschen und britischen Heer 1914-1918, Vol. 123 of Kritische Studien zur Geschichtswissenschaft / Kritische Studien zur Geschichtswissenschaft, Ruprecht Gmbh \& Company, 1998.

_ "War, Discipline, and Politics," in Jean-Marc Berlière, Jonas Campion, Luigi Lacchè, and Xavier Rousseaux, eds., Military Justices and World Wars (Europe 1914-1950), Presses universitaires de Louvain, 2014, pp. 73-105.

James, E. A., British Regiments, 1914-1918, London: Samson Books Limited, 1978.

Jeffery, Keith, Ireland and the Great War Lees Knowles lectures, Cambridge University Press, 2000.

Johnson, David, Executed at Dawn: British Firing Squads on the Western Front 1914-1918, The History Press, 2015.

Kahneman, Daniel, Thinking, Fast and Slow, Farrar, Straus and Giroux, 2011.

Katz, Lawrence, Steven D. Levitt, and Ellen Shustorovich, "Prison Conditions, Capital Punishment, and Deterrence," American Law and Economics Review, 2003, 5 (2), 318-343.

Leamer, Edward E, Specification searches: Ad hoc inference with nonexperimental data, Vol. 53, John Wiley \& Sons Incorporated, 1978.

Moore, William, The Thin Yellow Line, St. Martin's Press, 1975.

Nagin, Daniel S. and John V. Pepper, eds, Deterrence and the Death Penalty, Washington, D.C.: The National Academies Press, 2012. Committee on Deterrence and the Death Penalty; Committee on Law and Justice; Division on Behavioral and Social Sciences and Education; National Research Council.

Oram, Gerard Christopher, Worthless Men: Race, eugenics and the death penalty in the British Army during the First World War, London: Francis Boutle Publishers, 1998.

- Military Executions During World War I, New York: Palgrave Macmillan, 2003.

Peaty, John, "Haig and Military Discipline," in Brian Bond and Nigel Cave, eds., Haig: A Reappraisal Seventy Years On, Pen \& Sword Books, Ltd., 1999.

Perry, Nicholas, "Nationality in the Irish Infantry Regiments in the First World War," War and Society, May 1994, 12 (1), 65-95.

Posner, Eric A, "Do States Have a Moral Obligation to Obey International Law?," Stanford Law Review, 2003, pp. 1901-1919.

Putkowski, Julian and Julian Sykes, Shot at dawn : executions in World War One by authority of the British Army act, new \& revised ed., London: Leo Cooper, 2007.

and Mark Dunning, Murderous Tommies: The Courts Martial of Thirteen British Soldiers Executed for Murder During the First World War, Pen \& Sword Books Ltd., 2012.

Rubin, Donald B., "Estimating Causal Effects of Treatments in Randomized and Non-Randomized Studies," Journal of Educational Psychology, October 1974, 66 (5), 688-701.

Rubin, Gerry, "The Last Word on the Capital Courts Martial Controversy in Britain?," in Jean-Marc Berlière, Jonas Campion, Luigi Lacchè, and Xavier Rousseaux, eds., Justices militaires et guerres mondiales (Europe 1914-1950)/Military Justices and World Wars (Europe 1940-1950), Presses Universitaires de Louvain, 2013, pp. 39-56.

Sellers, Leonard, Death for Desertion: The Story of the Court Martial and Execution of Sub Lt. Edwin Dyett, Barnsley: Leo Cooper, July 2003.

Sheffield, Gary, "Officer-Man Relations, Discipline and Morale in the British Army of the Great War," in Hugh Cecil and Peter H. Liddle, eds., Facing Armageddon: The First World War Experienced, Leo Cooper/Pen \& Sword, 1996, pp. 413-424.

Sims, Christopher A., "Implications of Rational Inattention," Journal of Monetary Economics, April 
2003, $50(3), 665-690$.

The Generations Network, "Surnames of Irish Origin," Last Name Meanings Dictionary 2009. Retrieved from http://www.last-names.net/origincat.asp?origincat=Irish.

The War Office, Statistics of the military effort of the British Empire during the Great War, 1914-1920, London: His Majesty's Stationery Office, March 1922.

Turner, P. W. and R. H. Haigh, Not for Glory, first ed., London: Maxwell, 1969.

Tyler, Tom R. and Yuen J. Huo, Trust in the Law: Encouraging Public Cooperation with the Police and Courts Russell Sage Foundation Series on Trust, Russell Sage Foundation, 2002.

van Emden, Richard, The Soldiers' War: The Great War through Veterans' Eyes, A\&C Black, 2010. 
Table 1: Are Observable Characteristics Correlated with Execution Decisions? (Deserters)

\begin{tabular}{|c|c|c|c|c|c|c|c|c|c|c|c|}
\hline & $(1)$ & $(2)$ & $(3)$ & (4) & $(5)$ & (6) & $(7)$ & $(8)$ & (9) & $(10)$ & $(11)$ \\
\hline \multirow[t]{2}{*}{ Irish } & -0.00133 & -0.00162 & 0.00750 & -0.00261 & $-1.93 \mathrm{e}-14$ & -0.000283 & -0.000398 & -0.00313 & -0.0147 & -0.00467 & 0.0131 \\
\hline & $(0.0214)$ & $(0.0214)$ & $(0.0143)$ & $(0.0214)$ & $(0.230)$ & $(0.0215)$ & $(0.0214)$ & $(0.0219)$ & $(0.0244)$ & $(0.0218)$ & $(0.0181)$ \\
\hline \multirow[t]{2}{*}{ Private } & & -0.0577 & & & & & & & & & -0.0265 \\
\hline & & $(0.0443)$ & & & & & & & & & $(0.0371)$ \\
\hline \multirow[t]{2}{*}{ Age } & & & -0.00464 & & & & & & & & 0.00274 \\
\hline & & & $(0.00316)$ & & & & & & & & $(0.00396)$ \\
\hline \multirow[t]{2}{*}{1915} & & & & -0.138 & -0.135 & & & & & $-0.210+$ & -0.0495 \\
\hline & & & & $(0.0951)$ & $(0.107)$ & & & & & $(0.110)$ & $(0.115)$ \\
\hline \multirow[t]{2}{*}{1916} & & & & -0.148 & -0.150 & & & & & $-0.246^{*}$ & -0.00752 \\
\hline & & & & $(0.0934)$ & $(0.105)$ & & & & & $(0.109)$ & $(0.114)$ \\
\hline \multirow[t]{2}{*}{1917} & & & & $-0.205^{*}$ & $-0.205^{*}$ & & & & & $-0.288^{* *}$ & -0.0376 \\
\hline & & & & $(0.0930)$ & $(0.104)$ & & & & & $(0.109)$ & $(0.114)$ \\
\hline \multirow[t]{2}{*}{1918} & & & & $-0.222^{*}$ & $-0.219^{*}$ & & & & & $-0.320^{* *}$ & -0.0678 \\
\hline & & & & $(0.0939)$ & $(0.105)$ & & & & & $(0.110)$ & $(0.114)$ \\
\hline \multirow[t]{2}{*}{ Irish x 1915} & & & & & -0.0152 & & & & & & \\
\hline & & & & & $(0.237)$ & & & & & & \\
\hline \multirow[t]{2}{*}{ Irish x 1916} & & & & & 0.00798 & & & & & & \\
\hline & & & & & $(0.234)$ & & & & & & \\
\hline \multirow[t]{2}{*}{ Irish x 1917} & & & & & 0.00133 & & & & & & \\
\hline & & & & & $(0.233)$ & & & & & & \\
\hline \multirow[t]{2}{*}{ Irish x 1918} & & & & & -0.0156 & & & & & & \\
\hline & & & & & $(0.235)$ & & & & & & \\
\hline \multirow[t]{2}{*}{ New Army } & & & & & & & & & 0.0185 & & \\
\hline & & & & & & & & & $(0.0214)$ & & \\
\hline \multirow[t]{2}{*}{ Territorial Army } & & & & & & & & & -0.00713 & & \\
\hline & & & & & & & & & $(0.0303)$ & & \\
\hline \multirow[t]{2}{*}{$\Delta \log$ Casualties } & & & & & & & & & & -0.00134 & -0.00493 \\
\hline & & & & & & & & & & $(0.00742)$ & $(0.00565)$ \\
\hline \multirow[t]{2}{*}{$\Delta$ Log Casualties 30 Days Ago } & & & & & & & & & & 0.00327 & -0.00292 \\
\hline & & & & & & & & & & $(0.00718)$ & $(0.00540)$ \\
\hline Distance to Coast & & & & & & & & & & & $-0.000474+$ \\
\hline & & & & & & & & & & & $(0.000268)$ \\
\hline \multirow[t]{2}{*}{ Distance to Berlin } & & & & & & & & & & & 0.000240 \\
\hline & & & & & & & & & & & $(0.000467)$ \\
\hline Year Fixed Effects & $\mathrm{N}$ & $\mathrm{N}$ & $\mathrm{N}$ & $\mathrm{Y}$ & $\mathrm{Y}$ & $\mathrm{N}$ & $\mathrm{N}$ & $\mathrm{N}$ & $\mathrm{N}$ & $\mathrm{Y}$ & $\mathrm{Y}$ \\
\hline Month Fixed Effects & $\mathrm{N}$ & $\mathrm{N}$ & $\mathrm{N}$ & $\mathrm{N}$ & $\mathrm{N}$ & $\mathrm{Y}$ & $\mathrm{N}$ & $\mathrm{N}$ & $\mathrm{N}$ & $\mathrm{N}$ & $\mathrm{N}$ \\
\hline Day of Week Fixed Effects & $\mathrm{N}$ & $\mathrm{N}$ & $\mathrm{N}$ & $\mathrm{N}$ & $\mathrm{N}$ & $\mathrm{N}$ & $\mathrm{Y}$ & $\mathrm{N}$ & $\mathrm{N}$ & $\mathrm{N}$ & $\mathrm{N}$ \\
\hline Division Fixed Effects & $\mathrm{N}$ & $\mathrm{N}$ & $\mathrm{N}$ & $\mathrm{N}$ & $\mathrm{N}$ & $\mathrm{N}$ & $\mathrm{N}$ & Y & $\mathrm{N}$ & $\mathrm{Y}$ & $\mathrm{Y}$ \\
\hline Joint Test of Fixed Effects & & & & 0.000883 & 0.00575 & 0.750 & 0.258 & 0.0272 & 0.590 & & \\
\hline Joint Test of Irish x Year FE & & & & & 0.995 & & & & & & \\
\hline Joint Test of Casualties & & & & & & & & & & 0.839 & \\
\hline Joint Test of Distance & & & & & & & & & & & 0.209 \\
\hline \multirow[t]{2}{*}{ Constant } & $0.151^{* *}$ & $0.206^{* *}$ & $0.984^{* *}$ & $0.334^{* *}$ & $0.333^{* *}$ & $0.144^{* *}$ & $0.178^{* *}$ & $0.188^{*}$ & $0.162^{* *}$ & $0.493^{* *}$ & $0.757^{*}$ \\
\hline & $(0.00959)$ & $(0.0436)$ & $(0.0801)$ & $(0.0921)$ & $(0.103)$ & $(0.0306)$ & $(0.0275)$ & $(0.0889)$ & $(0.0154)$ & $(0.140)$ & $(0.379)$ \\
\hline $\mathrm{N}$ & 1741 & 1741 & 1741 & 1741 & 1741 & 1741 & 1741 & 1741 & 1418 & 1741 & 1190 \\
\hline R-sq & 0.000 & 0.001 & 0.554 & 0.011 & 0.011 & 0.004 & 0.004 & 0.055 & 0.001 & 0.066 & 0.609 \\
\hline
\end{tabular}

Notes: All regressions use ordinary least squares on death sentences occurring in France \& Flanders before the end of World War I. Death sentences recorded without Divisions or from the Labour Corps were removed. Log Casualties is calculated as $\log (1+$ Casualties $) . \Delta$ Log Casualties is defined as the difference in Log Casualties 1 to 29 Days Ago vs. 30 to 59 Days Ago. $\Delta$ Log Casualties 30 Days Ago is defined as the difference in Log Casualties 30 to 59 Days Ago vs. 60 to 89 Days Ago. Distances are set to missing before the first battle and after the last battle. Territorial/New/Regular Army status is not assigned for Indian, Australian, Canadian, or New Zealand Divisions. Regressions including age also dummy out age when it is missing (i.e., assign a constant and include an indicator for age being missing). Standard errors in parentheses; $+\mathrm{p}<0.10,{ }^{*} \mathrm{p}<0.05,{ }^{* *} \mathrm{p}<0.01$. Results are similar with Logit or Probit. 


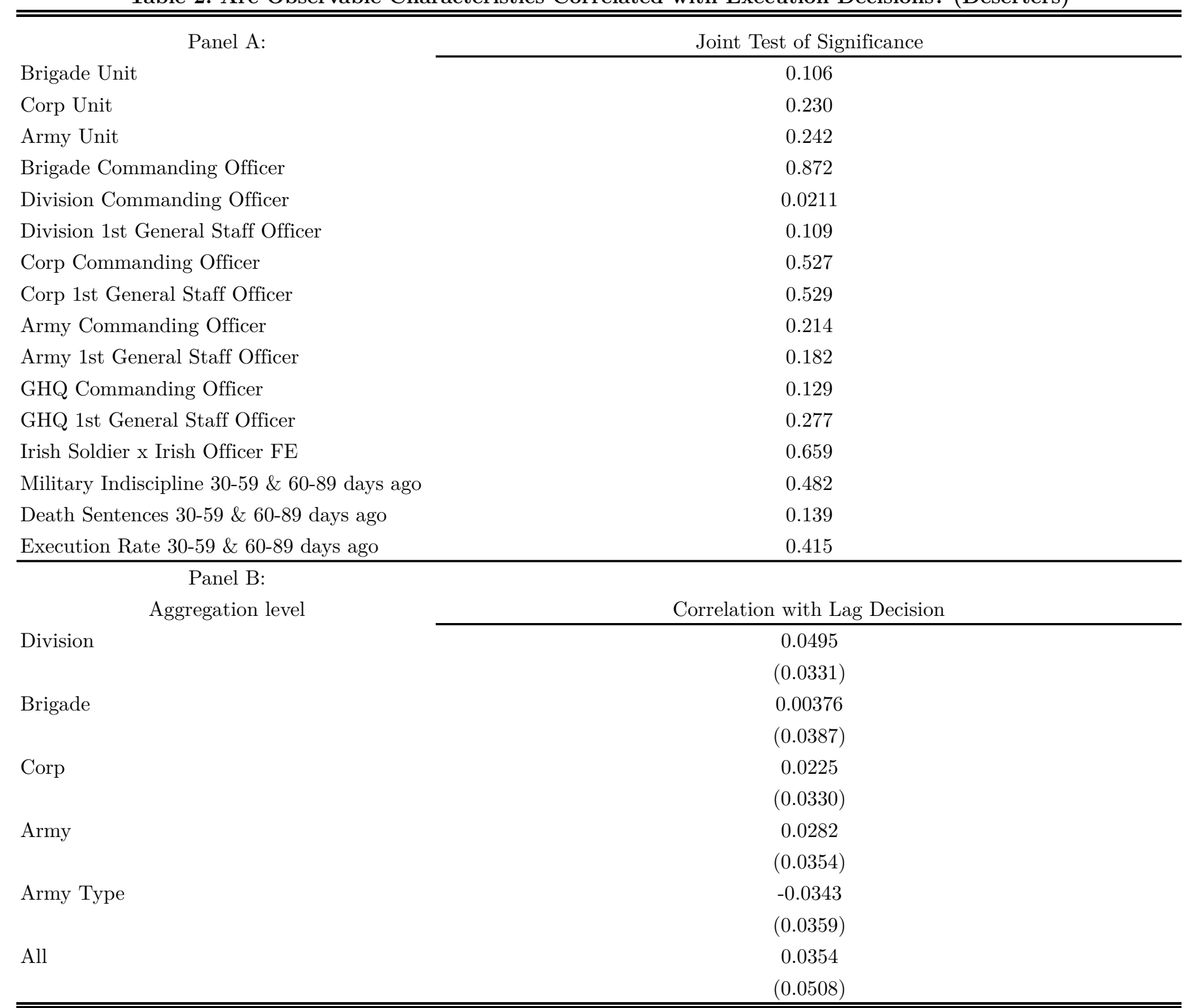

Notes: Data is restricted to death sentences occurring in France \& Flanders before the end of World War I. Death sentences recorded without Divisions or from the Labour Corps were removed. In Panel A, each row reports a separate ordinary least squares regression and tests of joint significance of the fixed effects or measures of the recent battle environment. Military indiscipline and death sentences are calculated as $\log (1+$ number $)$. Military indiscipline is the average of absentees and trials measured from the War Diaries, Police Gazettes, and FGCM trial registries. Lag execution rates is a set of controls comprising the numbers of executions and commutations within each time window. Units or officers that appeared with less than 10 frequency were categorized in a separate "other" category. All regression models include year, division, and Irish fixed effects. In Panel B, each row reports a separate ordinary least squares stacked autocorrelation regression. The strings of events within each unit were stacked and the first event within each unit was excluded as a dependent variable. If more than one event occurred on a day within a unit, the average outcome was calculated for that day. All regression models include year fixed effects and the leave-one-out mean execution rate of the unit. Standard errors in parentheses; $+\mathrm{p}<0.10,{ }^{*} \mathrm{p}<0.05,{ }^{* *} \mathrm{p}<0.01$. Results are similar with Logit or Probit. 
Table 3: Are Observable Characteristics Correlated with Execution Decisions? (All Death Sentences)

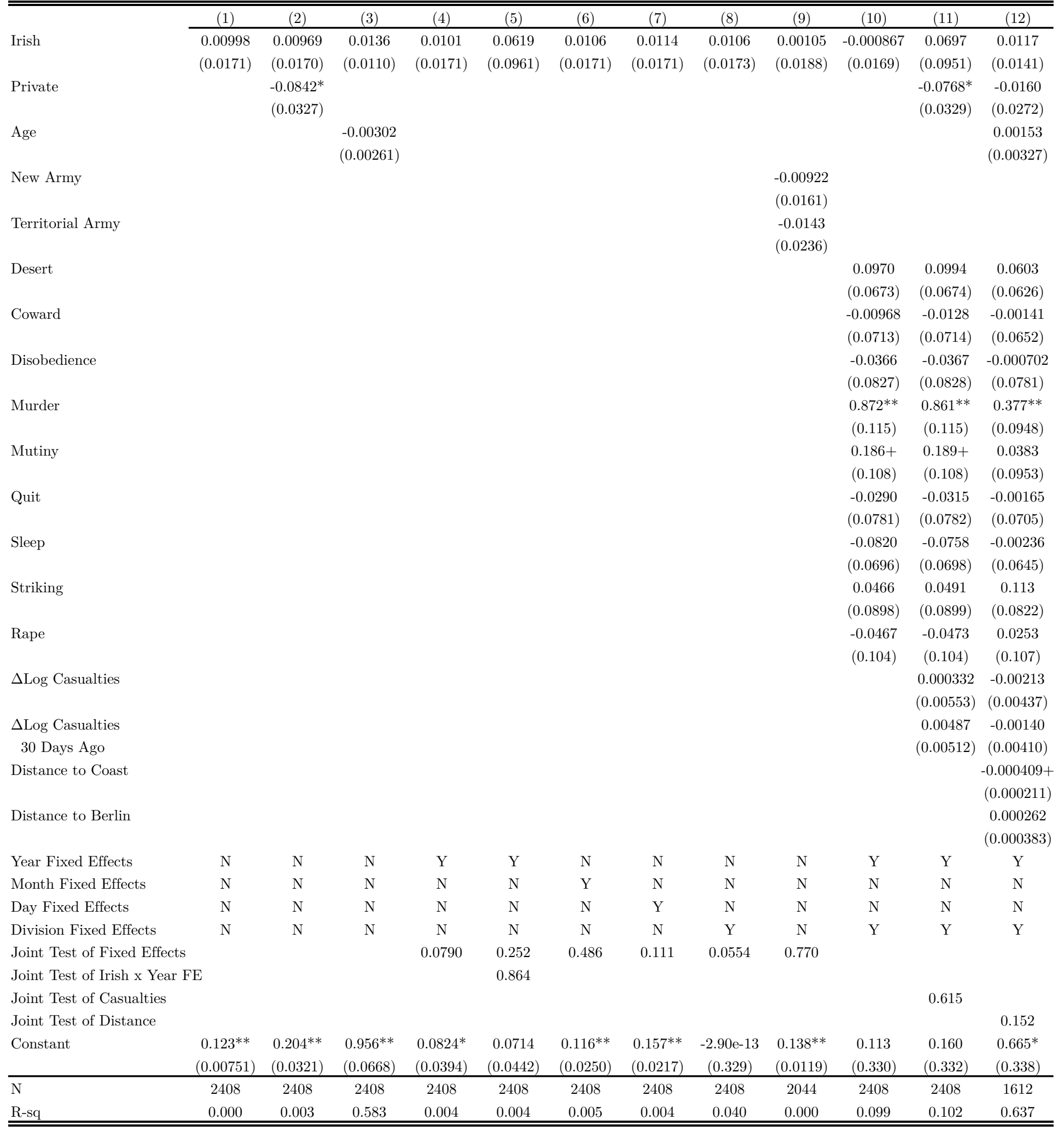

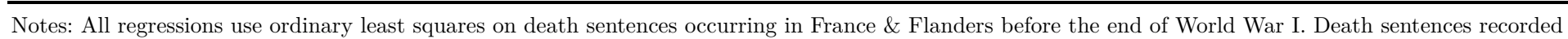
without Divisions or from the Labour Corps were removed. Log Casualties is calculated as $\log (1+$ Casualties). $\Delta$ Log Casualties is defined as the difference in Log Casualties 1 to 29 Days Ago vs. 30 to 59 Days Ago. $\Delta$ Log Casualties 30 Days Ago is defined as the difference in Log Casualties 30 to 59 Days Ago vs. 60 to 89 Days Ago. Distances are calculated based on the soldier's unit's participation in battles and are interpolated between battles. Distances are set to missing before the first battle and after the last battle. Territorial/New/Regular Army status is not assigned for Indian, Australian, Canadian, or New Zealand Divisions. Regressions including age also dummy out age when it is missing (i.e., assign a constant and include an indicator for age being missing). Standard errors in parentheses; $+\mathrm{p}<0.10,{ }^{*} \mathrm{p}<0.05,{ }^{*} \mathrm{p}<0.01$. Results are similar with Logit or Probit. 
Panel A:

Brigade Unit

Corp Unit

Army Unit

Brigade Commanding Officer

Division Commanding Officer

Division 1st General Staff Officer

Corp Commanding Officer

Corp 1st General Staff Officer

Army Commanding Officer

Army 1st General Staff Officer

GHQ Commanding Officer

GHQ 1st General Staff Officer

Irish Soldier x Irish Officer FE

Military Indiscipline 30-59 \& 60-89 days ago

Death Sentences 30-59 \& 60-89 days ago

Execution Rate 30-59 \& 60-89 days ago

\section{Panel B:}

Aggregation level

Division

Brigade

Corp

Army

Army Type

Joint Test of Significance

Joint Test of Significance

0.190

0.328

0.670

0.185

0.517

0.366

0.0900

0.0688

0.308

0.369

0.455

0.452

0.325

0.109

0.324

Correlation with Lag Decision

0.00486

$-0.00508$

$-0.00762$

(0.0333)

0.0790

All

$(0.0503)$

Notes: Data is restricted to death sentences occurring in France \& Flanders before the end of World War I. Death sentences recorded without Divisions or from the Labour Corps were removed. In Panel A, each row reports a separate ordinary least squares regression and tests of joint significance of the fixed effects or measures of the recent battle environment. Military indiscipline and death sentences are calculated as $\log (1+$ number $)$. Military indiscipline is the average of absentees and trials measured from the War Diaries, Police Gazettes, and FGCM trial registries. Lag execution rates is a set of controls comprising the numbers of executions and commutations within each time window. Units or officers that appeared with less than 10 frequency were categorized in a separate "other" category. All regression models include year, division, and Irish fixed effects. In Panel B, each row reports a separate ordinary least squares stacked autocorrelation regression. The strings of events within each unit were stacked and the first event within each unit was excluded as a dependent variable. If more than one event occurred on a day within a unit, the average outcome was calculated for that day. All regression models include year fixed effects and the leave-one-out mean execution rate of the unit. Standard errors in parentheses; $+\mathrm{p}<0.10,{ }^{*} \mathrm{p}<0.05,{ }^{* *} \mathrm{p}<0.01$. Results are similar with Logit or Probit. 

(1)
(2)
$(3)$
(4)
(5)
(6)
(7)
(8)

(9)

\begin{tabular}{|c|c|c|c|c|c|c|c|c|c|}
\hline Panel A: War Diaries & Exp/+14 & $\mathrm{Wb} /+14$ & Cox $/+14$ & Exp/NN & $\mathrm{Wb} / \mathrm{NN}$ & $\mathrm{Cox} / \mathrm{NN}$ & $\operatorname{Exp} / \mathrm{C}=\mathrm{T}$ & $\mathrm{Wb} / \mathrm{C}=\mathrm{T}$ & $\operatorname{Cox} / \mathrm{C}=\mathrm{T}$ \\
\hline \multirow[t]{2}{*}{ Execution } & -0.177 & -0.144 & -0.158 & 0.183 & 0.167 & 0.129 & $0.280+$ & $0.250+$ & 0.209 \\
\hline & $(0.174)$ & $(0.152)$ & $(0.155)$ & $(0.202)$ & $(0.171)$ & $(0.167)$ & $(0.147)$ & $(0.132)$ & $(0.129)$ \\
\hline & $(0.0671)$ & $(0.0579)$ & $(0.0516)$ & $(0.0833)$ & $(0.0715)$ & $(0.0638)$ & $(0.0629)$ & $(0.0562)$ & $(0.0505)$ \\
\hline 30 Days Ago & $(0.0601)$ & $(0.0506)$ & $(0.0444)$ & $(0.0692)$ & $(0.0573)$ & $(0.0515)$ & $(0.0600)$ & $(0.0519)$ & $(0.0454)$ \\
\hline $\mathrm{N}$ & 536 & 536 & 536 & 536 & 536 & 536 & 536 & 536 & 536 \\
\hline
\end{tabular}

Panel B: Police Gazette

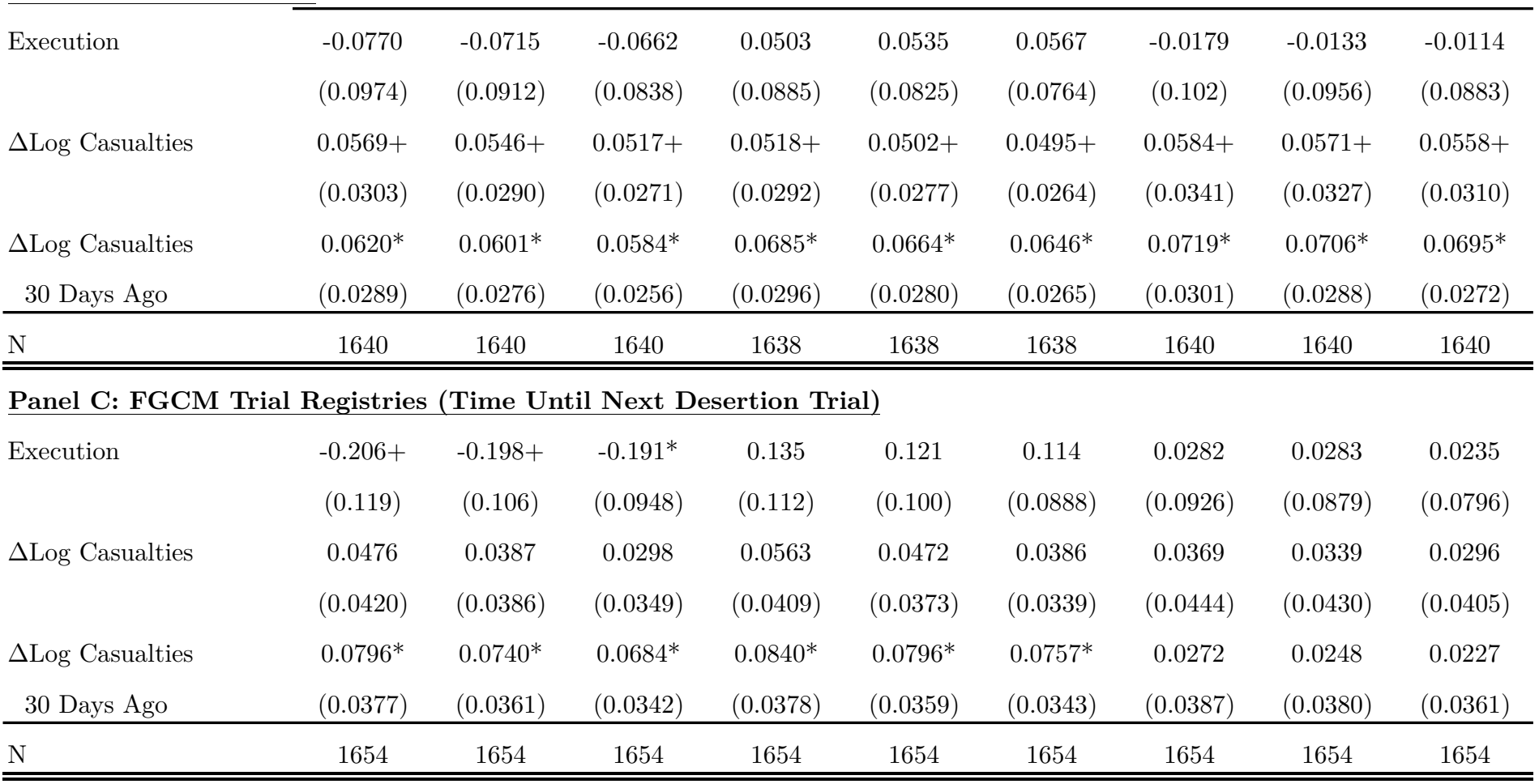

Notes: Outcome is elapsed time from death sentence resolution (execution or commutation) until next absence. "Exp", "Wb" and "Cox" use the exponential, Weibull and Cox models respectively to parameterize the baseline hazard. In columns sub-titled " +14 ", the announcement of the commutation is assumed to occur 14 days after trial. In columns subtitled "NN" the nearest-neighbor method is used, which means the imputed announcement of the commutation is same as the most nearby execution announcement, while in columns labeled " $\mathrm{C}=\mathrm{T}$ ", the trial date is used as the announcement date of the execution and commutation. Log Casualties is calculated as $\log (1+$ Casualties $) . \Delta \log$ Casualties is defined as the difference in Log Casualties 1 to 29 Days Ago vs. 30 to 59 Days Ago. $\Delta$ Log Casualties 30 Days Ago is defined as the difference in Log Casualties 30 to 59 Days Ago vs. 60 to 89 Days Ago. All specifications include division and year fixed-effects. War Diaries analysis restricts to July 1916-June 1917, which is the time window for the surviving data. Standard errors clustered at the division level in parentheses; $+\mathrm{p}<0.10,{ }^{*} \mathrm{p}<0.05,{ }^{* *} \mathrm{p}<0.01$ 
Table 6: Effects of Executions vs. Commutations on Elapsed Time Until Next Absence Differing by whether Case was a Desertion Trial and whether Soldier was Irish

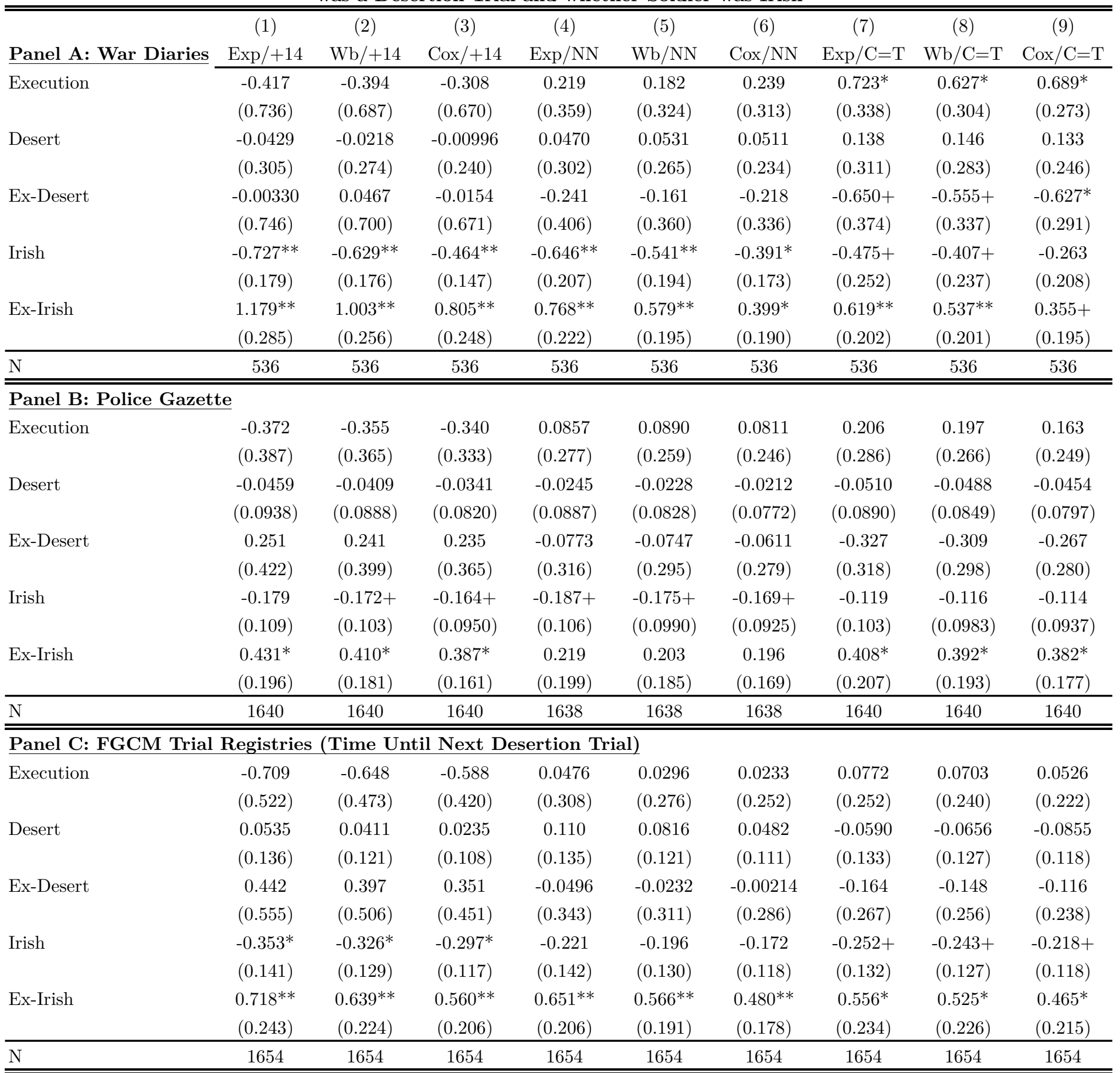

Notes: Outcome is elapsed time from death sentence resolution (execution or commutation) until next absence. "Exp", "Wb" and "Cox" use the exponential, Weibull and Cox models respectively to parameterize the baseline hazard. In columns sub-titled "+14", the announcement of the commutation is assumed to occur 14 days after trial. In columns subtitled "NN" the nearest-neighbor method is used, which means the imputed announcement of the commutation is same as the most nearby execution announcement, while in columns labeled " $\mathrm{C}=\mathrm{T}$ ", the trial date is used as the announcement date of the execution and commutation. All specifications include division and year fixed-effects and $\Delta \log$ Casualties and $\Delta \log$ Casualties 30 Days Ago. War Diaries analysis restricts to July 1916-June 1917, which is the time window for the surviving data. Standard errors clustered at the division level in parentheses; $+\mathrm{p}<$ $0.10,{ }^{*} \mathrm{p}<0.05,{ }^{* *} \mathrm{p}<0.01$ 
Table 7: Effects of Execution vs. Commutation on Elapsed Time Until Next Absence, Full Sample, Weak SUTVA

\begin{tabular}{|c|c|c|c|c|c|c|c|c|c|c|c|c|c|c|c|c|c|c|}
\hline & \multicolumn{6}{|c|}{ War Diaries } & \multicolumn{6}{|c|}{$\underline{\text { Police Gazettes }}$} & \multicolumn{6}{|c|}{ FGCM Trial Registries (Desertion Trials) } \\
\hline & $(1)$ & $(2)$ & (3) & $(4)$ & $(5)$ & $(6)$ & $(7)$ & (8) & (9) & $(10)$ & $(11)$ & $(12)$ & $(13)$ & $(14)$ & $(15)$ & $(16)$ & $(17)$ & $(18)$ \\
\hline Execution & $\begin{array}{l}-0.417 \\
(0.736)\end{array}$ & $\begin{array}{l}-0.390 \\
(0.798)\end{array}$ & $\begin{array}{l}-0.378 \\
(0.781)\end{array}$ & $\begin{array}{l}-0.368 \\
(0.742)\end{array}$ & $\begin{array}{l}-0.374 \\
(0.701)\end{array}$ & $\begin{array}{l}-0.389 \\
(0.679)\end{array}$ & $\begin{array}{l}-0.372 \\
(0.387)\end{array}$ & $\begin{array}{l}-0.544 \\
(0.527)\end{array}$ & $\begin{array}{l}-0.513 \\
(0.497)\end{array}$ & $\begin{array}{l}-0.475 \\
(0.447)\end{array}$ & $\begin{array}{l}-0.432 \\
(0.407)\end{array}$ & $\begin{array}{l}-0.411 \\
(0.393)\end{array}$ & $\begin{array}{l}-0.709 \\
(0.522)\end{array}$ & $\begin{array}{l}-0.919 \\
(0.699)\end{array}$ & $\begin{array}{l}-0.895 \\
(0.675)\end{array}$ & $\begin{array}{l}-0.856 \\
(0.622)\end{array}$ & $\begin{array}{l}-0.791 \\
(0.566)\end{array}$ & $\begin{array}{l}-0.752 \\
(0.541)\end{array}$ \\
\hline Ex-Desert & $\begin{array}{c}-0.00330 \\
(0.746)\end{array}$ & $\begin{array}{l}-0.0249 \\
(0.782)\end{array}$ & $\begin{array}{r}-0.0306 \\
(0.762)\end{array}$ & $\begin{array}{r}-0.0251 \\
(0.728)\end{array}$ & $\begin{array}{c}0.000868 \\
(0.697)\end{array}$ & $\begin{array}{l}0.0202 \\
(0.683)\end{array}$ & $\begin{array}{c}0.251 \\
(0.422)\end{array}$ & $\begin{array}{c}0.312 \\
(0.562)\end{array}$ & $\begin{array}{c}0.284 \\
(0.529)\end{array}$ & $\begin{array}{c}0.258 \\
(0.480)\end{array}$ & $\begin{array}{c}0.234 \\
(0.441)\end{array}$ & $\begin{array}{c}0.228 \\
(0.426)\end{array}$ & $\begin{array}{c}0.442 \\
(0.555)\end{array}$ & $\begin{array}{l}0.518 \\
(0.741)\end{array}$ & $\begin{array}{c}0.504 \\
(0.716)\end{array}$ & $\begin{array}{c}0.474 \\
(0.663)\end{array}$ & $\begin{array}{c}0.430 \\
(0.607)\end{array}$ & $\begin{array}{c}0.411 \\
(0.580)\end{array}$ \\
\hline Irish & $\begin{array}{c}-0.727^{* *} \\
(0.179)\end{array}$ & $\begin{array}{c}-0.769^{* *} \\
(0.181)\end{array}$ & $\begin{array}{c}-0.784^{* *} \\
(0.190)\end{array}$ & $\begin{array}{c}-0.822^{* *} \\
(0.212)\end{array}$ & $\begin{array}{c}-0.850^{* *} \\
(0.226)\end{array}$ & $\begin{array}{c}-0.836^{* *} \\
(0.220)\end{array}$ & $\begin{array}{l}-0.179 \\
(0.109)\end{array}$ & $\begin{array}{l}-0.158 \\
(0.110)\end{array}$ & $\begin{array}{l}-0.172 \\
(0.109)\end{array}$ & $\begin{array}{c}-0.186+ \\
(0.107)\end{array}$ & $\begin{array}{c}-0.189+ \\
(0.108)\end{array}$ & $\begin{array}{c}-0.185+ \\
(0.108)\end{array}$ & $\begin{array}{c}-0.353^{*} \\
(0.141)\end{array}$ & $\begin{array}{c}-0.351^{*} \\
(0.143)\end{array}$ & $\begin{array}{c}-0.365^{*} \\
(0.144)\end{array}$ & $\begin{array}{c}-0.373^{* *} \\
(0.145)\end{array}$ & $\begin{array}{c}-0.366^{*} \\
(0.144)\end{array}$ & $\begin{array}{l}-0.358^{*} \\
(0.143)\end{array}$ \\
\hline Ex-Irish & $\begin{array}{l}1.179^{* *} \\
(0.285)\end{array}$ & $\begin{array}{l}1.258^{* *} \\
(0.323)\end{array}$ & $\begin{array}{c}1.262^{* *} \\
(0.308)\end{array}$ & $\begin{array}{c}1.310^{* *} \\
(0.282)\end{array}$ & $\begin{array}{c}1.359^{* *} \\
(0.270)\end{array}$ & $\begin{array}{l}1.347^{* *} \\
(0.268)\end{array}$ & $\begin{array}{l}0.431^{*} \\
(0.196)\end{array}$ & $\begin{array}{l}0.432^{*} \\
(0.210)\end{array}$ & $\begin{array}{l}0.440^{*} \\
(0.202)\end{array}$ & $\begin{array}{l}0.437^{*} \\
(0.196)\end{array}$ & $\begin{array}{l}0.424^{*} \\
(0.196)\end{array}$ & $\begin{array}{l}0.420^{*} \\
(0.196)\end{array}$ & $\begin{array}{c}0.718^{* *} \\
(0.243)\end{array}$ & $\begin{array}{c}0.726^{* *} \\
(0.260)\end{array}$ & $\begin{array}{c}0.750^{* *} \\
(0.255)\end{array}$ & $\begin{array}{c}0.778^{* *} \\
(0.253)\end{array}$ & $\begin{array}{c}0.775^{* *} \\
(0.251)\end{array}$ & $\begin{array}{c}0.761^{* *} \\
(0.249)\end{array}$ \\
\hline$\Delta$ Log Casualties & $\begin{array}{c}0.0870 \\
(0.0602)\end{array}$ & $\begin{array}{c}0.0812 \\
(0.0602)\end{array}$ & $\begin{array}{c}0.0781 \\
(0.0599)\end{array}$ & $\begin{array}{c}0.0721 \\
(0.0595)\end{array}$ & $\begin{array}{c}0.0626 \\
(0.0597)\end{array}$ & $\begin{array}{c}0.0574 \\
(0.0603)\end{array}$ & $\begin{array}{l}0.0537+ \\
(0.0301)\end{array}$ & $\begin{array}{c}0.0738^{* *} \\
(0.0269)\end{array}$ & $\begin{array}{c}0.0774^{* *} \\
(0.0281)\end{array}$ & $\begin{array}{l}0.0748^{*} \\
(0.0292)\end{array}$ & $\begin{array}{l}0.0682^{*} \\
(0.0294)\end{array}$ & $\begin{array}{l}0.0629 * \\
(0.0293)\end{array}$ & $\begin{array}{c}0.0422 \\
(0.0413)\end{array}$ & $\begin{array}{c}0.0597 \\
(0.0371)\end{array}$ & $\begin{array}{c}0.0658+ \\
(0.0380)\end{array}$ & $\begin{array}{c}0.0662+ \\
(0.0389)\end{array}$ & $\begin{array}{c}0.0605 \\
(0.0394)\end{array}$ & $\begin{array}{c}0.0543 \\
(0.0398)\end{array}$ \\
\hline $\begin{array}{l}\Delta \text { Log Casualties } \\
30 \text { Days Ago }\end{array}$ & $\begin{array}{l}0.170^{* *} \\
(0.0569)\end{array}$ & $\begin{array}{l}0.173^{* *} \\
(0.0596)\end{array}$ & $\begin{array}{l}0.170^{* *} \\
(0.0599)\end{array}$ & $\begin{array}{l}0.163^{* *} \\
(0.0613)\end{array}$ & $\begin{array}{c}0.153^{*} \\
(0.0634)\end{array}$ & $\begin{array}{c}0.148^{*} \\
(0.0641)\end{array}$ & $\begin{array}{l}0.0652^{*} \\
(0.0286)\end{array}$ & $\begin{array}{l}0.0619^{*} \\
(0.0276)\end{array}$ & $\begin{array}{l}0.0681^{*} \\
(0.0272)\end{array}$ & $\begin{array}{c}0.0719^{* *} \\
(0.0275)\end{array}$ & $\begin{array}{c}0.0709^{* *} \\
(0.0275)\end{array}$ & $\begin{array}{l}0.0689^{*} \\
(0.0274)\end{array}$ & $\begin{array}{l}0.0856^{*} \\
(0.0370)\end{array}$ & $\begin{array}{l}0.0826^{*} \\
(0.0358)\end{array}$ & $\begin{array}{l}0.0924^{* *} \\
(0.0350)\end{array}$ & $\begin{array}{l}0.100^{* *} \\
(0.0344)\end{array}$ & $\begin{array}{c}0.0987^{* *} \\
(0.0342)\end{array}$ & $\begin{array}{l}0.0944^{* *} \\
(0.0343)\end{array}$ \\
\hline Ex's - 7d & & $\begin{array}{l}-0.194 \\
(0.214)\end{array}$ & & & & & & $\begin{array}{c}0.214^{*} \\
(0.0939)\end{array}$ & & & & & & $\begin{array}{c}0.356^{* *} \\
(0.116)\end{array}$ & & & & \\
\hline Ex's - 14d & & & $\begin{array}{l}-0.146 \\
(0.155)\end{array}$ & & & & & & $\begin{array}{c}0.0840 \\
(0.0788)\end{array}$ & & & & & & $\begin{array}{c}0.172+ \\
(0.0901)\end{array}$ & & & \\
\hline Cm's - 14d & & & $\begin{array}{r}-0.0439 \\
(0.108)\end{array}$ & & & & & & $\begin{array}{l}0.156^{* *} \\
(0.0383)\end{array}$ & & & & & & $\begin{array}{l}0.140^{* *} \\
(0.0328)\end{array}$ & & & \\
\hline Ex's - 30d & & & & $\begin{array}{l}-0.147 \\
(0.130)\end{array}$ & & & & & & $\begin{array}{l}-0.0270 \\
(0.0703)\end{array}$ & & & & & & $\begin{array}{c}0.0216 \\
(0.0738)\end{array}$ & & \\
\hline Cm's - 30d & & & & $\begin{array}{l}-0.0653 \\
(0.0722)\end{array}$ & & & & & & $\begin{array}{l}0.105^{* *} \\
(0.0267)\end{array}$ & & & & & & $\begin{array}{c}0.0990^{* *} \\
(0.0255)\end{array}$ & & \\
\hline Ex's - 60d & & & & & $\begin{array}{l}-0.193 \\
(0.132)\end{array}$ & & & & & & $\begin{array}{l}-0.0734 \\
(0.0643)\end{array}$ & & & & & & $\begin{array}{l}-0.0390 \\
(0.0667)\end{array}$ & \\
\hline Cm's - 60d & & & & & $\begin{array}{l}-0.0856 \\
(0.0546)\end{array}$ & & & & & & $\begin{array}{c}0.0651^{* *} \\
(0.0211)\end{array}$ & & & & & & $\begin{array}{c}0.0623^{* *} \\
(0.0206)\end{array}$ & \\
\hline Ex's - 90d & & & & & & $\begin{array}{c}-0.222+ \\
(0.132)\end{array}$ & & & & & & $\begin{array}{l}-0.0857 \\
(0.0624)\end{array}$ & & & & & & $\begin{array}{l}-0.0569 \\
(0.0650)\end{array}$ \\
\hline Cm's - 90d & & & & & & $\begin{array}{r}-0.0887+ \\
(0.0480) \\
\end{array}$ & & & & & & $\begin{array}{l}0.0455^{*} \\
(0.0190) \\
\end{array}$ & & & & & & $\begin{array}{l}0.0425^{*} \\
(0.0181) \\
\end{array}$ \\
\hline
\end{tabular}

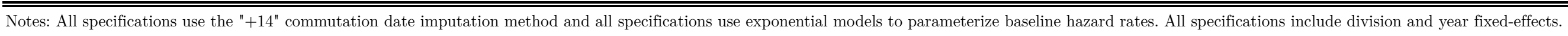

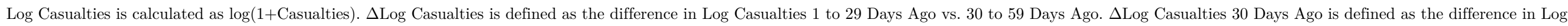

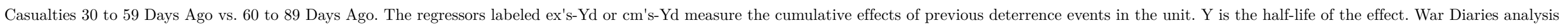
restricts to July 1916-June 1917, which is the time window for the surviving data. Standard errors clustered at the division level in parentheses; $+\mathrm{p}<0.10, * \mathrm{p}<0.05,{ }^{* *} \mathrm{p}<0.01$ 


\section{Panel A: +14 Imputation}

\section{All Death Sentences}

Irish Execution

Non-Irish Execution

Irish Commutation

Non-Irish Commutation $\underline{\text { War Diaries }}$

$19.2 \%$

$11.1 \%$

$13.3 \%$

$13.1 \%$

$\%$ of Next Absences that are Irish

$\underline{\text { Police Gazettes }}$

$9.8 \%$

$9.0 \%$

$16.4 \%$

$14.4 \%$
FGCM (Desertion Trials)
$21.6 \%$
$15.3 \%$
$12.0 \%$
$13.3 \%$

\section{Desertion Death Sentences}

Irish Execution

Non-Irish Execution

Irish Commutation

Non-Irish Commutation

Panel B: NN Imputation

\section{All Death Sentences}

Irish Execution

Non-Irish Execution

Irish Commutation

Non-Irish Commutation

$\begin{array}{lcc}19.2 \% & 9.8 \% & 21.6 \% \\ 11.1 \% & 9.0 \% & 15.3 \% \\ 12.5 \% & 16.4 \% & 12.4 \% \\ 12.6 \% & 13.7 \% & 13.5 \%\end{array}$

\section{Desertion Death Sentences}

Irish Execution

$20.0 \%$

$9.3 \%$

$23.3 \%$

Non-Irish Execution

$9.5 \%$

$9.1 \%$

$15.5 \%$

Irish Commutation

$10.4 \%$

$17.4 \%$

$13.2 \%$

Non-Irish Commutation

$12.1 \%$

$15.8 \%$

$14.2 \%$

Panel C: $\mathrm{C}=\mathrm{T}$ Imputation

\section{All Death Sentences}

Irish Execution

Non-Irish Execution

Irish Commutation

Non-Irish Commutation

$\begin{array}{ccc}15.4 \% & 7.8 \% & 15.7 \% \\ 10.4 \% & 10.0 \% & 16.2 \% \\ 9.1 \% & 17.6 \% & 11.0 \% \\ 14.0 \% & 13.8 \% & 12.1 \%\end{array}$

\section{Desertion Death Sentences}

Irish Execution

$15.0 \%$

$7.4 \%$

$9.6 \%$

$13.8 \%$
$7.0 \%$

$10.2 \%$

$20.6 \%$

$15.6 \%$
$16.3 \%$

$16.5 \%$

$10.8 \%$

$13.1 \%$

Non-Irish Commutation

Notes: In panels sub-titled "+14", the announcement of the commutation is assumed to occur 14 days after trial. In panels subtitled "NN" the nearest-neighbor method is used, which means the imputed announcement of the commutation is same as the most nearby execution announcement, while in panels labeled " $\mathrm{C}=\mathrm{T}$ ", the trial date is used as the announcement date of the execution and commutation. War Diaries analysis restricts to July 1916-June 1917, which is the time window for the surviving data. 
Table 9: Day-by-Day Framework, All Absences

\begin{tabular}{|c|c|c|c|c|c|}
\hline Panel A: War Diaries & $(1)$ & $(2)$ & $(3)$ & $(4)$ & $(5)$ \\
\hline Half-life & 1 week & $\underline{2 \text { weeks }}$ & $\underline{1 \text { month }}$ & $\underline{2 \text { months }}$ & $\underline{3 \text { months }}$ \\
\hline \multirow[t]{2}{*}{ Execution } & 0.00894 & 0.00760 & 0.00804 & 0.00920 & 0.00957 \\
\hline & $(0.0110)$ & $(0.00925)$ & $(0.00902)$ & $(0.00832)$ & $(0.00742)$ \\
\hline \multirow[t]{2}{*}{ Death Sentence } & 0.00170 & 0.000383 & -0.000446 & -0.000740 & -0.000807 \\
\hline & $(0.00202)$ & $(0.00108)$ & $(0.000769)$ & $(0.000766)$ & $(0.000768)$ \\
\hline \multirow[t]{2}{*}{ Ex-Irish } & -0.0124 & -0.00516 & -0.00106 & -0.00260 & -0.00453 \\
\hline & $(0.0119)$ & $(0.0108)$ & $(0.00944)$ & $(0.00767)$ & $(0.00688)$ \\
\hline \multirow[t]{2}{*}{ Irish } & 0.00608 & 0.00486 & 0.00191 & 0.000680 & 0.000635 \\
\hline & $(0.00877)$ & $(0.00669)$ & $(0.00490)$ & $(0.00353)$ & $(0.00316)$ \\
\hline \multirow[t]{2}{*}{ Ex-Desert } & -0.0177 & -0.0135 & -0.0114 & -0.0111 & -0.0112 \\
\hline & $(0.0112)$ & $(0.00890)$ & $(0.00841)$ & $(0.00799)$ & $(0.00736)$ \\
\hline \multirow[t]{2}{*}{ Desert } & 0.000511 & 0.000805 & 0.00127 & 0.00207 & $0.00271+$ \\
\hline & $(0.00280)$ & $(0.00169)$ & $(0.00125)$ & $(0.00131)$ & $(0.00146)$ \\
\hline $\mathrm{N}$ & 20750 & 20750 & 20750 & 20750 & 20750 \\
\hline \multicolumn{6}{|c|}{ Panel B: Police Gazettes } \\
\hline \multirow[t]{2}{*}{ Execution } & $-0.0188^{* *}$ & $-0.0174^{*}$ & -0.0133 & -0.00861 & -0.00639 \\
\hline & $(0.00601)$ & $(0.00752)$ & $(0.00794)$ & $(0.00683)$ & $(0.00578)$ \\
\hline \multirow[t]{2}{*}{ Death Sentence } & 0.00340 & 0.00348 & 0.00329 & 0.00274 & $0.00238+$ \\
\hline & $(0.00211)$ & $(0.00242)$ & $(0.00230)$ & $(0.00166)$ & $(0.00127)$ \\
\hline \multirow[t]{2}{*}{ Ex-Irish } & -0.00932 & -0.00846 & -0.00875 & $-0.0115^{*}$ & $-0.0128^{*}$ \\
\hline & $(0.00618)$ & $(0.00557)$ & $(0.00529)$ & $(0.00539)$ & $(0.00527)$ \\
\hline \multirow[t]{2}{*}{ Irish } & 0.00316 & 0.00327 & 0.00363 & 0.00399 & 0.00396 \\
\hline & $(0.00486)$ & $(0.00508)$ & $(0.00452)$ & $(0.00345)$ & $(0.00270)$ \\
\hline \multirow[t]{2}{*}{ Ex-Desert } & 0.0115 & 0.0118 & 0.0102 & 0.00751 & 0.00626 \\
\hline & $(0.00791)$ & $(0.00860)$ & $(0.00882)$ & $(0.00723)$ & $(0.00600)$ \\
\hline \multirow[t]{2}{*}{ Desert } & -0.00385 & -0.00438 & $-0.00419+$ & $-0.00331+$ & $-0.00278^{*}$ \\
\hline & $(0.00289)$ & $(0.00279)$ & $(0.00247)$ & $(0.00165)$ & $(0.00115)$ \\
\hline $\mathrm{N}$ & 54605 & 54605 & 54605 & 54605 & 54605 \\
\hline \multicolumn{6}{|c|}{ Panel C: FGCM Desertion Trial Registries } \\
\hline \multirow[t]{2}{*}{ Execution } & 0.0122 & 0.0146 & 0.00819 & 0.000144 & -0.00264 \\
\hline & $(0.0223)$ & $(0.0205)$ & $(0.0158)$ & $(0.0116)$ & $(0.00992)$ \\
\hline \multirow[t]{2}{*}{ Death Sentence } & $0.0106^{*}$ & $0.00628^{*}$ & 0.00356 & 0.00210 & 0.00145 \\
\hline & $(0.00403)$ & $(0.00311)$ & $(0.00219)$ & $(0.00155)$ & $(0.00134)$ \\
\hline \multirow[t]{2}{*}{ Ex-Irish } & -0.00844 & -0.0143 & -0.0111 & -0.00676 & -0.00469 \\
\hline & $(0.0194)$ & $(0.0144)$ & $(0.0102)$ & $(0.00814)$ & $(0.00763)$ \\
\hline \multirow[t]{2}{*}{ Irish } & -0.000543 & 0.00317 & 0.00454 & 0.00489 & 0.00484 \\
\hline & $(0.00855)$ & $(0.00661)$ & $(0.00468)$ & $(0.00344)$ & $(0.00304)$ \\
\hline \multirow[t]{2}{*}{ Ex-Desert } & -0.0125 & -0.0156 & -0.0121 & -0.00601 & -0.00362 \\
\hline & $(0.0193)$ & $(0.0179)$ & $(0.0147)$ & $(0.0116)$ & $(0.0102)$ \\
\hline \multirow[t]{2}{*}{ Desert } & 0.00236 & 0.00320 & 0.00256 & 0.00159 & 0.00108 \\
\hline & $(0.00388)$ & $(0.00357)$ & $(0.00277)$ & $(0.00204)$ & $(0.00175)$ \\
\hline $\mathrm{N}$ & 59355 & 59355 & 59355 & 59355 & 59355 \\
\hline
\end{tabular}

Notes: Outcome is whether there was any absence on that day and division. All specifcations use the "+14" commutation date imputation method and include division and year fixed-effects, $\Delta \log$ Casualties, and $\Delta \log$ Casualties 30 Days Ago. The half-life row indicates the assumed exponential half-life of the effect of past events. War Diaries analysis restricts to July 1916-June 1917, which is the time window for the surviving data. War Diaries analysis restricts to July 1916June 1917, which is the time window for the surviving data. Standard errors clustered at the division level in parentheses; $+\mathrm{p}<0.10, * \mathrm{p}<0.05, * * \mathrm{p}<0.01$ 
Table 10: Day-by-Day Framework, Irish - non-Irish Absence

\begin{tabular}{|c|c|c|c|c|c|}
\hline Panel A: War Diaries & $(1)$ & $(2)$ & $(3)$ & $(4)$ & $(5)$ \\
\hline Half-life & 1 week & 2 weeks & 1 month & 2 months & 3 months \\
\hline \multirow[t]{2}{*}{ Execution } & -0.0207 & -0.0129 & -0.00711 & -0.00546 & -0.00531 \\
\hline & $(0.0143)$ & $(0.0124)$ & $(0.00923)$ & $(0.00664)$ & $(0.00554)$ \\
\hline \multirow[t]{2}{*}{ Death Sentence } & -0.00106 & -0.000889 & -0.000577 & -0.000368 & -0.000286 \\
\hline & $(0.00162)$ & $(0.00137)$ & $(0.00113)$ & $(0.000938)$ & $(0.000830)$ \\
\hline \multirow[t]{2}{*}{ Ex-Irish } & $0.0255^{*}$ & $0.0219^{*}$ & $0.0156+$ & $0.0126+$ & $0.0119+$ \\
\hline & $(0.0127)$ & $(0.0105)$ & $(0.00839)$ & $(0.00686)$ & $(0.00611)$ \\
\hline \multirow[t]{2}{*}{ Irish } & 0.0000700 & -0.000649 & -0.000233 & 0.000565 & 0.00105 \\
\hline & $(0.00781)$ & $(0.00643)$ & $(0.00491)$ & $(0.00356)$ & $(0.00296)$ \\
\hline \multirow[t]{2}{*}{ Ex-Desert } & $0.0268+$ & 0.0174 & 0.00913 & 0.00542 & 0.00468 \\
\hline & $(0.0153)$ & $(0.0131)$ & $(0.00926)$ & $(0.00665)$ & $(0.00569)$ \\
\hline \multirow[t]{2}{*}{ Desert } & $-0.00595+$ & $-0.00439+$ & -0.00241 & -0.00159 & -0.00158 \\
\hline & $(0.00331)$ & $(0.00244)$ & $(0.00178)$ & $(0.00149)$ & $(0.00140)$ \\
\hline $\mathrm{N}$ & 20750 & 20750 & 20750 & 20750 & 20750 \\
\hline \multicolumn{6}{|c|}{ Panel B: Police Gazettes } \\
\hline \multirow[t]{2}{*}{ Execution } & $0.00661+$ & 0.00495 & 0.000708 & -0.00208 & -0.00266 \\
\hline & $(0.00388)$ & $(0.00448)$ & $(0.00454)$ & $(0.00403)$ & $(0.00363)$ \\
\hline \multirow[t]{2}{*}{ Death Sentence } & -0.000576 & -0.00118 & -0.00120 & -0.00108 & $-0.00100+$ \\
\hline & $(0.00143)$ & $(0.00142)$ & $(0.00116)$ & $(0.000747)$ & $(0.000544)$ \\
\hline \multirow[t]{2}{*}{ Ex-Irish } & $0.0121^{*}$ & $0.00937^{*}$ & $0.00784^{* *}$ & $0.00760^{* *}$ & $0.00736^{* *}$ \\
\hline & $(0.00545)$ & $(0.00412)$ & $(0.00289)$ & $(0.00239)$ & $(0.00233)$ \\
\hline \multirow[t]{2}{*}{ Irish } & -0.00474 & -0.00312 & -0.00200 & -0.00120 & -0.000779 \\
\hline & $(0.00314)$ & $(0.00237)$ & $(0.00192)$ & $(0.00144)$ & $(0.00119)$ \\
\hline \multirow[t]{2}{*}{ Ex-Desert } & -0.00778 & -0.00491 & -0.000327 & 0.00160 & 0.00150 \\
\hline & $(0.00595)$ & $(0.00547)$ & $(0.00521)$ & $(0.00448)$ & $(0.00388)$ \\
\hline \multirow[t]{2}{*}{ Desert } & 0.000462 & 0.00136 & 0.00123 & 0.000937 & 0.000832 \\
\hline & $(0.00169)$ & $(0.00167)$ & $(0.00136)$ & $(0.000872)$ & $(0.000635)$ \\
\hline $\mathrm{N}$ & 54605 & 54605 & 54605 & 54605 & 54605 \\
\hline \multicolumn{6}{|c|}{$\begin{array}{l}\text { Panel C: FGCM Desertion Trial Registries } \\
\end{array}$} \\
\hline \multirow[t]{2}{*}{ Execution } & -0.0240 & -0.0183 & -0.00784 & 0.00197 & 0.00559 \\
\hline & $(0.0162)$ & $(0.0131)$ & $(0.00972)$ & $(0.00716)$ & $(0.00620)$ \\
\hline \multirow[t]{2}{*}{ Death Sentence } & -0.00425 & -0.00241 & -0.00147 & -0.00104 & -0.000829 \\
\hline & $(0.00514)$ & $(0.00329)$ & $(0.00193)$ & $(0.00114)$ & $(0.000885)$ \\
\hline \multirow[t]{2}{*}{ Ex-Irish } & 0.00333 & 0.00267 & -0.000828 & -0.00408 & -0.00540 \\
\hline & $(0.0160)$ & $(0.0120)$ & $(0.00782)$ & $(0.00576)$ & $(0.00510)$ \\
\hline \multirow[t]{2}{*}{ Irish } & 0.00498 & 0.00192 & 0.0000538 & -0.000915 & -0.00116 \\
\hline & $(0.00575)$ & $(0.00451)$ & $(0.00328)$ & $(0.00236)$ & $(0.00202)$ \\
\hline \multirow[t]{2}{*}{ Ex-Desert } & $0.0313+$ & $0.0258^{*}$ & $0.0162+$ & 0.00644 & 0.00249 \\
\hline & $(0.0157)$ & $(0.0120)$ & $(0.00883)$ & $(0.00679)$ & $(0.00618)$ \\
\hline \multirow[t]{2}{*}{ Desert } & -0.00724 & $-0.00605+$ & $-0.00400+$ & -0.00230 & -0.00153 \\
\hline & $(0.00517)$ & $(0.00350)$ & $(0.00222)$ & $(0.00146)$ & $(0.00120)$ \\
\hline$\overline{\mathrm{N}}$ & 59355 & 59355 & 59355 & 59355 & 59355 \\
\hline
\end{tabular}

Notes: Outcome is whether there was any Irish absence on that day and division minus whether there was any non-Irish absence on that day and division. All specifcations use the " +14 " commutation date imputation method and include division and year fixed-effects, $\Delta$ Log Casualties, and $\Delta$ Log Casualties 30 Days Ago. The half-life row indicates the assumed exponential half-life of the effect of past events. War Diaries analysis restricts to July 1916-June 1917, which is the time window for the surviving data. War Diaries analysis restricts to July 1916-June 1917, which is the time window for the surviving data. Standard errors clustered at the division level in parentheses; $+\mathrm{p}<0.10,{ }^{*} \mathrm{p}<0.05,{ }^{* *} \mathrm{p}<0.01$ 
For Online Publication 


\section{A Appendix: Description of Merging Process}

The data is the outcome of the following data generating process: absentees, which led to $->$ trials, which led to $->$ convictions, which led to $->$ death sentences, which led to $->$ executions or commutations, which led to a potential causal effect on subsequent absentees. Absentees are measured in the War Diaries, Police Gazette (B.E.F. subset), and Trials (absentee and deserters subset).

Each event (death sentence, absence, or casualty) needs to be assigned a particular division. Six datasets are merged into the Order of Battle: Absentees-War Diaries, Absentees-Police Gazettes, Trials, Death sentences, Casualties, and Officer lists.Each dataset has a different set of keys, the most important of which is date, because the lower level military units moved between different higher level units throughout the war. Each of the six datasets is also merged into the Irish surname dictionary. The Order of Battle is itself merged into a list of battle locations to yield geocodes. The Service and Pension Records is merged by name into each of the six datasets to obtain a handful of its covariates, such as age and birthplace. No attempt is made to merge any other datasets by soldier name because of the difficulty due to spelling and non-unique names.

The original sources are typed, with the exception of the trial registers, which are hand written. This paper digitizes absentees, trials, officers, battle locations, and the Order of Battle. Casualties, capital sentences, Irish surnames, the Medal Rolls Index, and the Services and Pensions Records were previously digitized. Unit names were not the same in different data sources because of data quality and different ways of spelling or abbreviation. As a first step in the data cleaning, names of military units were disabbreviated with the help of historical sources and historians. For instance, the short form (e.g., ASC, RFA, DAC, etc.) is changed to the respective long form (e.g., Army Service Corps, Royal Field Artillery, etc.). The Order of Battle also presented some difficulty. Battalions are recorded both on regimental pages and divisional pages. Regiment pages appear to be more complete and reliable and are given priority in data entry. Additional information on the Order of Battle digitization is provided in Appendix B below.

Linking the datasets to the Order of Battle is based on up to three variable keys: 1) Battalion name (sometimes company or platoon name) and/or battalion number, 2) Regiment name, and 3) Date (absence, casualty, or trial date). A regiment name typically refers to a geographic location in the UK. Each regiment has many numbered battalions. The battalions usually travelled in different divisions. All three variable keys are necessary for an exact match. In addition, matching on only battalion number and regiment string is possible because battalions within a regiment typically had unique battalion numbers.

The data linkages are generated through two steps: exact matching and algorithms. For exact matching, all datasets employed a manual look-up table to serve as an exact translation of a unit to a combination of regiment and battalion in the Order of Battle. Cross-checking with historical sources and historians yielded a manual look-up table linking the battalion/regiment string in each of the six datasets to the equivalent battalion/regiment in the Order of Battle.

The exact look-up is composed of two steps: the actual exact look-up of the unit followed by date matching in the Order of Battle. If both conditions yield a match, then the first round is deemed successful. Most matches were derived from this exact look-up. In a few instances, battalions are formed from existing battalions that do not have an official separate entry in the Order of Battle or are renamed into new battalions that also do not have a separate entry, resulting in the soldier being listed as deserting or dying on a date when the battalion does not exist in the Order of Battle. In these instances, the nearest date on which the brigade and division is affiliated with the named battalion is used. Where a precise date is 
identified, it usually refers to only the headquarters arrival or departure ${ }^{62}$ The nearest-date assumption allows time for a unit to reorganize during relocation. If the battalion is not listed affirmatively as not having a brigade/division in some date range (for instance, headquarters may be moving from one location to another), the battalion will be assigned to the nearest brigade/division by date. If the battalion is listed affirmatively as not having a brigade/division in some date range (for instance, the battalion is in another part of the world when the war began) but the soldier's date falls in that range, he will be un-assigned.

For example, if a battalion is stated as being part of a brigade/division and does not mention a date, it will be associated for the entire war. If a battalion is stated as being part of a brigade/division and forming on December 1914, the Order of Battle will not have an entry for this battalion before December 1914 and the soldier will also have that association for dates prior to December 1914. On the other hand, if the battalion is stated as forming in August 1914 and then arrives in December 1914 as part of a brigade/division, then the Order of Battle will have an entry of "null" for this battalion before December 1914 and it will not be associated with anything before December 1914. Further, if it is first mentioned on December 1914 as being affiliated with that brigade/division but the Order of Battle does not state a date of formation, then the battalion will have an entry of "null" in the Order of Battle prior to December 1914 and will not be associated with anything before December 1914. Previous analyses making different assumptions about the dates of battalion associations do not seem to be material to the final inference. In addition, the first date of the war and the last date of the war are assumed when the first date at the beginning of the war and last date at the end of the war for a battalion's association with a brigade and division are not explicitly stated.

In some instances, the military unit could not be identified easily by hand for an exact look-up. An algorithm is then used, which involves approximate string distance matching and the prioritization of variable keys to allow for minor typos in the original record or data entry. For example, the Order of Battle occasionally lists battalions together as a single record. In some datasets, battalion and regiment are not separated into distinct variables in the original raw data. The raw data would leave the information in such an abbreviated form that the entire string was used to match against the battalion and regiment keys. This algorithmic step extracts the battalion number and separates it from the regiment, because in most cases, battalions can be uniquely identified simply by its number within a regiment. Some inference can also be made if the best possible matches all locate the battalion in the same division. In the algorithmic step, the nearest date is not used to facilitate the merge; an exact match for the date is required. Matching the regiment string also involved de-abbreviations, or if no de-abbreviation, a manual look-up. A Jaro-Winkler string distance score was calculated comparing the closest OOB regiment match with the extracted regiment. When multiple matches were available within a string distance of 0.20 , it was checked whether all potential matches yielded the same division and brigade. If only a single match was available, then any match with string distance worse than 0.05 was discarded. Records without absence dates or battalion numbers were discarded.

Finally, after merging the records into the Order of Battle brigade and division, the brigades and divisions are assigned unique identifiers because the Order of Battle occasionally uses different names to refer to the same division or brigade. One form of measurement error is unavoidable: when the Order of Battle does not record the exact day when a battalion moves to another division, I assume the transition occurs on the first day of the month. Other measurement errors in the merging process are assumed to be orthogonal to the execution or commutation decision.

\footnotetext{
$\overline{{ }^{62} \text { Email from Putkowski on September 14, }} 2015$.
} 
Duplicates are also removed during the data cleaning process. Any soldier with the same first name, last name, regiment number, and record date are made unique in the following datasets. Any soldier's record without a date is also dropped.

A.1 Merging Capital Sentences to the Order of Battle The capital sentences dataset already provides a numerical code for brigade and division, so linking to the Order of Battle merely required decoding. However, brigade data was often not included in the original data, so these were entered manually by searching for the regiment and battalion, checking that the original division data is correct for the record's date, and entering the brigade that is correspondingly listed in the Order of Battle.

A.2 Merging Absentees-War Diaries to the Order of Battle The War Diaries dataset is merged using the Unit (which contains battalion name, battalion number, and regiment name) to the Order of Battle. The units are first matched manually, using consultations with historians, de-abbreviations, and a look-up table. Units are dropped when there is no possible way to uniquely identify the match (e.g., a unit listed as, $1^{\text {st }}$ Engineers, would be impossible to disambiguate). The second round of matching uses the Jaro string distance between the combination of battalion number, battalion name, and regiment name with its equivalent in the Order of Battle. The algorithm makes pairwise comparisons between every possible match in the Order of Battle and takes the best match if the distance is below a threshold. Battalion and regiment string distances are given equal weight in priority. However, the battalion number is required to be an exact match.

A.3 Merging Absentees-Police Gazettes to the Order of Battle The Police Gazettes dataset is merged using Corps (which contains battalion name, battalion number, and regiment name) to the Order of Battle. The units are first matched manually, using consultations with historians, de-abbreviations, and a look-up table. The second round of matching uses the Jaro string distance between the combination of battalion number, battalion name, and regiment name with its equivalent in the Order of Battle. The algorithm makes pairwise comparisons between every possible match in the Order of Battle and takes the best match if the distance is below a threshold. Battalion and regiment string distances are given equal weight in priority. However, the battalion number is required to be an exact match.

Dates in the Police Gazettes did not include the calendar year. Calendar year is inferred from the publication date of the newspaper gazette. For example, a December absence recorded in a January gazette would have the year be set as the year prior to the publication date.

A.4 Merging Trials to the Order of Battle The FGCM dataset contains only regiment name and battalion number. The regiment name is first matched manually to the regiment in the Order of Battle, using consultations with historians, de-abbreviations, and a look-up table,. Then additional records with spellings that are close to the matchable FGCM regiment strings are replaced with the matchable spellings via algorithm to address minor errors in transcription. The battalion number and regiment string are then used to find its equivalent in the Order of Battle. The second round of matching uses string distance between the combination of battalion number and regiment name to find its equivalent in the Order of Battle. The algorithm makes pairwise comparisons between every possible match in the Order of Battle and takes the best match if the distance is below a threshold. Because these strings are noisier than in the other datasets, both the Jaro string distance and the Levenshtein string distance are employed. The battalion number is sometimes missing in FGCM. In this scenario, all possible matches are examined and checked to see if they all yield the same brigade/division. If so, then that brigade/division is assigned. Note that because the exact date of absence is not recorded, I assume that the absence occurred one month before the trial date and deduct this month accordingly before merging with the Order of Battle. 
This ensures that the news a potential deserter responds to is merged in from the correct division in case the battalion has moved divisions in the meantime. However, the true trial date is kept for all analyses.

A.5 Merging Casualties to the Order of Battle The casualties dataset contains battalion, regiment, and battalion number. This dataset was previously digitized, so linking to the Order of Battle merely required decoding. However, some records are lost in the process because the Order of Battle did not provide information on the brigade and division for some battalions. These casualties are dropped.

A.6 Merging the Officer List to the Order of Battle The officers are already organized by each of the higher level units (brigade, division, corp, army, and general headquarters).

A.7 Merging to Service and Pension Records Linking to the Service and Pension Records requires the soldier's name. The first name is often abbreviated. If so, only the first letter of the first name is used in the merge. Sometimes the raw data includes first and middle initials in capital letters without punctuation separating the two initials. The two initials would be separated before merging by name.

The matching algorithm involves a mix of exact-match requirements and minimum distance calculations. Battalion number and first letter of the first name are required to match exactly. Matching based on unit names and the remainder of a soldier's name is based on approximate string distance: Levenshtein distance is used for soldiers' names and the Jaro distance is used for unit name. The reason for using Jaro when matching military units is that the number of strings describing the military unit often differs across datasets. These extra strings do not impose as much of a penalty when using the Jaro distance.

The Levenshtein distance counts the number of deletions $(d)$, insertions $(i)$ and substitutions $(s)$ necessary to turn two strings, $A$ and $B$, in the other. All characters, including spaces and punctuations, count. This distance is bounded, for instance if $\mathrm{A}$ contain $n_{A}$ characters and $\mathrm{B}$ contains $n_{B}$ characters, the lower bound is $n_{A}-n_{B}$ and the upper bound is $n_{A}$ (if $n_{A}>n_{B}$ ) or $n_{B}\left(\right.$ if $n_{B}>n_{A}$ ). This distance metric is more appropriate for a single string, such as a surname.

The Jaro distance is a heuristic measure. Let $n_{A B}$ be the number matching characters between $A$ and $B$ and $n_{t}$ the number of transpositions of the $n_{A B}$ matching characters. Two characters $c_{A}$ and $c_{B}$ are said to be matching in $A$ and $B$ if and only if $c_{A}=c_{B}$ and the index (position) of $c_{A}$ in $A$ is less or equal to $\left\lfloor 0.5 \cdot \max \left(n_{A}, n_{B}\right)-1\right\rfloor$. Then, the Jaro distance is:

$$
d_{A, B}=1-\frac{1}{3}\left(\frac{n_{A B}}{n_{A}}+\frac{n_{A B}}{n_{B}}+\frac{n_{A B}-n_{t}}{n_{A B}}\right) .
$$

This distance is bounded between 0 (exact match) and 1 (complete dissimilarity). It is also defined as 1 when there are no characters in common between $A$ and $B$.

Given two vector of strings $\underline{A}$ and $\underline{B}$, each element of $\underline{A}$ is compared with each element of $\underline{B}$. Let $A_{1}$, $B_{1}$, and $B_{2}$ be strings. $A_{1}$ matches $B_{1}$ better than $B_{2}$ if and only if $d_{A_{1}, B_{1}}<d_{A_{1}, B_{2}}$. In declaring a string match of one element $A_{j}$ of $\underline{A}$ with one element $B_{k}$ of $\underline{B}$, two conditions must be satisfied:

1. $A_{j}$ matches better to $B_{k}$ than how it matches to any other element of $\underline{B}: d_{A_{j}, B_{k}}=\min \left\{d_{A_{j}, B_{s}}, s=1, \ldots, m_{B}\right\}$, where $m_{B}$ is the number of elements in $\underline{B}$.

2. $d_{A_{j}, B_{k}}<\tau$, where $\tau$ is a deterministic threshold

A higher threshold is allowed for merging Service and Pension Records than for merging the Order of Battle because the data is recorded with poor quality. Data that was hand-entered as "[?]" could have 
been treated as a wildcard for the purposes of matching, which would have greatly increased computation time. Instead, wildcards are dropped since dropping them does not affect the string distance functions much.

A.8 Irish Indicator Each of the six datasets is also merged into the Irish surname dictionary. This is based on an exact name match. A second Irish indicator is imputed using the merge with Service and Pension Records. The place of birth is matched to Ireland. The second indicator is used in robustness checks but is not the main indicator because the Service and Pension Records merge is not strong, but it is used to conduct validity checks on the surname dictionary.

A.9 Merging with Higher Order Units (Corps, Army, and General Headquarters) Linking the division to the higher order units is more straightforward because it does not involve data external to the Order of Battle. However, sometimes the Order of Battle does not report the association of a division to a particular corps or army for some dates. In this case, a match is made to the chronologically closest corps or army of which the division is part. This is because the official dates of association typically refer to the headquarters' relocation, but given the size of the unit, the soldiers themselves could take quite a while to relocate. If the previous hierarchy is unknown for matching divisions to corps, a match is made by looking forward in time and for the next corps that the division is associated with. If the previous hierarchy is unknown for matching corps to army, a match is made by looking forward in time and for the next army that the corps is associated with, with exceptions noted below. In a handful of cases, the Order of Battle reports that the division is associated with more than one corps/army. In those cases, a match is made to the corps/army that has the longest association with the division.

Corps outside of France and Flanders are linked directly to a general headquarter. The four other general headquarters whose officers are recorded are located in Salonika, Egypt (Palestine), Gallilopi (Mediterranean), and Italy. Some corps fought first in Italy and then in France. Only corps in Italy have an associated army unit. Units associated with these corps are assigned to the appropriate army while they are fighting outside France. Army units are associated to general headquarters on exact dates.

A.10 Geolocation Linking to the battle is straightforward because it does not involve data external to the Order of Battle. A battalion is not assigned a geolocation before its first battle or after its last battle and is assumed to travel incrementally from one battle to the next. The air distance is calculated to the English Channel and to Berlin.

A.11 Final Dataset The final dataset contains 14,466 unique records of soldiers who were absent or sentenced to death. Observable individual, unit, and environmental characteristics are merged from all other datasets. The variables are summarized below:

Environmental characteristics are derived as follows:

- Battle environment: Number of casualties in each division and brigade at each point in time. One number for British and one for Irish.

- Morale: Number of absentees in each division and brigade at each point in time. One number comes from each of the War Diaries, Police Gazettes, and FGCM. These numbers are further broken down by British and Irish.

- Disciplinary environment: Number of death sentences and number of trials in each division and brigade at each point in time. The death sentences number comes from the capital sentences dataset and the number of trials comes from the trial dataset. These numbers are further broken down by British and Irish. 
- Executions environment: Number of executions in each division and brigade at each point in time. This number comes from the capital sentences dataset. These numbers are further broken down by British and Irish.

The environmental factors are calculated in and around a time window of 30,60, and 90 days before, after, or before and after the current day, never including the current day (so a 30 day window is really a 29 day window before and after the current day).

The final list of variables are:

- Name - Name of the soldier

- Unit - Unit of the soldier, typically battalion

- Rank - Rank of the soldier, typically private but in some cases also specific officer rank

- Date - Absence date (War Diaries and Police Gazette), sentence date (Capital Sentences), or trial date minus 30 (FGCM dataset)

- CaseType - Crime such as desertion, absence, or quitting (FGCM dataset)

- Sentence - Commutation or execution

- Location - The city name (FGCM dataset) or a general indication such as B.E.F. (War Diaries and Police Gazette) or F\&F

- OtherType - Other crimes the soldier was tried for or miscellaneous info about the sentence

- Brigade, Division, Regiment, Battalion - Name of each unit the soldier was part of on that date

- Dataset - Name of the dataset where the record comes from

- LastName, FirstName, FirstLetterLastName - Soldier's name

- DeathSent - Indicator for whether the soldier is sentenced to death (FGCM dataset)

- CorpName, ArmyName, GHQName - Name of additional units the soldier was part of on that date

- BrigOfficerName, BrigOfficerRank - Name and rank of the $1^{\text {st }}$ officer in command of the soldier's brigade

- DivGOCName, DivGOCRank, DivGSO1Name, DivGSO1Rank - Name and rank of the Division General Officer Commanding (GOC) and Division $1^{\text {st }}$ grade staff officer (SO)

- CorpGOCName, CorpGOCRank, CorpBGGSName, CorpBGGSRank - Name and rank of the Corps GOC and Corps staff officer

- ArmGOCName, ArmGOCRank, ArmMGGSName, ArmMGGSRank - Name and rank of the Army GOC and Army staff officer

- GHQChiefName, GHQChiefRank, GHQCGSName, GHQCGSRank - Name and rank of the C-in-C and the staff officer of the B.E.F.

- LastName_SP, BirthParish, BirthCounty, Residence, Age, DocYear_SP, regiment_SP, FirstName_SP - Information from the Service and Pension Records 
- Irish - Indicator of whether the soldier's surname is Irish

- DistCoast, DistBerlin - The air distance of the division of the soldier record to the English Channel and to Berlin, obtained from linking with the Geo Location dataset 


\section{B Order of Battle}

This section describes some of the assumptions and procedures used when entering the entire Order of Battle from The Long, Long Trail (http://www.1914-1918.net/). Battalions are recorded both on regimental pages and divisional pages. Regiment pages appear to be more complete and reliable and are given priority in data entry.

Battalions, brigades, and divisions also had multiple spellings, e.g., Highland Division and $51^{\text {st }}$ or Highland Division and $51^{\text {st }}$ Division. Priority was given to the longest spelling and, in general, to make all identifiers unique even when the original data did not provide a unique string for a single military unit. The division pages sometimes have much more specific information than the regiment page on the exact name of the brigade or division. The division page would be relied upon for the more complete information. Geography or unit number often uniquely identify the military unit. However, some data records needed to be dropped because there was either contradictory geography and unit number identifiers (e.g., $55^{\text {th }}$ $2^{\text {nd }}$ West Lancashire Division would be dropped because there was a $57^{\text {th }} 2^{\text {nd }}$ West Lancashire Division) or the information was not specific enough to identify the unit (e.g., Welsh Division).

Interpreting the Order of Battle also required several assumptions. The regimental pages are organized by battalion. For each battalion, each of its associations to a particular brigade and division would come with the identity of the brigade and division and the beginning and end date of the association. If the start or end date of a battalion is not listed and the association is chronologically the first or last for the battalion, then the first and last date of the war is assumed. When only month and year are provided, the $1^{\text {st }}$ of the month is assumed.

Sometimes, a battalion is amalgamated with or absorbed into another battalion. In this case, the division and brigade of the new battalion is entered for the old absorbed battalion from the date of absorption all the way to its end date to ensure that data was not lost in merging. The other datasets would sometimes record a soldier as being part of the absorbed battalion after the battalion was absorbed. For example, 11th service battalion pioneers of the King's Liverpool Regiment was absorbed by the $15^{\text {th }}$ Battalion of the Loyal North Lancashire Regiment on 17 June 1918. The details for the 11th service battalion June 17 onwards would be entered from information for the $15^{\text {th }}$ battalion, because the $11^{\text {th }}$ service battalion is now part of the $15^{\text {th }}$ battalion.

If a battalion is formed on a certain date, say 1 Aug 1914, but is assigned a division and brigade at a later date, say 1 September 1914, the first entry for this battalion would be 1 Aug 1914-1 September 1914, and the division and brigade would be null. If a battalion was disbanded on a particular date, the date of disbandment would be the end date. In practice, this means any soldier attached to the battalion before it got assigned to a division and brigade or after the battalion was disbanded would not merge into the other datasets. This is because if a soldier deserted or was sentenced on a particular date in this unit, we affirmatively know that the soldier should not be part of a division or brigade. In contrast, if the Order of Battle simply has no information for a battalion, the soldier is attached to the division or brigade nearest in date (see Appendix A), because we do not know affirmatively that the soldier should not be part of a division or brigade.

Continuous connections to brigade or division are assumed unless the original data said explicitly that the battalion left the division or brigade and there is no information on another division or brigade assigned. For example, if the battalion was assigned to another division without any information on brigade, the previous brigade information was assumed. Similarly, previous division information was assumed if the battalion was assigned to a new brigade without any new information being provided on 
division. In all instances, the divisional page would be cross-checked for more information. Sometimes, a battalion may move to another division as "divisional troops," in which case no brigade would be recorded in the data entry.

As long as there is information available on the original battalion, this information would be tracked in data entry. For instance, if a battalion is reduced to cadre strength, and personnel are transferred to another battalion (hence, usually to another division) and the cadre is reported to be in a different division, information on the cadre is entered for the battalion (i.e., entries reflect the division and brigade information of the cadre).

Sometimes, the Order of Battle would report the battalion assignments to be "same as" or "similar to" another battalion. Sometimes battalions would be listed together with identical battalion assignments. This information would be carefully separated out to facilitate merges. Sometimes the location assignments were not detailed enough for data entry (e.g., data on cyclist units). Occasionally, absentees would be recorded as part of training reserve battalions, which were in the UK, so these absentees were also dropped during the merge. Cavalry divisions were also ambiguous so if a battalion was listed as being associated with a numbered cavalry division and then an unnumbered cavalry division, the numbered cavalry division was assumed. Finally, sometimes the battalion has different names but are identical as far as one can tell from the Order of Battle (e.g., $483^{\text {rd }}$ field company and 1 ea anglian field company); they are listed in the Order of Battle under each name in case the raw data lists soldiers as being part of one battalion or the other. 


\section{Assessing Irish Ethnicity}

There are three ways to assess Irish ethnicity: Irish surname dictionaries, regiment, and birthplace. Each source of data on absentees, death sentences, and casualties has name and regiment, but only three databases-the Service and Pension Records, Casualties, and Police Gazettes-have birthplace and enlistment location. For reasons described below, I use surname instead of regiment to infer Irish ethnicity. Linking by name to access location data is impracticable because of slight differences in spelling, typographical errors in the originals or in transcriptions, a large number of people with shared names, and the fact that the Service and Pension Records are incomplete samples of the universe of soldiers who served.

However, the availability of these datasets with surname and birthplace allows for assessment of 1) how closely Irish surname and Irish birthplace align; 2) the relative loyalty of Irish and non-Irish soldiers by birthplace (I can do this because the birthplace data is available in conceptually distinct datasets); 3) the differences between being born in Ireland or Britain vs. being enlisted in Ireland or Britain vs. having an Irish or non-Irish surname; 4) the quality of geolocation; and 5) the population representativeness of casualties. Differences in distance-in-time to Irish roots can be related to differences between having male Irish ancestry vs. having Irish birthplace. Those born and raised in Britain with Irish male ancestry may be more loyal than those born and raised in Ireland, but those having male Irish ancestry may be less loyal than those without male Irish ancestry even among soldiers born and raised in Britain.

C.1 Irish Regiment Some previous researchers have relied on regiment to infer Irish ethnicity and to analyze how the WWI experience differed for Irish and non-Irish soldiers. The casualties database has both regiment and birthplace, so, assuming that those who died are a representative sample, it can be used to assess the validity of using regiment to infer Irish ethnicity by birthplace. I proceed in two steps to identify the geographic location of every birthplace and enlistment location. The first step uses a list of counties. I first construct a single address string if both parish and county are available. I then look for exact string matches with the list of counties. For example, "down" and "derry," which are Irish counties, would have to appear as a separate string. Occasionally the address would have multiple strings that match the county list. To address this, if the data has "co" or "co.," the string that appears right after would be prioritized in the matching, or if the string comes after a comma, it would be prioritized. The second step uses Google Map's API to locate the remaining locations.

Previous analysis (Perry 1994, p. 67) and my own analysis of the casualties database indicate that some regiments are disproportionately composed of soldiers whose birthplaces were in Ireland. Northern Irish regiments were: Royal Irish Rifles, Royal Inniskilling Fusiliers, and Royal Irish Fusiliers. Southern Irish regiments were: Irish Guards, Royal Irish Regiment, Connaught Rangers, Royal Dublin Fusiliers, Leinster Regiment, and Royal Munster Fusiliers. Among soldiers whose birthplaces could be appropriately located by the API ( $82 \%$ of the 660,585 casualties had birthplaces that could be located in the UK using the two-step algorithm), the Northern Irish regiment with the fewest Irish soldiers had $38 \%$ of its casualties born in Northern Ireland and the one with the largest proportion was $62 \%$. Between $67-74 \%$ of casualties in Southern Irish regiments were born in Southern Ireland. Before proceeding, it is important to note that all percentages discussed in this section are reported as a percent of the soldiers whose birthplaces could be located in the UK. 19,241 casualties were marked as being born in Southern Ireland and 10,189 were marked as being born in Northern Ireland.

About $30 \%$ of those whose birthplaces were in Ireland were assigned to non-Irish regiments. While many

soldiers were allocated to their regiments according to their birthplace, the military command changed its policy during the war. It began allocating soldiers according to need instead of by geography, which 
avoided the decimation of entire youth cohorts of villages. Using regiments to base the analysis of how the WWI experience differed for Irish and non-Irish soldiers may be confounded with changes in military policy.

An analysis using surnames to infer ethnicity (99,433 soldiers have Irish surnames) would be unaffected by policy changes in allocation of soldiers to regiment. Moreover, disparate treatment of minorities need not be limited to soldiers being born in Ireland. Disparate treatment can affect soldiers who had Irish male ancestry. British-born soldiers without Irish ancestry but assigned to Irish regiments are unlikely to have experienced disparate treatment of the kind that soldiers with male Irish ancestry would have experienced. If they experienced advantaged treatment, then using regiment would render a greater violation of monotonicity (if we analogize the use of Irish regiment as an instrumental variable for Irish identity). Counting British-born soldiers without Irish ancestry as "Irish" for statistical analysis can lead to a qualitatively different kind of measurement error. Finally, a more practical concern that precludes the use of regiments is simply that they are not always cleanly available in different datasets due to idiosyncratic abbreviations, spelling errors in the originals, or typographical errors in data entry. Thus, my analysis relies on Irish surnames rather than Irish regiment.

The consistency in the proportion of soldiers deemed Irish is not present when I use Irish regiment. In the B.E.F. Police Gazette sample of deserters, $17.5 \%$ are from Irish regiments. This is close to the $16.5 \%$ with Irish birthplaces. However, in the War Diaries sample of deserters, only $10.5 \%$ come from Irish regiments. The reason is partly due to the fact that names are recorded better than regiments, which often appear inside an idiosyncratic spelling or abbreviation of the military unit, which can be merged to brigade and division but not always cleanly to regiment. In the capital sentences data, $8.1 \%$ come from Irish regiments, further corroborating the difficulty of using regiments to identify Irish ethnicity. The lower percentage could mean that those from Irish regiments were treated very favorably by the military justice system conditional on deserting, but no historical evidence suggests that this is the case. Alternatively, the quality of the spelling of regiments could be lowest in the capital sentences data, which used very short abbreviations, relative to the War Diaries and Police Gazette data sources. Thus, I use surname instead of regiment to identify Irish soldiers.

Notably, despite the potentially poor transcription of regiment, within the capital sentences dataset, $7.1 \%$ of executed soldiers, $7.1 \%$ of deserters with capital sentences, and $7.4 \%$ of executed deserters come from Irish regiments. The consistency of proportion of soldiers deemed Irish within-dataset-regardless of how Irishness is measured - is consistent with the hypothesis that the decision to execute or commute any soldier was quasi-random and unrelated to, for example, the soldier's Irish identity.

C.2 Medal Rolls Using the Medal Rolls Index, which contains the near universe of all soldiers who enlisted in WWI, I compare the identification of soldiers with male Irish ancestry as a percentage of overall enlistment with the official government statistics reported on Irish enlistment by place of birth (which is 3.9\%). The Medal Rolls Index does not contain county of origin, but contains last name, first name (and, if available, middle name or initials), rank, regiment, and regiment number. There is no battalion number, battalion string, or date. Merging the Irish surname dictionary with the Medal Rolls yields an estimate of $14.1 \%$ having male Irish ancestry out of 5.4 million soldiers. The figure, $14.1 \%$, is $250 \%$ higher than the $3.9 \%$ of the UK soldiers in France and Flanders as reported in government statistics as being born in Ireland.

C.3 Casualties Using the casualties database, I compare the identification of soldiers with male Irish ancestry with the identification of soldiers born in Ireland. Roughly $15.1 \%$ or 99,433 of the 658,616 
casualties are identified as having male Irish ancestry according to the surname dictionary. A similar 15\% of the 549,884 listed as dying in France and Flanders are also identified as Irish according to surname. This $15 \%$ ratio is similar to the $14.1 \%$ of the Medal Rolls identified as having male Irish ancestry. Those with Irish surnames appear to have been dying at the same rate at which they were enlisted. Three-month aggregates of Irish and non-Irish casualty rates are correlated at 0.9 in my data, so I use overall casualties as proxy for battle environment.

Turning to an analysis of birthplace, according to the Irish National War Memoria 63 , only 49,000 of the casualties were Irish and most estimates range from 30,000 to 50,000. In a separate analysis of birthplace, 29,739 men in the casualties database were born in Ireland (Jeffery 2000, p. 150). Another source, analyzing the Irish census, reports 27,405 Irish deaths, a rate of $14 \%$ out of the enlisted Irish and "the same proportion as for the British army overall" (Fitzpatrick 1996, p. 392), which was 12\%. My geolocation algorithm yields 29,430 Irish deaths. The 27,405 Irish census deaths account for $4.1 \%$ of the casualties database, which is close to the $3.9 \%$ reported in government statistics of the percent of all enlistees being born in Ireland.

On the basis of the analysis of casualties according to surname or casualties according to birthplace, one may assume - as other historical researchers, such as Perry (1994) and Oram (1998), have assumed - that the casualties reflect a representative sample of the overall enrollment. Moreover, three analyses of birthplace and surnames - government statistics and the Medal Rolls Index surnames, Irish census (Fitzpatrick 1996) and casualties surnames, and geolocation and casualties surnames - suggest that the surname dictionary results in a similar 240-250\% more soldiers being identified with male Irish ancestry compared to soldiers who were born in Ireland, so the "measurement error" (if we think of surname as measuring birthplace with error) when using Irish surname is at least similar across enlistment and casualties statistics.

C.4 Police Gazettes Using the entire Police Gazettes database on 152,699 deserters and absentees (including those who deserted in the UK), I compare the identification of Irish soldiers using the surname dictionary with the Irish identification based on county of origin in a large sample. Among the Police Gazettes' deserters, $21.7 \%$ have Irish surnames. Among the B.E.F. sub-sample of deserters, $22.7 \%$ have Irish surnames. In the sample of deserters recorded in the War Diaries, $21 \%$ have Irish surnames.The higher percentage of soldiers counted as Irish in these desertion samples is consistent with the Irish having a lower morale and deserting at a higher rate than the British. Using birthplace data, $13.4 \%$ of B.E.F. deserters were born in Southern Ireland and $4.4 \%$ were born in Northern Ireland. (All percentages are reported as a fraction of geolocateable soldiers.) In this dataset, $62 \%$ of soldiers could be geolocated. The higher rates of desertion from Southern Ireland would be consistent with priors.

The increase in the share of soldiers with Irish birthplace in this database $(13.4+4.4=17.8 \%$ of geolocateable birthplaces) as opposed to the casualties database (5.4\% of geolocateable birthplaces 4 is notable as it indicates that the Irish-born were more inclined to desert in the field. Dividing 17.8 by 5.4 indicates that the Irish-born were deserting at roughly 3.3 times the rate at which they enlisted (using the reasonable assumption that the casualty statistics are representative of enlistment statistics). Those with Irish surnames were deserting at 1.5 times the rate at which they enlisted. The ratio of $22.7 \%$ to

\footnotetext{
${ }^{63} \mathrm{http}: / /$ imr.inflandersfields.be/index.html

${ }^{64}$ Note that the figure $5.4 \%$ differs from $4.1 \%$ in the previous sub-section because only $82 \%$ of casualties are geolocateable and I geolocated about 2,000 additional casualties as being born in Ireland than the 27,405 reported in the Irish census.
} 
$17.8 \%$ indicates that, among deserters, Irish surnames are only $28 \%$ more frequent than Irish birthplace, not $240-250 \%$ as found in the analysis of enlistment and casualties. The dramatic decrease in the ratio of the number of soldiers with Irish surname to the number of soldiers with Irish birthplace is notable because it suggests that length of time from Irish roots is predictive of morale.

C.5 Irish Loyalty and Length of Time from Irish Roots Analysis of birthplace data across these datasets provides additional evidence that the Irish were probably less loyal than the British. The casualties database has $1.9 \%$ of its soldiers being born in Northern Ireland and $3.6 \%$ of its soldiers being born in Southern Ireland. The Police Gazettes has $4.5 \%$ of its soldiers being born in Northern Ireland and $9.8 \%$ of its soldiers being born in Southern Ireland. In the sub-sample of B.E.F. deserters, $4.4 \%$ were born in Northern Ireland and $13.4 \%$ were born in Southern Ireland. Since B.E.F. deserters are those who deserted in the field, whereas Police Gazette desertion can be interpreted as desertion that occurred during training, the higher share of Southern Irish-born in the B.E.F. sub-sample suggests that lower morale among Irish soldiers was more relevant for Southern Irish when choosing to desert in the field of battle than when choosing to desert in the UK.

Comparing desertion statistics with enlistment statistics suggests that lower duty to fight is also observed among the enlisted Irish-born soldiers compared to enlisted British-born soldiers. As a share of enlistment, Irish-born soldiers were $170 \%$ (dividing $4.5 \%+9.8 \%$ by $1.9 \%+3.6 \%$ ) more likely to desert during training in the UK, but Southern Irish-born were $270 \%$ times more likely to desert in France and Flanders (dividing $13.4 \%$ by $3.6 \%$ ) while Northern Irish-born were $130 \%$ more likely to desert in the field (dividing $4.4 \%$ by $1.9 \%$ ). This finding suggests that, despite Northern Ireland remaining part of Britain after WWI, the Northern Irish-born were over twice as likely to desert as British-born enlistees.

Next, I analyze enlistment location data. Analysis of enlistment location suggests that the gradient in the duty to fight is similar according to enlistment location and according to birthplace: $1.8 \%$ of casualties, $4.1 \%$ of Police Gazette, and 3.8\% of Police Gazette B.E.F. deserters were enlisted in Northern Ireland while $2.2 \%$ of casualties, $7.2 \%$ of Police Gazette, and $8.1 \%$ of Police Gazette B.E.F. deserters were enlisted in Southern Ireland. As a share of enlistment, soldiers who enlisted in Ireland were 180\% (dividing 4.1\% $+7.2 \%$ by $1.8 \%+2.2 \%$ ) more likely to desert during training in the UK, but Southern Irish-enlistees were $270 \%$ times more likely to desert in France and Flanders (dividing $8.1 \%$ by $2.2 \%$ ) while Northern Irish-enlistees were $110 \%$ more likely to desert in the field (dividing $7.2 \%$ by $1.8 \%$ ). In sum, desertion in the field was also higher for soldiers who enlisted in Ireland relative to those who enlisted elsewhere. These results suggest that birthplace is a stronger predictor of loyalty, but enlistment location and surname are also strong predictors.

Together, the fact that both the Northern Irish-born and the Northern Irish enlistees were over twice as likely to desert assuages the concern that the use of the Irish surname does not distinguish between Southern and Northern Irish. Therefore, not distinguishing between the two groups in the main analyses is unlikely to be problematized by the potential for the Northern Irish to have equal or heightened loyalty compared to the British. At present, I do not have historical information on Catholic or Protestant birth parishes to ascertain whether Protestant Irish had heightened loyalty, but there is little in the discriminatory statements made by British officers indicating that they made a distinction on the basis of religion. The use of surnames is still likely superior to the use of regiment to mark "Irish" because $27 \%$ of soldiers in Irish regiments were born in Britain. The mix of Protestant and Catholic Irish would also still exist in the regiments.

Finally, even though British-born soldiers were far more loyal, British-born soldiers with Irish surnames, 
were disproportionately disloyal. This further supports the use of Irish male ancestry as a proxy for "Irishness." In the data, soldiers with Irish surnames and Irish birthplaces comprise $2.0 \%$ of casualties and, with the assumption of population representative death rate, $2.0 \%$ of enlistment, but $6.5 \%$ of the Police Gazette (225\% more likely to desert). Soldiers with Irish surnames and British birthplaces comprise $13.2 \%$ of casualties and $15.6 \%$ of the Police Gazette (20\% more likely to desert). Soldiers without Irish surnames and with Irish birthplaces comprise $3.4 \%$ of casualties and $8.2 \%$ of the Police Gazette $(140 \%$ more likely to desert). Soldiers without Irish surnames and with British birthplaces comprise $81.4 \%$ of casualties and $69.7 \%$ of the Police Gazette (15\% less likely to desert).

C.6 FGCM Notably, the proportion of soldiers with Irish surnames is $20 \%$ in the desertion and absence trials, $23 \%$ in the B.E.F. Police Gazette sample of deserters, $21 \%$ in the War Diaries sample of deserters, and $19 \%$ of the death sentences (and 17\% of executions). Assuming that the Police Gazette and War Diaries sample represent the true desertion rate, the consistency in the share with Irish surnames suggests that the military command did not disproportionately target or disfavor Irish soldiers in the apprehension and trial stage nor in the sentencing and execution stage.

C.7 Service and Pension Records Finally, I investigate the Service and Pension Records, a large sample based on pension eligibility, which also contains data on birthplace. The quality of location data here is particularly low. Only 815,000 soldiers or $29 \%$ could be geolocated, unlike the $82 \%$ geolocation rate for the casualties data. This low rate is largely due to the fact that 1.9 million soldiers did not have birthplace data. In this data, $15.3 \%$ of the 2.7 million soldiers have Irish surnames, which is consistent with the percentage found for the Medal Rolls and Casualties databases. Interestingly, $9.1 \%$ of geolocateable soldiers are identified as born in Ireland. This would seem to suggest a larger proportion of Irish-born soldiers who joined after 1914 but left before 1920 (and were thus not eligible for pensions) in the Service Records or a larger proportion of Irish-born soldiers who were discharged for medical reasons during the war, or who were killed and whose dependents claim a pension in the Pension Records. I have no good reason to think that Irish-born would been more likely to suffer illness or wounds leading to medical discharge, since the Irish-born constitute a fraction of the casualties database representative of their enrollment. I have no strong reason to think they would be more likely to have dependents. One possible reason for the higher proportion of Irish-born, then, is they were more likely to demobilize at the end of the war. This would be consistent with their falling enlistment rates throughout the war, and the fact that the Irish war for independence commenced in 1919.

In addition to birthplace, another means of geolocating the soldiers is the residence data, though this variable is missing for 1.3 million records. Of the geolocateable soldiers, $2.4 \%$ are identified as residing in Ireland. However, many Irish soldiers who served in the British army chose not to or could not live in Ireland after Ireland declared independence. In fact, this analysis provides quantitative evidence suggesting that only $26 \%$ of soldiers born in Ireland returned after the war.

Irish surname is still predictive of being born in Ireland and is also predictive of residing in Ireland. Pairwise regressions yield coefficients of 0.21 for residence and 0.23 for birthplace (and pairwise regressions in Police Gazettes and casualties yield 0.25 and 0.24 respectively). Irish surname is more strongly correlated with Southern Irish locales. In casualties, 0.3 and 0.29 for Southern Irish enlistment and birthplace and 0.14 for Northern Irish enlistment and birthplace. In Police Gazettes, 0.28 and 0.29 for Southern Irish enlistment and birthplace and 0.12 for Northern Irish enlistment and birthplace. In Service and Pension Records, 0.28 and 0.25 for Southern Irish birthplace and residence and 0.12 and 0.15 for Northern Irish birthplace and residence. This would be consistent with Irish surname being a decent proxy for Irish 
ethnicity. 


\section{Additional Discussion}

D.1 Is the Sequence of Decisions Within a Unit Non-Random? Even if confirmation decisions are uncorrelated with observable individual and environmental characteristics, they may be correlated with unobservable time-varying characteristics within a division, such as time-varying perceived indiscipline, officer fixed effects, or lower-level groups or units of bad apples that may be correlated with subsequent absences. Confirmations may be mean reverting. Appendix Figure 1 shows that for each of the divisions separately, while there are concentrated periods of death sentences, there do not appear to be concentrated periods of executions. Two animated graphs to explore relationships over time are available at this link, which displays the cumulative measure, and at this link, which displays "last 120 day" measures 65

Appendix Figure 4 shows a static final snapshot indicating that execution rates in a division are uncorrelated with total casualties in that division. Appendix Figure 2 shows another snapshot indicating that execution rates in a division are uncorrelated with total absences (i.e., military discipline) in that division. This pattern is also visible in Appendix Figures 4 and 5 the circle sizes correspond to the number of absentees recorded in the War Diaries and Police Gazettes respectively. The circle sizes are unrelated to deviations from the $12 \%$ line.

Appendix Figure 6 shows a snapshot of the "last 120 day" animation indicating that death sentences and executions are positively and tightly correlated. Appendix Figure 7 shows that absences and casualties in the last 120 days are also positively (though less tightly) correlated. This pattern is consistent with soldiers deserting more when battlefield danger is high. Importantly, Appendix Figure 9 shows that casualties in the last 120 days are uncorrelated with the execution rate in the last 120 days. This pattern is similar to what was found in Tables 1 and 2. Moreover, Appendix Figure 8 indicates that absences in the last 120 days are uncorrelated with execution rates. Taken together, these figures suggest that even if the military command (more specifically, the panel of officers of field rank major, lieutenant colonel, or colonel) took into account point-in-time danger in sentencing soldiers to death, the Commander-in-Chief did not make the execution decision depend on point-in-time danger or discipline within a unit.

I next turn to a random strings test. This approach is analogous to a Fisher exact test, except that: 1) I propose a statistic that can be computed from a sequence of $1 \mathrm{~s}$ and $0 \mathrm{~s}$ (executions and commutations) within a unit $i$; ) I compute the statistic for the actual sequence, $\left.s^{*} ; 3\right)$ I compute the statistic for each of 1,000 bootstrap samples from the actual sequence (i.e., $\hat{s}_{1}, \hat{s}_{2}, \hat{s}_{3} \ldots \hat{s}_{n}$ ). Since there were peaks and troughs in the execution rate, I treat the bootstrap samples as a vector of realized Bernoulli random variables, with the probability of a success (i.e., execution) equal to the global execution rate within fifty days of that trial time, not including the unit under consideration; 4) I compute the empirical p-value, $p_{i}$ by determining where $s^{*}$ fits into $\left.\hat{s}_{1}, \hat{s}_{2}, \hat{s}_{3} \ldots \hat{s}_{n} .5\right)$ repeat steps $1-4$ for each $i$.

The statistics usee are: 1) Autocorrelation. I see if the decision made in the $j$ th cases depends on the outcome in the $j-1$ th case. This statistic can detect whether executions are "clustered," meaning a higher than expected number of back-to-back executions. This test tells me whether commanders executed soldiers in pairs, as in the case of two friends deserting together (they do, and the historical record confirms this (Putkowski and Sykes 2007, p. 64), so in these assessments of randomization, I treat multiple observations of executions (commutations) of death sentences whose trials occurred on the same

\footnotetext{
${ }^{65}$ In the graphs, the axes can be chosen by the user. For example, the user can choose to display executions, execution rates, casualties, absences, death sentences, and time. Each division is labeled with the actual divisional number. The diameter of the circle around each division is proportional to the number of absences recorded for that unit. The colors correspond to army type.
} 
Appendix Figure 1.- Distribution of Executions and Commutations Across Divisions Over Time

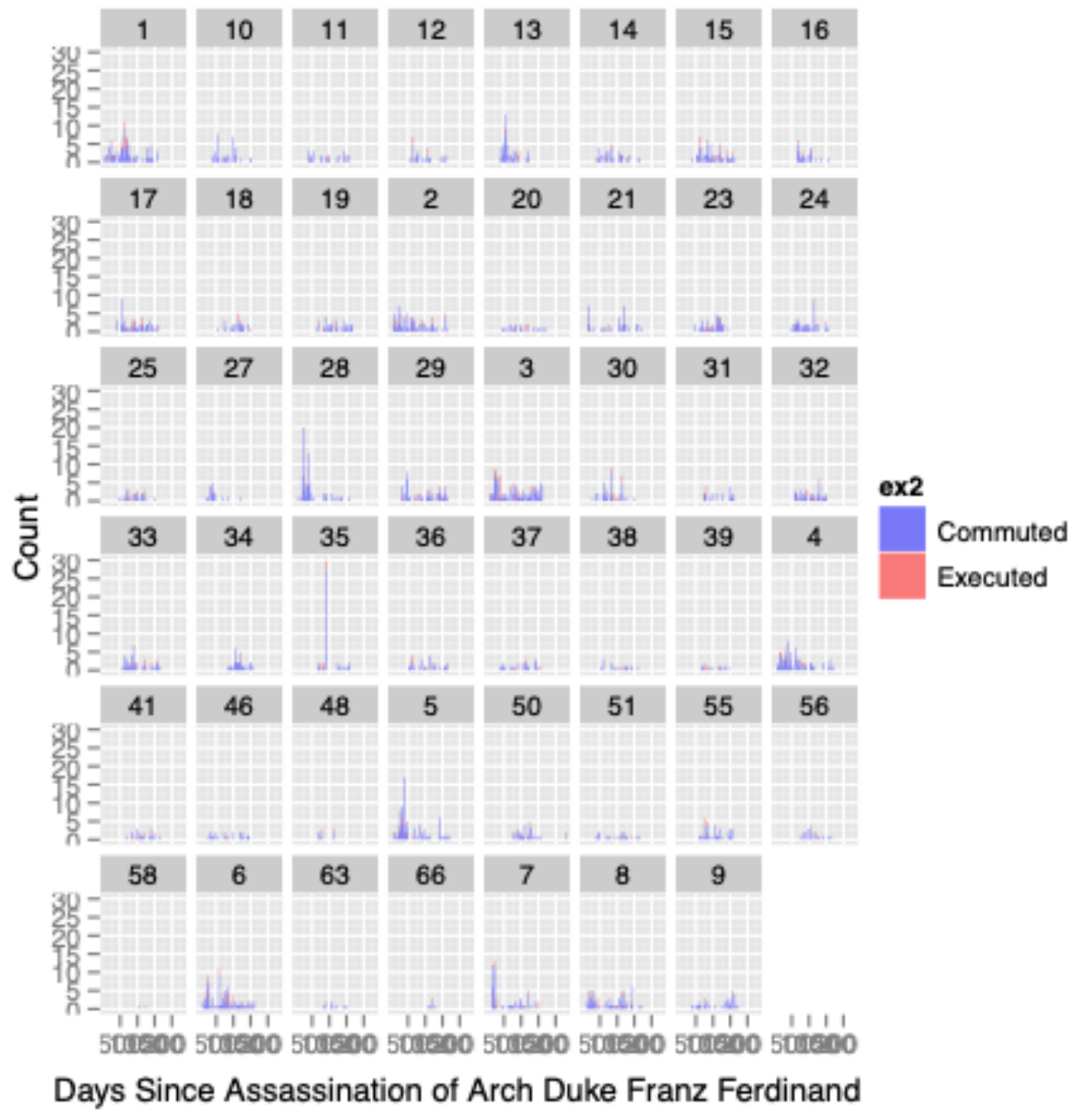

Notes: This figure plots the distribution of executions and commutations in each division over the war. 


\section{Appendix Figure 2.- Execution Rate and Absences Across Divisions}

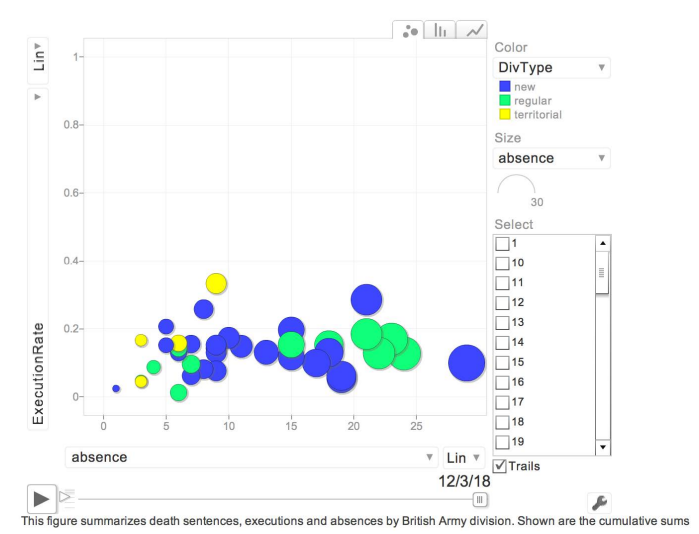

Notes: This figure shows a snapshot of a data explorer for death sentences, executions, casualties, and absences by division. Shown are cumulative sums. Execution rates and absences appear uncorrelated.

\section{Appendix Figure 3.- Execution Rate and Casualties Across Divisions}

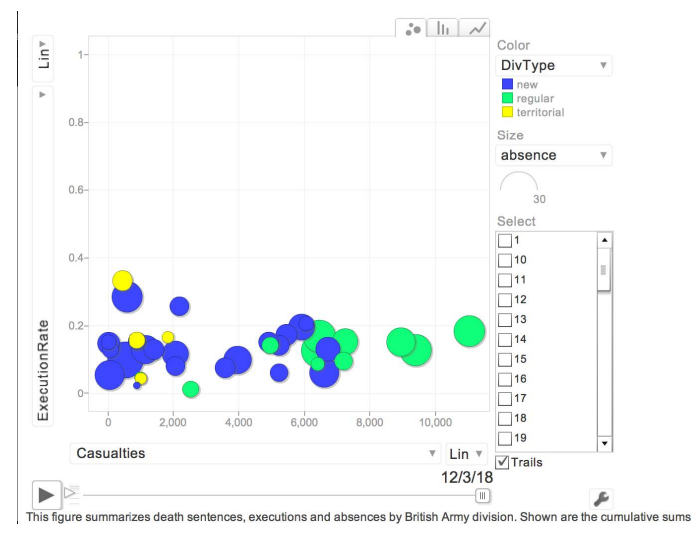

Notes: This figure shows a snapshot of a data explorer for death sentences, executions, casualties, and absences by division. Shown are cumulative sums. Execution rates and casualties appear uncorrelated. 


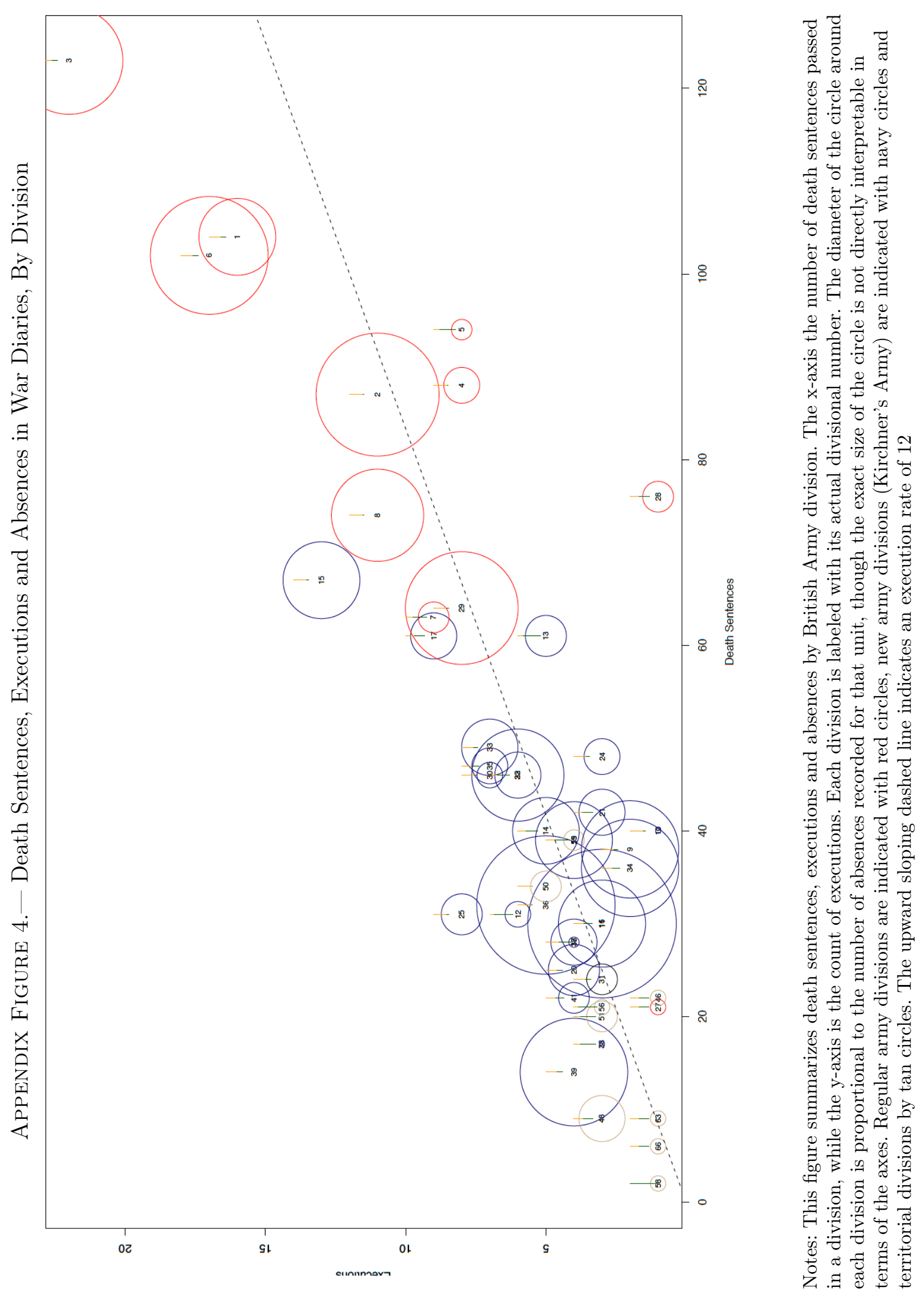


Appendix Figure 5.- Death Sentences, Executions and Absences in Police Gazettes, By Division

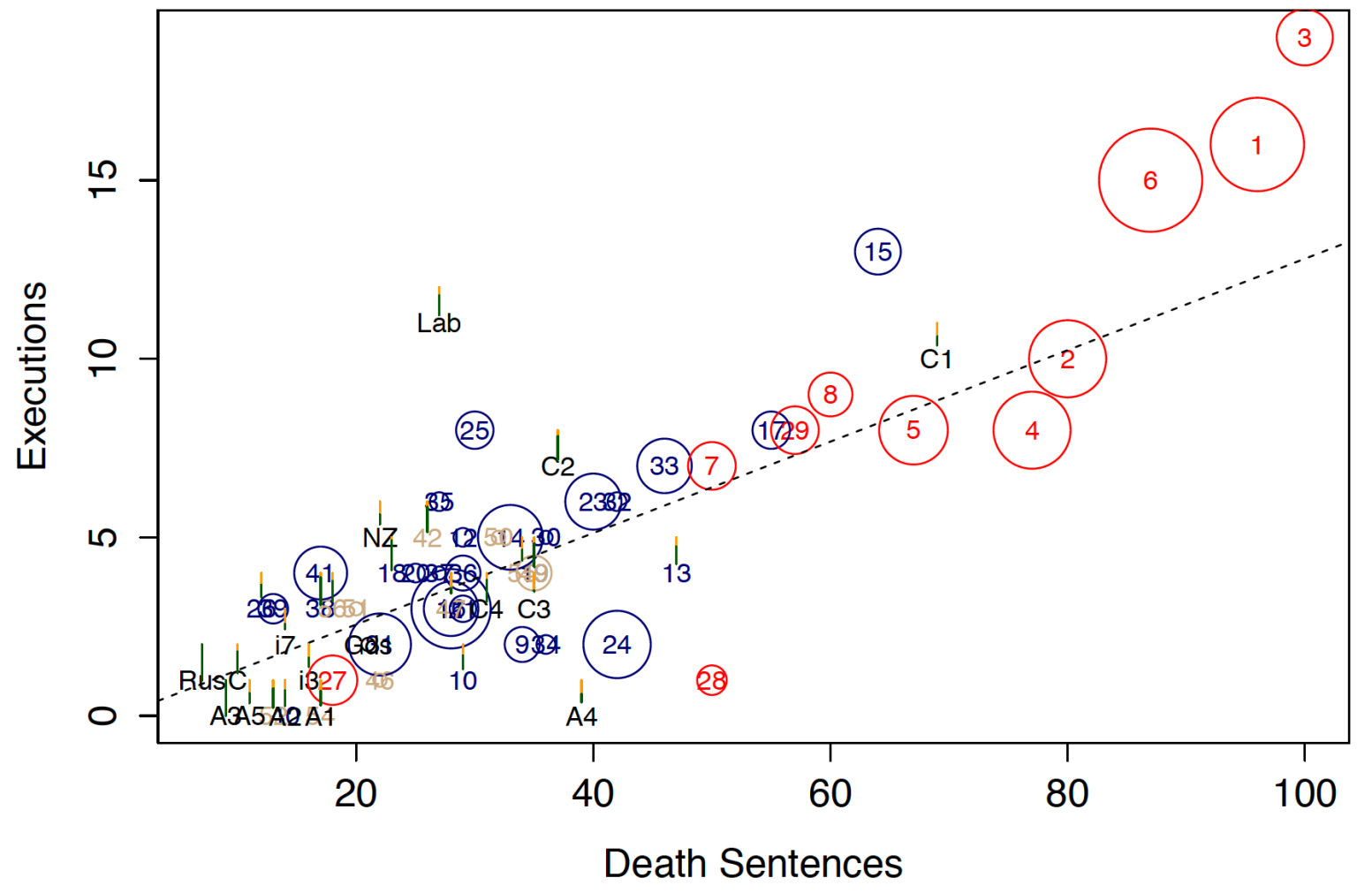

Notes: This figure is similar to the previous figure except the absences data come from the Police Gazettes. 
Appendix Figure 6.- Executions and Death Sentences Across Divisions (120 Day Window)

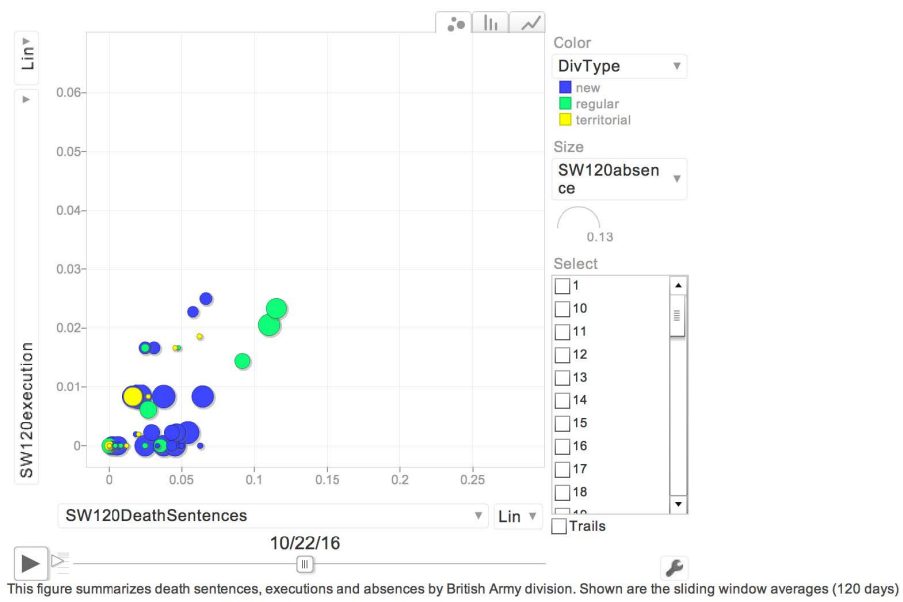

Notes: This figure shows a snapshot of a data explorer for death sentences, executions, casualties, and absences by division. Shown are sliding window averages (120 days). Death sentences and executions appear positively correlated.

Appendix Figure 7.- Absences and Casualties Across Divisions (120 Day Window)

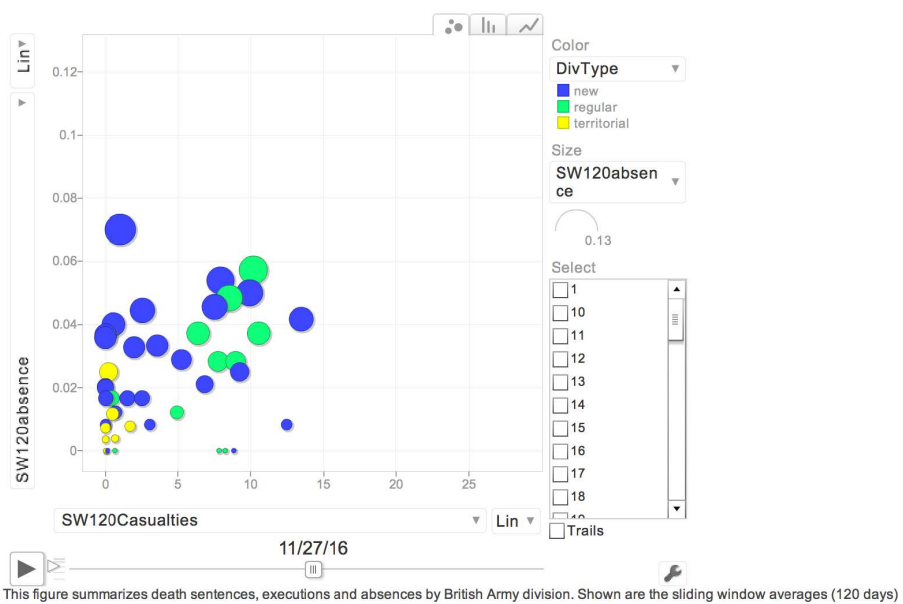

Notes: This figure shows a snapshot of a data explorer for death sentences, executions, casualties, and absences by division. Shown are sliding window averages (120 days). Absences and casualties appear positively correlated. 
Appendix Figure 8.- Absences and Execution Rates Across Divisions (120 Day Window)

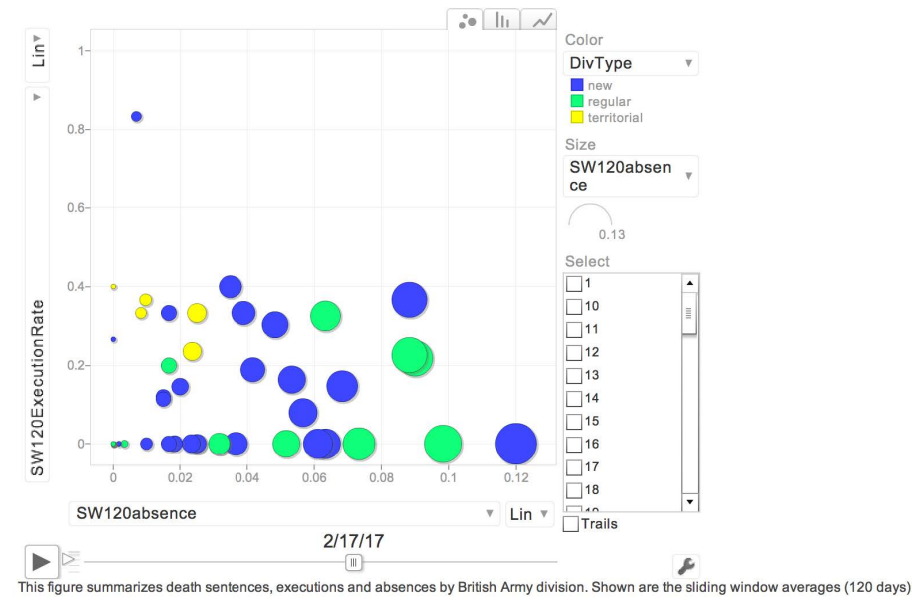

Notes: This figure shows a snapshot of a data explorer for death sentences, executions, casualties, and absences by division. Shown are sliding window averages (120 days). Execution rates and absences appear uncorrelated.

Appendix Figure 9.- Casualties and Execution Rates Across Divisions (120 Day Window)

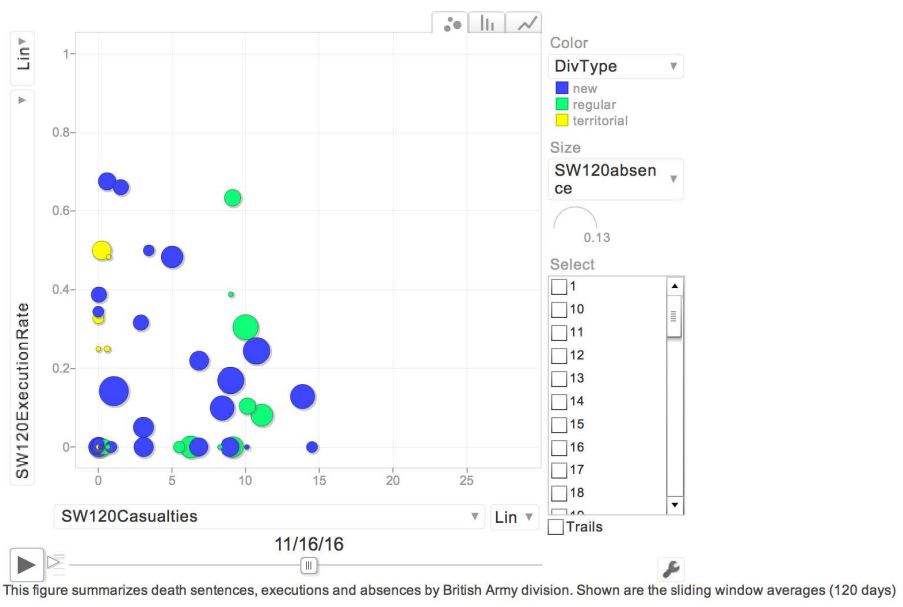

Notes: This figure shows a snapshot of a data explorer for death sentences, executions, casualties, and absences by division. Shown are sliding window averages (120 days). Execution rates and casualties appear uncorrelated. 
day and for the same division as 1 observation). The autocorrelation test also reveals if commanders targeted divisions for poor discipline, or if lower level brigades or battalions generated a disproportionate share of desertions and death sentences and were targeted for discipline. 2) Mean-Reversion. I test whether there is any form of mean reversion in the sequence, meaning that the execution in the $j$ th case is correlated with the deviation of the actual execution rate in previous $j-1$ cases from the expected execution rate. This test reveals whether the Commander-in-Chief was attempting to equilibrate his decisions, considering whether a unit was "due" for an execution or whether they became more lenient after an execution ${ }_{6}^{66} 3$ ) Longest-Run. I test whether there are abnormally long "runs" without any executions or long runs without commutations. This test reveals whether certain units may have been favored with commutations during certain time periods. For example, if a unit's commanding officer always recommended commuting a death sentence, and the Commander-in-Chief was influenced by the lower level officer's recommendation, or if lower-level groups of bad apples were being targeted for executions.

I use a Kolmogorov-Smirnov (KS) Test to determine whether the empirical distribution of p-values approaches the CDF of a uniform distribution using the one-sided critical value with $n=46{ }^{67}$ Appendix Figure 10 plots the empirical distribution for my three test statistics and the corresponding table in that figure confirms the visual intuition that the p-values are uniformly distributed for all tests.

Showing that residuals behave like a random string does not address the possibility that individuallevel characteristics (randomly distributed over time) are correlated with executions. But only examining orthogonality between executions and individual-level characteristics could miss correlated temporal patterns in executions and desertions.

D.2 Power of random strings test In Appendix Figure 11, $m_{1}$ represents the assumed autocorrelation between successive execution decisions (if $p$ is the correct marginal probability of an execution, the transition probability from one execution to the next is $\left.m_{1} p\right)$. For autocorrelation as low as 1.5 , the distribution of p-values in one simulation is significantly different from the uniform CDF at the $10 \%$ level. In order to estimate the type-II error rate, thousands of strings are simulated. For each individual realization, the Null $H_{0}$ : noautocorrelation is rejected if the p-value from the KS test is less than $\alpha=0.05$. The fraction of incorrect decisions (failures to reject $H_{0}$ ) serves as an estimate for the type-II error. Appendix Figure 12 displays the distribution of the KS p-values for 4 different values of $m_{1}$, which for convenience have already been translated into the corresponding values of the autocorrelation coefficient. For values of autocorrelation between 0.13 and 0.17 , the estimated power lies between 0.74 and 0.9 . For example, for autocorrelation, I show the degree of autocorrelation that would show statistically significant KS-tests of deviation from a uniform distribution. I then show the distribution of KS-test statistics for many simulations of autocorrelated strings.

D.3 Commutation date Assuming that commutation dates occur on the upper end of the time range, 14 days after the trial date, would tend to magnify the estimated deterrent effect, since time between commutation and subsequent absence is minimized. Assuming that only the original trial date is relevant could reduce the chance to detect either deterrence or spurring effects, since an intervening absence after the trial (but before the execution or commutation) can occur. This interpretation is somewhat consistent with the patterns in the data. Table 5 Panel A displays a slight spurring effect of executions (as we can see

\footnotetext{
${ }^{66}$ Results are similar when examining whether execution in the $j$ th case is correlated with the deviation of the actual cumulative sum of executions in previous $j-1$ cases from the expected sum.

${ }^{67}$ Imagine generating summary statistics for 1000 random strings. The $1001^{\text {th }}$ random string should have a summary statistic that is equally likely to be anywhere from 1 to 1000 .
} 
Appendix Figure 10.- Random strings test for sequence of executions in each division
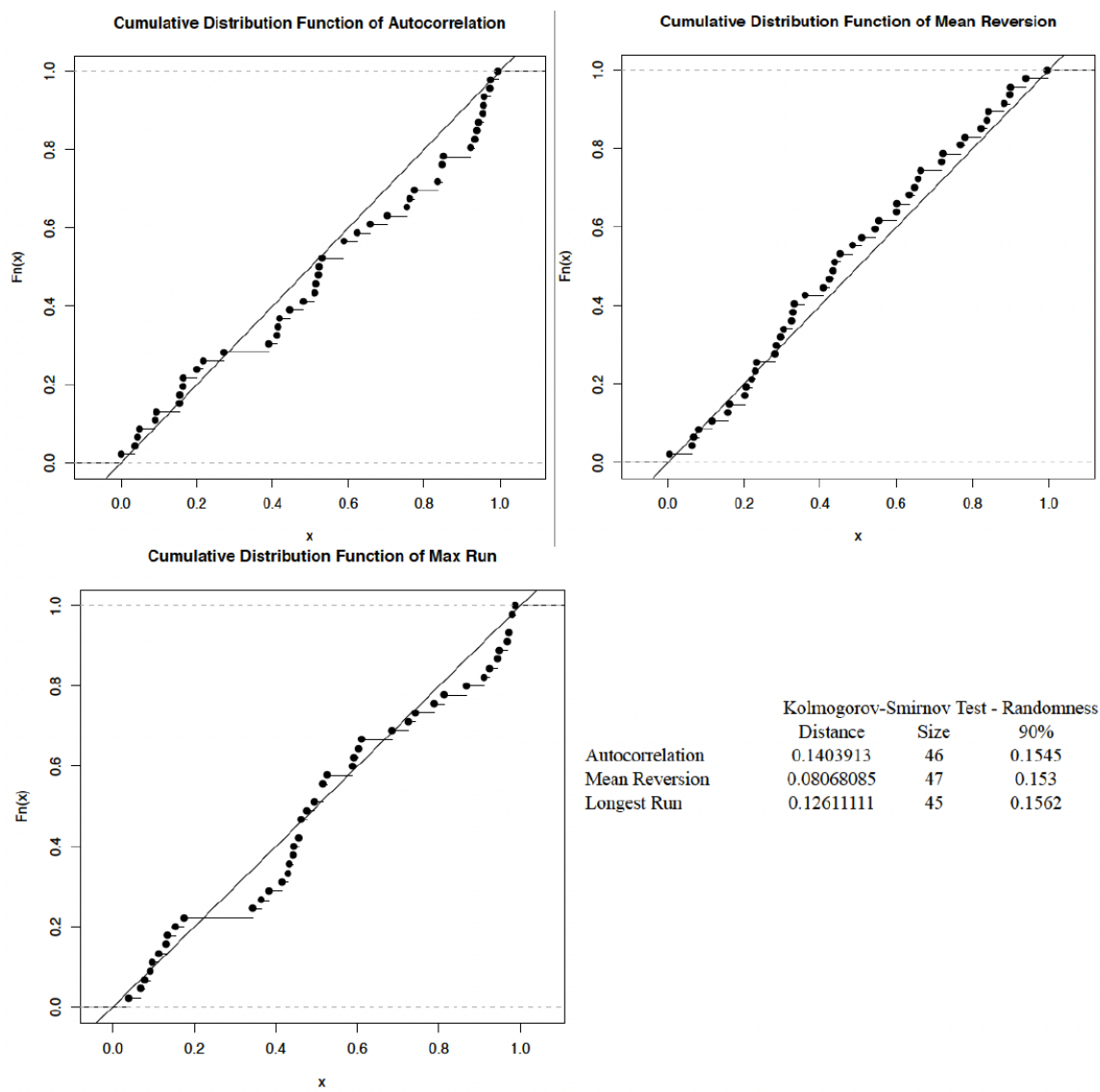

\begin{tabular}{ccccc}
\multicolumn{6}{c}{ Kolmogorov-Smirnov Test - Randomness } & Check of P-Values \\
Distance & Size & $90 \%$ & $95 \%$ & $99 \%$ \\
0.1403913 & 46 & 0.1545 & 0.1767 & 0.2195 \\
0.08068085 & 47 & 0.153 & 0.1748 & 0.2171 \\
0.12611111 & 45 & 0.1562 & 0.1786 & 0.2219
\end{tabular}

Notes: This figure plots the empirical distribution of p-values across divisions for whether the string of executions displays autocorrelation, mean reversion, or runs. The KS-test is reported along with the critical values. 
APPENDIX FiguRE 11.- Distribution of simulated p-values in assessment of random strings test
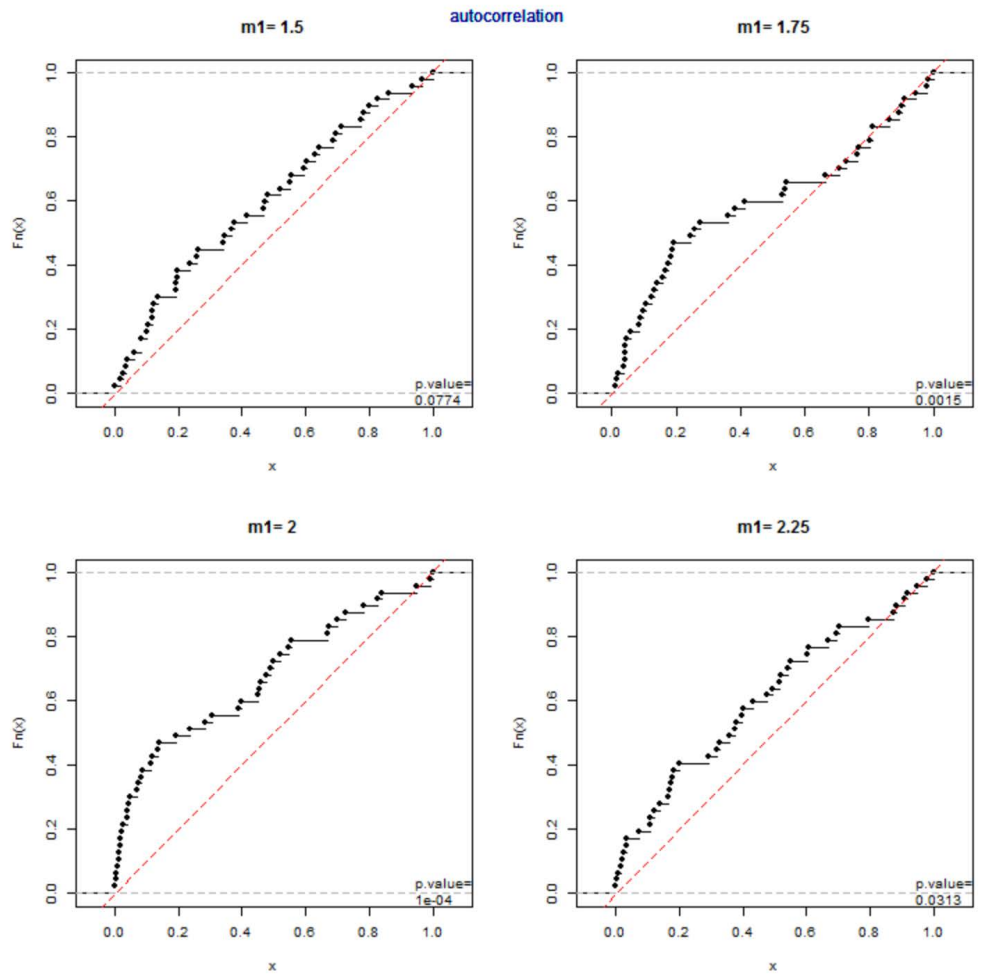

Notes: This figure simulates p-values for different levels of autocorrelation. 
ApPendix Figure 12.- Distribution of KS-test statistics in assessment of random strings test
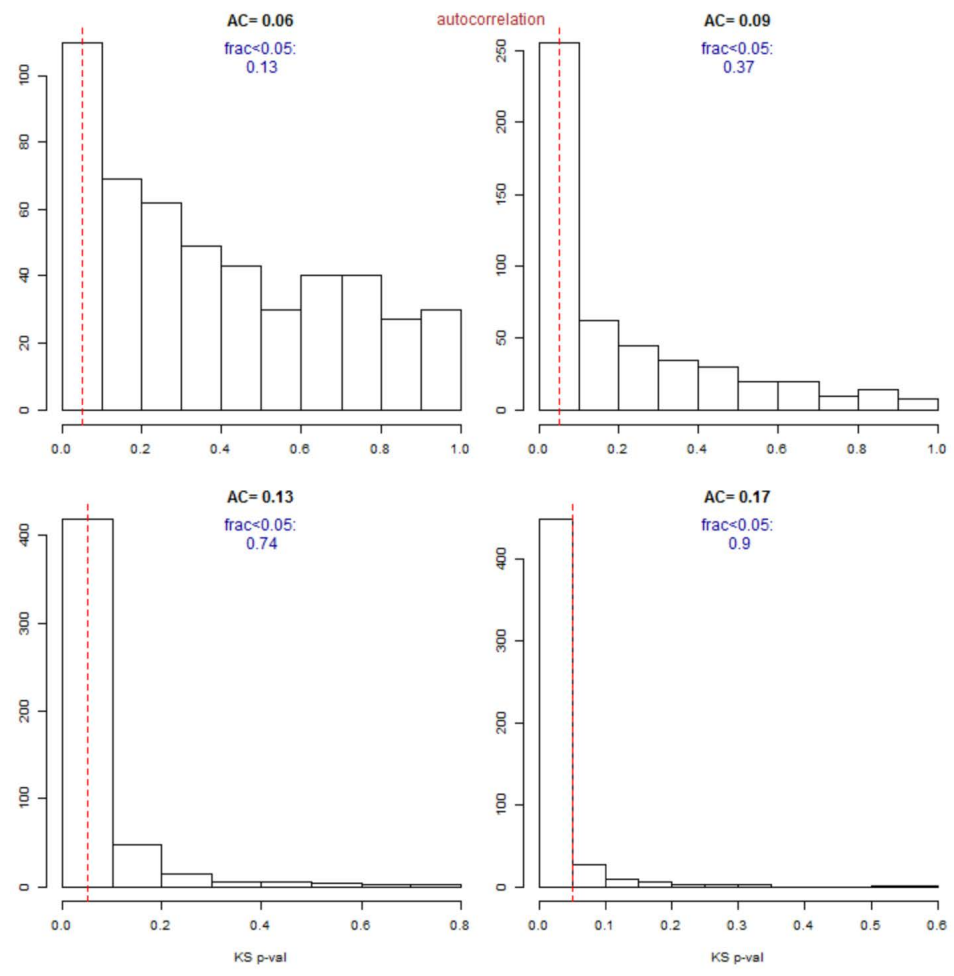

Notes: This figure displays the distribution of KS-test statistics for many different simulations. 
from the positively-signed coefficients) in Columns 7 and 8 and Panel $\mathrm{C}$ displays a slight deterring effect in Columns 1-3. These coefficients are significant at the $10 \%$ level; more generally, 4 of 27 specifications display a significant impact of executions at the $10 \%$ level (and 1 of 27 at the $5 \%$ level), but they do so in opposite ways, which cautions against strong conclusions in either direction.

D.4 Execution rates When the half-life is assumed to be short (7 days), the two coefficients in Table 7 tend to be of the same sign and not statistically significantly distinguishable from each other. However, as the half-life is extended, the coefficient on the cumulative measure of executions becomes significantly more negative relative to the coefficient on commutations. The significant difference can be inferred from fact that the coefficient for commutations is positive and significant at the $5 \%$ level while the coefficient for executions is negative and not significantly different from 0 . This means that the execution rate has a deterrence effect and it is observed in models that assume a longer half-life. This pattern is observed for the Police Gazette and FGCM data, while the pattern is less statistically significant in the War Diaries data, though the coefficient on the execution term is always more negative relative to the commutation term.

The reader can interpret any of the specifications in Appendix Table 11, but to take just one, for illustrative purposes, in the specification assuming a half-life of one month, the difference between the cumulative execution measure (-0.027) and commutation measure $(0.105)$ is 0.12 , or a $12 \%$ decrease in hazard rate for executions relative to commutations. Another way to interpret the coefficient magnitudes would involve the counterfactual of no death penalty - the difference between all death sentences leading to execution vs. all death sentences leading to commutations. Such an extrapolation involves recalculating the cumulative half-life measure (sum of the execution and commutation measures), and multiplying this sum by 0.12 . Taking the product, then averaging for all divisions and all days, would yield the counterfactual effect of having the death penalty on time to the next absence.

D.5 Ethnic identity of the subsequent deserter Panel A of Table 8 Column 1, which uses the +14 imputation date for a commutation trial, shows that after the execution of an Irish soldier, $19 \%$ of the War Diaries absences that immediately follow are Irish, but after executing a non-Irish soldier, $11 \%$ of the immediately following War Diaries absences are Irish. That is, Irish executions double the likelihood the following absentee is Irish. A similar pattern is observed for desertion death sentences $(9.5 \%$ increasing to $20.0 \%$ ).

Focusing still on War Diaries absentees and moving to another imputation assumption in Panel B, a difference is also visible for Irish vs. British executions, while no difference is observed for Irish vs. British commutations, when using the nearest-neighbor imputation. The doubling reported in the execution rows should be unaffected since the execution date is not being changed moving from Panel A to B. Commutation statistics change slightly and are consistent with their still being invisible.

Turning to the other datasets, we see similar but muted patterns in FGCM in Column 3, where a difference is also visible for Irish vs. British executions (e.g., 15.3\% increasing to $21.6 \%$ ) and no difference observed for Irish vs. British commutations, at least for Panels A and B. However, in Column 2 we no longer see that Irish executions spurred absences of the Irish more than the British. I have no theoretical reason for this to be the case, but an explanation for the weaker Police Gazette result is its density of absences is far lower than the other datasets, which would result in more measurement error. From the War Diaries data, I identify 676 usable matches for one-third of the war. From the Police Gazettes, 1,319 of these are mergeable for the entire war. Indeed, one might interpret the greater differences in ethnic composition of subsequent Irish vs. British commutations to be consistent with greater measurement 
error.

In Panel $\mathrm{C}$, the execution and commutation dates are both set to the trial date. The increase in Irish absences after Irish execution is muted though still sizable. Interestingly, the percentage of next absences that are Irish become more dissimilar after Irish and non-Irish commutations when the trial date is used (e.g., $9.1 \%$ vs. 14.0\%). This suggests that the third imputation method may be the worst one in introducing noise to the control, whereas 2 weeks after a trial is a good metric for the time between sentence and confirmation/commutation decision. Alternatively if military events for some reason made it possible to hold the the trial but delayed the confirmation/commutation decision, then the nearestneighbor assumption is also a good one.. In addition, using the trial date instead of execution date introduces noise to the treatment variable. On this basis, we might rely less on estimates using this imputation.

D.6 Robustness checks Appendix Tables 1-2 report falsification checks where the analysis is run backwards in time. I start the clock 90 days before the treatment event to ensure the subject of the death sentence does not affect the outcome variable. A handful of significant coefficients appear, in particular, 13 of 81 coefficients that would have a causal interpretation (executions or their interactions) are significant at the $10 \%$ level in Appendix Table 1. Appendix Table 2 is mirror to Table 7 (which may arguably be the preferred specification-assuming a 14-day commutation imputation and using exponential hazard-and including weak SUTVA coefficients). None of the execution salience coefficients are statistically significant. Several of the execution rate coefficients are statistically significant in the FGCM data. Notably the casualties coefficient is still positive, as we would expect with associations between casualties and temporally local rates of absence, in the War Diaries. However, it becomes negative in FGCM. This would be consistent with FGCM being a poorer measure of absences, since in order for the field trials to be conducted, there should not be pitched battle. In Tables 5 and 7 , the associations between casualties and FGCM absences were also not as large as the associations observed for the War Diaries.

To see if some of the significant placebo results are due to inappropriate clustering of standard errors, Appendix Tables 3-5 report results without clustering of standard errors, where similar inferences are obtained as in the main tables. Appendix Table 3 indicates no robust deterrent effect of execution salience. Consistent spurring effects of Irish executions are found in Appendix Tables 4 and 5. Deterrent effects of execution rates are found in Appendix Table 5 for Police Gazettes and FGCM under longer half-life assumptions.

Appendix Tables 6-7 report the backwards analysis without clustering. What is worth noting is that 6 of 81 coefficients that would have a causal interpretation are significant at the $10 \%$ level in Appendix Table 6. In Appendix Table 7, only the execution salience coefficients would be worth interpreting and here there are no significant coefficients. To be sure, any interpretation of weak-SUTVA coefficients without accounting for clustering warrants strong caution. These are cumulative measures, therefore they are, by definition, positively serially correlated. Thus, not accounting for the correlation could render results that are artificially significant. The fact that this does not seem to be materially relevant warrants further caution on strong inferences regarding the deterrence of execution rates, as does the fact that placebo deterrence is observed for FGCM trials, which constitute half of the evidence in favor of deterrence of execution rates in Table 7 .

Appendix Table 10 shows that the results of Table 7 are robust to including the following variables: Irish indicators for each officer in the chain-of-command, whether the executed soldier was an officer, the executed soldier's age, distance to coast, distance to Berlin, fixed effects for the identities of the 
Appendix Figure 13.- Non-Parametric Survival Distributions (War Diaries) assuming censoring when death sentences occur before another absence

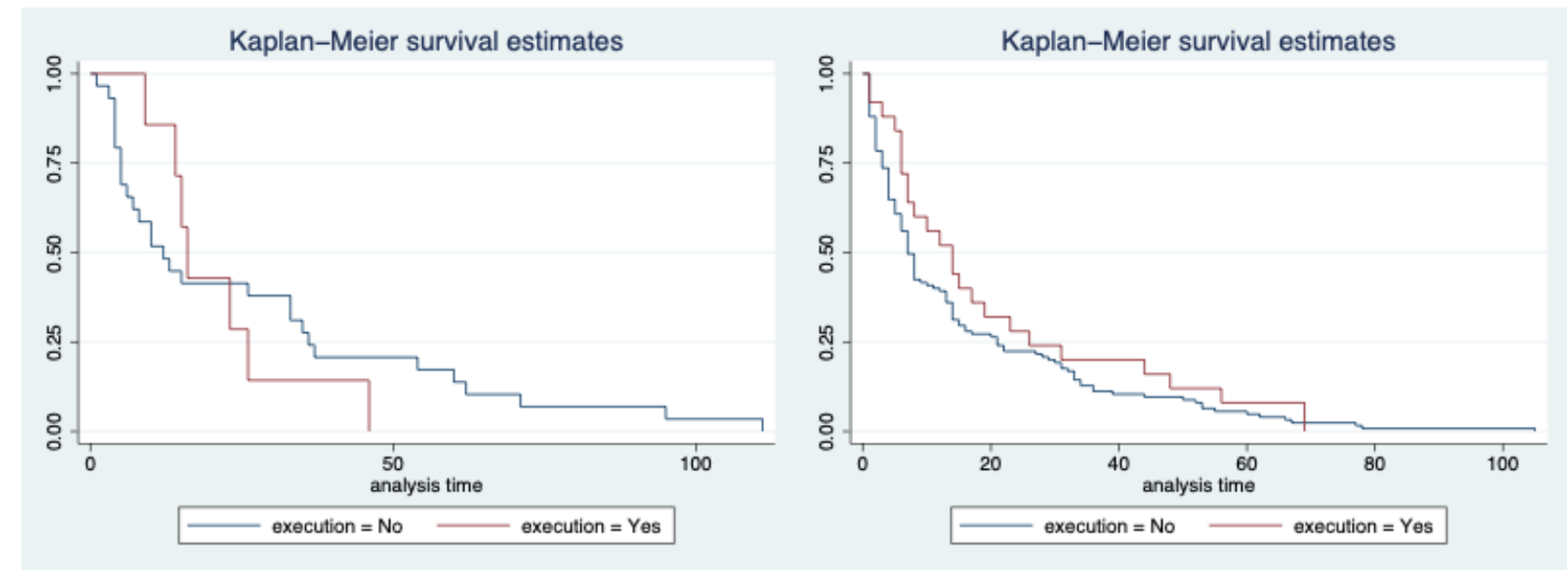

Notes: This figure shows the impact of Irish (left) and British (right) executions on time until next absence in the War Diaries dataset. Death sentences that occur before another absence are treated as a censored event.

Division Commanding Officer and Division $1^{\text {st }}$ General Staff Officer (Officers that appear with less than 10 frequency are categorized in an Other category), and lag measures of absences and of death sentences (the log of absences and the log of death sentences in the time window 30-59 Days Ago and 60-89 Days Ago). As before, when officer or age data is missing, it is dummied out (i.e., set to a constant and another variable indicating whether it is missing is included). To speed calculations, the exponential models do not include officer identity fixed effects, but the Weibull and Cox models do. The results of this table would support the earlier inferences.

In Appendix Table 12, as always, missing data is dummied out (i.e., set to a constant and another variable indicating whether it is missing is included), and for interaction analysis, that means that interactions with the dummy are included.

Appendix Table 14 reports this robustness to pooling the data. There are relatively few absences that follow a death sentence event when each absentee dataset is used individually, as can be seen in the visual univariate analyses of Appendix Figures 13, 14, and 15. However, the graphical intuition of Irish executions spurring rather than deterring is still present in these figures as in Figures 17, 18, and 19 .

D.7 Day-by-day framework The size of the effects are largest with the smaller half-life assumptions. They are larger in the War Diaries dataset, but more statistically significant in the Police Gazettes dataset. One might interpret the sum of the level term (on execution) and interaction term (with Irish) as still suggesting a net spurring effect, despite any potential deterrent effect of British executions as articulated in the theory section. The FGCM data suggest some spurring of Irish desertion relative to non-Irish desertion but only when it comes to the execution of deserters. Again, the size of the effects are largest with the smaller half-life assumptions.

Another way to interpret the magnitudes, the average value of the outcome is -0.002 in the Police Gazettes, and the average value of the Irish execution variable is 0.003 . So multiplying the coefficient 
Appendix Figure 14.- Non-Parametric Survival Distributions (Police Gazettes) assuming censoring when death sentences occur before another absence

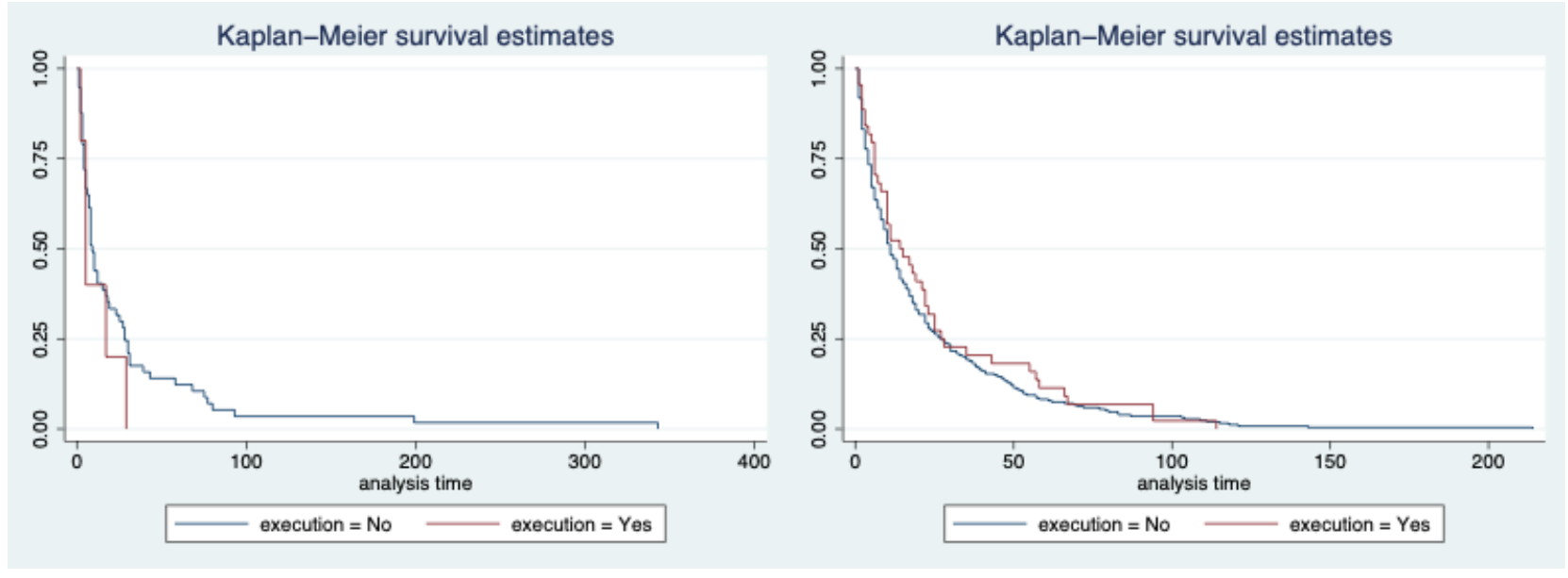

Notes: This figure shows the impact of Irish (left) and British (right) executions on time until next absence in the Police Gazettes dataset. Death sentences that occur before another absence are treated as a censored event.

Appendix Figure 15.- Non-Parametric Survival Distributions (FGCM Trial Registries) assuming censoring when death sentences occur before another absence

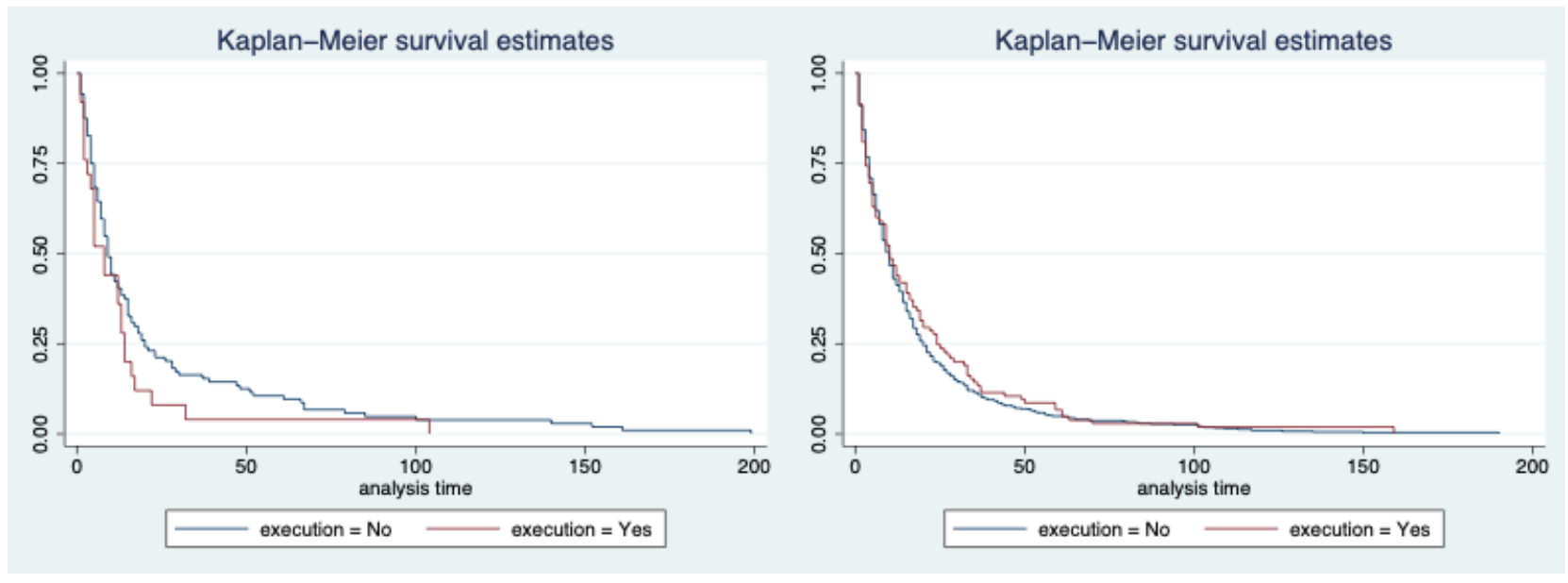

Notes: This figure shows the impact of Irish (left) and British (right) executions on time until next absence in the FGCM Trial Registries dataset. Death sentences that occur before another absence are treated as a censored event. 
0.012 by 0.003 yields roughly $2 \%$ of the average outcome. The standard deviation of the Irish execution variable is 0.045 and the standard deviation of the outcome is 0.057 , so multiplying by the coefficient would yield roughly $1 \%$ of the standard deviation of the outcome.

Finally, to assuage concerns that these treatment variables are measured in a cumulative fashion with strong positive serial correlation affecting inference, in Appendix Tables 8 and 9, I run the clock backwards and examine the effect of future events on previous absences. I again shift the absence data by 90 days earlier to ensure the subject of the death sentence are excluded from the outcome variable. For example, consider March 1, 1916. I do not correlate the absence on March 1 with executions and commutations beginning on March 1, 1916. This is because an absence on March 1 could appear in the treatment data and would be on both the left- and right-hand side of the specification. Instead, I correlate the absence on December 1, 1915 with forward-treatment (future executions and commutations) beginning on March 1, 1916 in the placebo check for null results. What emerges is that 5 out of 90 coefficients on an execution term are significant at the $10 \%$ level, which is consistent with the low rate of significant coefficients in prior randomization and placebo checks.

D.8 Death Sentences Following Executions as Potential Source of Bias In my final robustness check, I examine what happened after an execution and whether military justice changed. It is entirely possible that judicial panels comprised of lower-level officers sought lesser sentences than capital punishment following an execution since they had already "made their point," consistent with models of residual deterrence ${ }^{68}$ With the FGCM data, we can assess how malleable the sentence charged at court martial could be, since the chances of being convicted of desertion was almost $100 \%$, but the chances of being sentenced to death roughly 1 in 569

Appendix Table 13 finds that British (but not Irish) desertion cases received temporary amnesty, particularly after Irish executions. After a division executed an Irish, $14 \%$ of the next desertion trials resulted in a death sentence, whereas after a commutation, the figure was $22 \%$. However, death sentencing rates of Irish desertion trials were $20 \%$ regardless of the previous execution event. The pattern of temporary "amnesty"-lower rates of death-sentencing after a recent execution-emerges across different imputation assumptions for the commutation dates in Panels B and C. In this analysis, the numbers differ slightly across Panels for the execution rows because if the next event was a capital sentence, a "1" was coded. The capital sentence data is treated as data that should be a subset of the FGCM. However, temporary amnesty did not seem to exist for Irish desertion trials, whose death sentencing rates were roughly the same (around 20\%) regardless of the previous death sentence being executed or commuted. This is certainly observed in the 14-day imputation assumption of Panel A. In Panels B and C, the average death-sentencing subsequent Irish and British executions vs. average death-sentencing subsequent Irish and British commutations would also mute any temporary amnesty.

This provides quantitative evidence that the Irish may have been differentially mistreated in their exclusion from what appears to be temporary amnesty that other soldiers in desertion trials received. Using death sentences as a measure of absence would bias towards finding deterrence, since after an execution, the likelihood of the next desertion trial resulting in a death sentence was lower. This mechanical bias towards finding deterrence would be greatest for Irish executions.

It is important to emphasize that endogenous justice or temporary amnesty could not have been known to soldiers (and affect $C(p)$ in the opposite direction of what was intended). Informing the offender and

\footnotetext{
${ }^{68}$ Endogenous justice could only appear at sentencing. Not reporting absences was abetting desertion.

${ }^{69}$ Executions could also affect lawyers' behavior.
} 
no one else of the charge, finding, sentence, and confirmation was sufficient promulgation to satisfy the military laws. It was unlikely that the 130,936 FGCM convictions were circulated to the entire army (90 per day would likely reduce their impact). Public knowledge of lesser sentences for deserters would be inconsistent with repeated admonishments that "it should be remembered that on active service the usual penalty is death" for leaving post, cowardice, sleeping on post, etc. And neither soldiers at the time nor British military historians of WWI analyzing qualitative records knew about the low rate of death sentences for convicted deserters. If soldiers knew about temporary amnesty and acted on this knowledge, then this would bias towards finding a spurring effect among British soldiers; instead, I find a spurring effect among Irish. 
Appendix Table 1: Effects of Executions vs. Commutations on Elapsed Time Until Previous Absence Differing by whether Case was a Desertion Trial and whether Soldier was Irish

$\begin{array}{llllllll}(1) & (2) & (3) & (4) & (5) & (6) & (7) & (8)\end{array}$

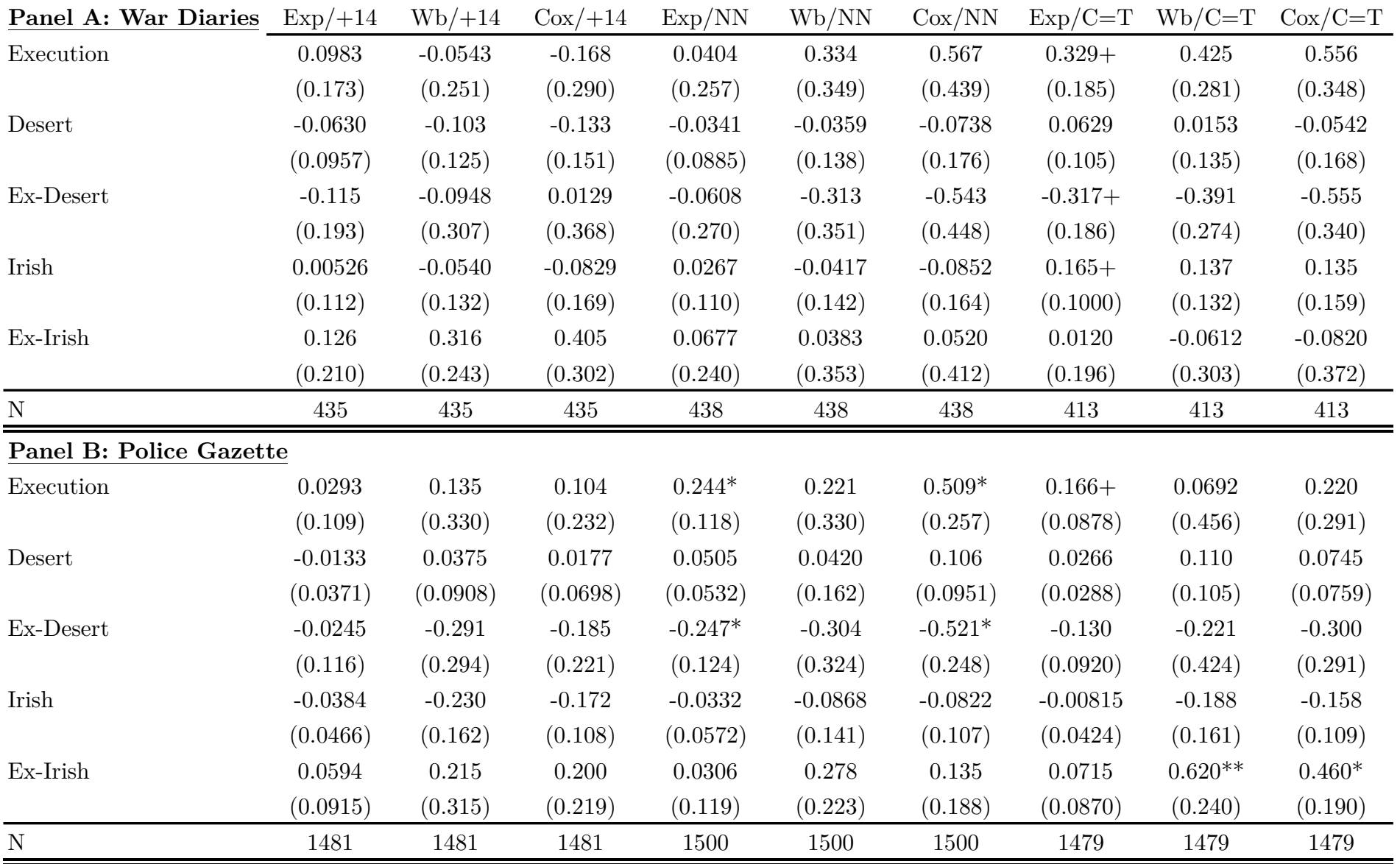

\begin{tabular}{|c|c|c|c|c|c|c|c|c|c|}
\hline \multicolumn{10}{|c|}{ Panel C: FGCM Trial Registries (Time Until Next Desertion Trial) } \\
\hline Execution & -0.177 & 0.0193 & -0.0555 & $0.335^{*}$ & 0.303 & $0.517^{*}$ & -0.133 & 0.118 & 0.00467 \\
\hline & $(0.262)$ & $(0.385)$ & $(0.351)$ & $(0.154)$ & $(0.331)$ & $(0.252)$ & $(0.242)$ & $(0.369)$ & $(0.349)$ \\
\hline & $(0.0934)$ & $(0.173)$ & $(0.101)$ & $(0.0677)$ & $(0.106)$ & $(0.0844)$ & $(0.0810)$ & $(0.175)$ & $(0.108)$ \\
\hline Ex-Desert & 0.174 & 0.110 & 0.137 & $-0.463^{* *}$ & -0.427 & $-0.580^{*}$ & 0.0957 & -0.0744 & 0.00106 \\
\hline & $(0.0910)$ & $(0.173)$ & $(0.121)$ & $(0.0811)$ & $(0.145)$ & $(0.123)$ & $(0.0907)$ & $(0.162)$ & $(0.125)$ \\
\hline \multirow[t]{2}{*}{ Ex-Irish } & -0.0397 & -0.125 & -0.119 & -0.00562 & 0.0560 & 0.0490 & 0.0572 & 0.0739 & 0.142 \\
\hline & $(0.208)$ & $(0.308)$ & $(0.250)$ & $(0.222)$ & $(0.314)$ & $(0.209)$ & $(0.241)$ & $(0.355)$ & $(0.284)$ \\
\hline $\mathrm{N}$ & 1648 & 1648 & 1648 & 1526 & 1526 & 1526 & 1642 & 1642 & 1642 \\
\hline
\end{tabular}

Notes: Outcome is elapsed time from death sentence resolution (execution or commutation) until previous absence at least 90 days before the death sentence. "Exp", "Wb" and "Cox" use the exponential, Weibull and Cox models respectively to parameterize the baseline hazard. In columns sub-titled " +14 ", the announcement of the commutation is assumed to occur 14 days after trial. In columns subtitled "NN" the nearest-neighbor method is used, which means the imputed announcement of the commutation is same as the most nearby execution announcement, while in columns labeled "C=T", the trial date is used as the announcement date of the execution and commutation. All specifications include division and year fixed-effects and $\Delta$ Log Casualties and $\Delta \log$ Casualties 30 Days Ago. War Diaries analysis restricts to July 1916-June 1917, which is the time window for the surviving data. Standard errors clustered at the division level in parentheses; $+\mathrm{p}<0.10,{ }^{*} \mathrm{p}<0.05, * * \mathrm{p}<0.01$ 
Appendix Table 2: Effects of Execution vs. Commutation on Elapsed Time Until Previous Absence, Full Sample, Weak SUTVA

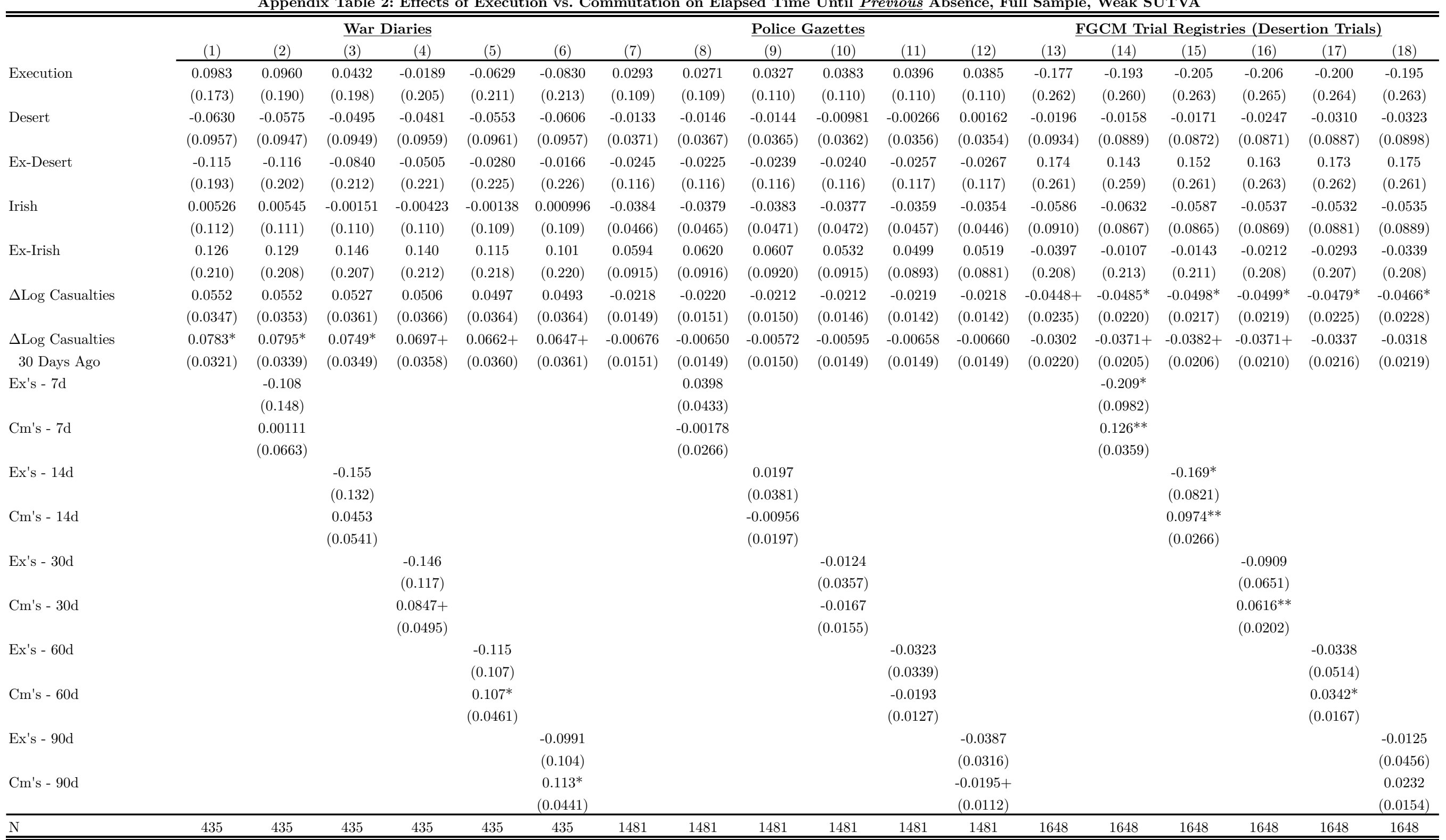

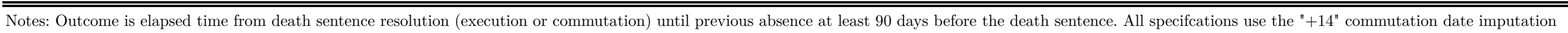

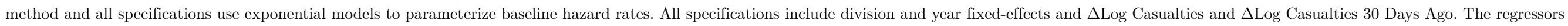

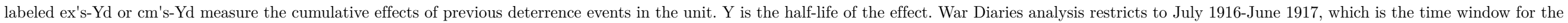
surviving data. Standard errors clustered at the division level in parentheses; $+\mathrm{p}<0.10,{ }^{*} \mathrm{p}<0.05,{ }^{* *} \mathrm{p}<0.01$ 

(1)
(2)
$(3)$
(4)
(5)
(6)
(7)
(8)
(9)

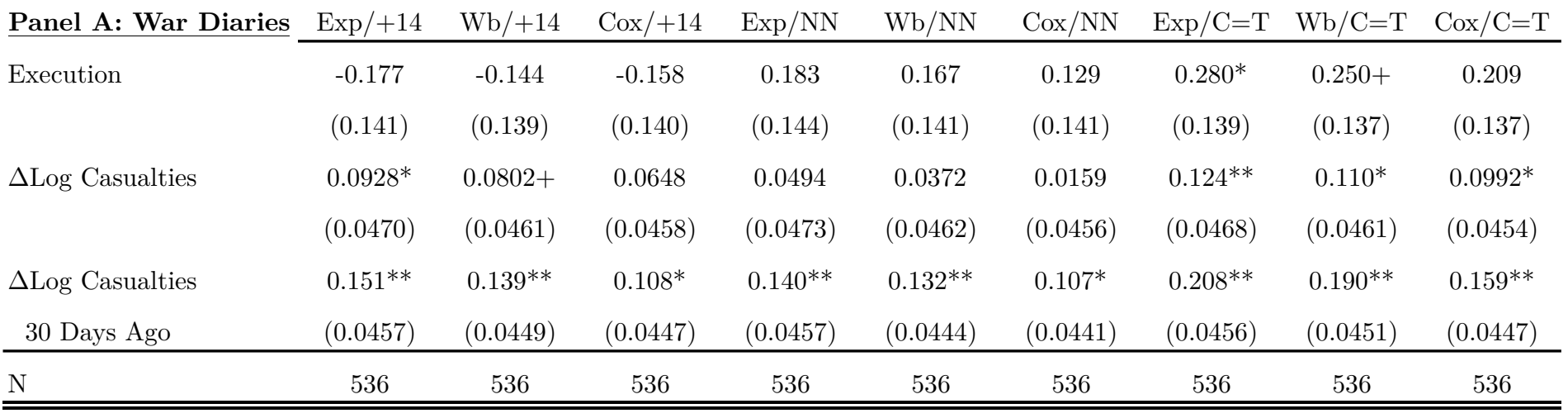

Panel B: Police Gazette

\begin{tabular}{|c|c|c|c|c|c|c|c|c|c|}
\hline Execution & -0.0770 & -0.0715 & -0.0662 & 0.0503 & 0.0535 & 0.0567 & -0.0179 & -0.0133 & -0.0114 \\
\hline \multirow[t]{2}{*}{$\Delta \log$ Casualties } & $0.0569^{*}$ & $0.0546^{*}$ & $0.0517^{*}$ & $0.0518^{*}$ & $0.0502^{*}$ & $0.0495^{*}$ & $0.0584^{*}$ & $0.0571^{*}$ & $0.0558^{*}$ \\
\hline & $(0.0228)$ & $(0.0227)$ & $(0.0226)$ & $(0.0226)$ & $(0.0225)$ & $(0.0225)$ & $(0.0229)$ & $(0.0228)$ & $(0.0228)$ \\
\hline$\Delta \log$ Casualties & $0.0620^{* *}$ & $0.0601^{* *}$ & $0.0584^{* *}$ & $0.0685^{* *}$ & $0.0664^{* *}$ & $0.0646^{* *}$ & $0.0719^{* *}$ & $0.0706^{* *}$ & $0.0695^{* *}$ \\
\hline $\mathrm{N}$ & 1640 & 1640 & 1640 & 1638 & 1638 & 1638 & 1640 & 1640 & 1640 \\
\hline \multicolumn{10}{|c|}{ Panel C: FGCM Trial Registries (Time Until Next Desertion Trial) } \\
\hline \multirow[t]{2}{*}{ Execution } & $-0.206+$ & $-0.198+$ & $-0.191+$ & 0.135 & 0.121 & 0.114 & 0.0282 & 0.0283 & 0.0235 \\
\hline & $(0.105)$ & $(0.104)$ & $(0.104)$ & $(0.0991)$ & $(0.0986)$ & $(0.0983)$ & $(0.107)$ & $(0.106)$ & $(0.106)$ \\
\hline$\Delta \log$ Casualties & $0.0796^{* *}$ & $0.0740^{* *}$ & $0.0684^{* *}$ & $0.0840^{* *}$ & $0.0796^{* *}$ & $0.0757^{* *}$ & 0.0272 & 0.0248 & 0.0227 \\
\hline 30 Days Ago & $(0.0261)$ & $(0.0260)$ & $(0.0259)$ & $(0.0259)$ & $(0.0258)$ & $(0.0258)$ & $(0.0278)$ & $(0.0277)$ & $(0.0277)$ \\
\hline $\mathrm{N}$ & 1654 & 1654 & 1654 & 1654 & 1654 & 1654 & 1654 & 1654 & 1654 \\
\hline
\end{tabular}

Notes: Outcome is elapsed time from death sentence resolution (execution or commutation) until next absence. "Exp", "Wb" and "Cox" use the exponential, Weibull and Cox models respectively to parameterize the baseline hazard. In columns sub-titled " +14 ", the announcement of the commutation is assumed to occur 14 days after trial. In columns subtitled "NN" the nearest-neighbor method is used, which means the imputed announcement of the commutation is same as the most nearby execution announcement, while in columns labeled " $\mathrm{C}=\mathrm{T}$ ", the trial date is used as the announcement date of the execution and commutation. Log Casualties is calculated as $\log (1+$ Casualties $) . \Delta \log$ Casualties is defined as the difference in Log Casualties 1 to 29 Days Ago vs. 30 to 59 Days Ago. $\Delta$ Log Casualties 30 Days Ago is defined as the difference in Log Casualties 30 to 59 Days Ago vs. 60 to 89 Days Ago. All specifications include division and year fixed-effects. War Diaries analysis restricts to July 1916-June 1917, which is the time window for the surviving data. Standard errors in parentheses; $+\mathrm{p}<0.10,{ }^{*} \mathrm{p}<0.05,{ }^{* *} \mathrm{p}<0.01$ 
Appendix Table 4: Effects of Executions vs. Commutations on Elapsed Time Until Next Absence Differing by whether Case was a Desertion Trial and whether Soldier was Irish

$\begin{array}{llllll}(1) & (2) & (3) & (4) & (5) & (6)\end{array}$

7) (8)

(9)

Panel A: War Diaries $\quad$ Exp/+14 $\quad \mathrm{Wb} /+14 \quad \mathrm{Cox} /+14 \quad \operatorname{Exp} / \mathrm{NN} \quad \mathrm{Wb} / \mathrm{NN} \quad \mathrm{Cox} / \mathrm{NN} \quad \operatorname{Exp} / \mathrm{C}=\mathrm{T} \quad \mathrm{Wb} / \mathrm{C}=\mathrm{T} \quad \mathrm{Cox} / \mathrm{C}=\mathrm{T}$

Execution

$-0.417-0.394$

0.219

0.182

0.239

$0.723+$

0.627
$0.689+$

(0.446)

(0.441)

(0.439)

(0.418)

(0.414)

(0.411)

(0.397)

(0.396)

(0.393)

Desert

$-0.0429$

(0.174)

(0.172)

(0.172)

0.0531

0.0511

0.138

0.146

0.133

Ex-Desert

$-0.00330$

0.0467

$-0.0154$

$-0.241$

(0.167)

(0.178)

(0.175)

(0.172)

(0.468)

(0.464)

(0.461)

(0.439)

$-0.161$

$-0.218$

$-0.650$

$-0.555$

$-0.627$

Irish

$-0.727^{* *}$

$-0.629 * *$

$-0.464^{* *}$

$-0.646^{* *}$

$(0.435)$

(0.431)

(0.417)

(0.415)

(0.412)

(0.181)

(0.182)

(0.180)

(0.178)

$0.541^{* *}$

$-0.391 *$

$-0.475^{*}$

$-0.407^{*}$

$-0.263$

Ex-Irish

$1.179 * * \quad 1.003^{* *}$

$0.805^{*}$

0.768 *

(0.178)

(0.177)

(0.186)

(0.185)

(0.182)

$(0.356) \quad(0.357)$ (0.355)

(0.359)

$(0.358)$

$(0.355)$

$0.619+$

0.537

0.355

\begin{tabular}{l}
$\mathrm{N}$ \\
\hline \hline Panel B: Police Gazette
\end{tabular}

Execution

536

536

536

536

536

(0.340)

$(0.340)$

(0.341)

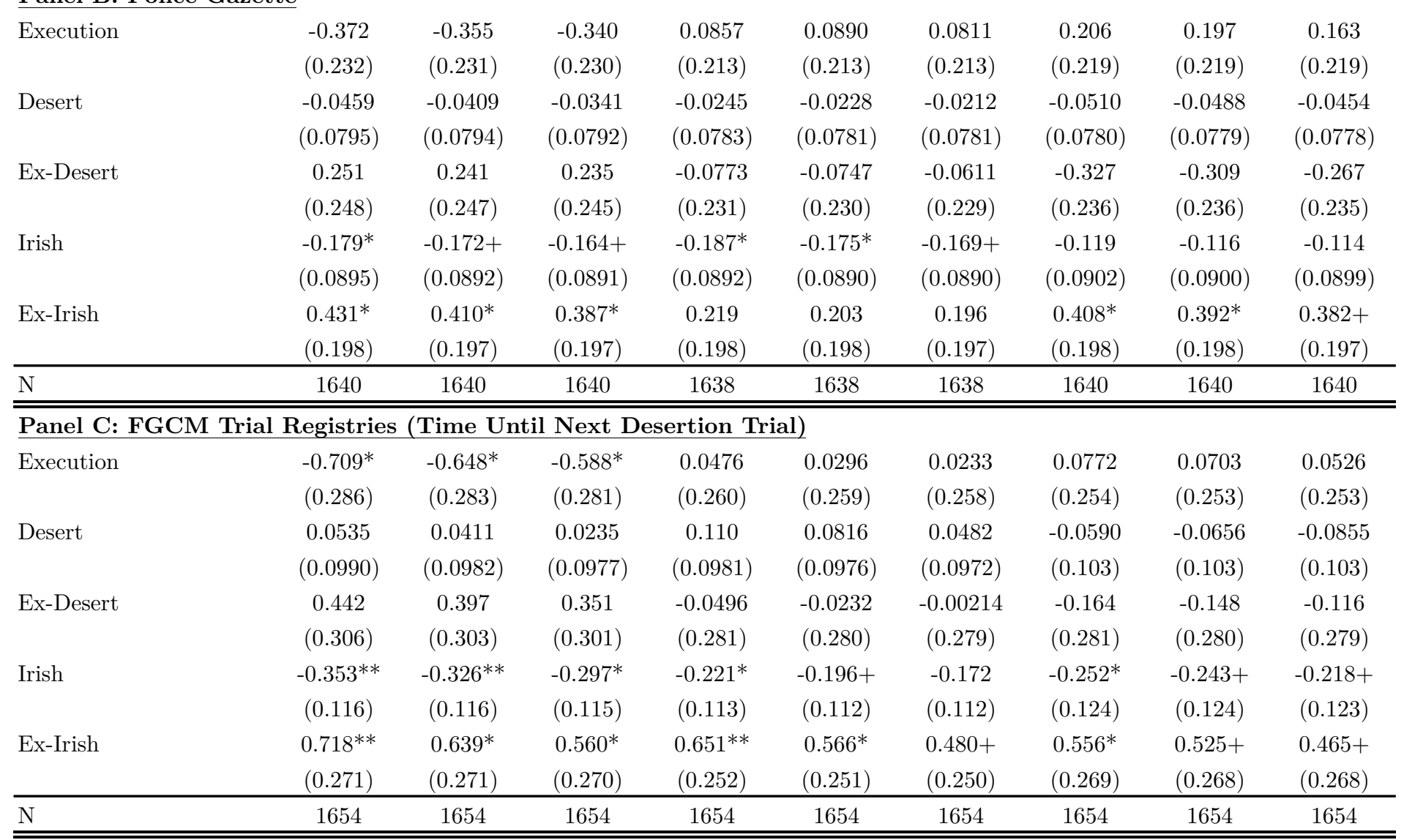

Notes: Outcome is elapsed time from death sentence resolution (execution or commutation) until next absence. "Exp", "Wb" and "Cox" use the exponential, Weibull and Cox models respectively to parameterize the baseline hazard. In columns sub-titled " +14 ", the announcement of the commutation is assumed to occur 14 days after trial. In columns subtitled "NN" the nearest-neighbor method is used, which means the imputed announcement of the commutation is same as the most nearby execution announcement, while in columns labeled " $\mathrm{C}=\mathrm{T}$ ", the trial date is used as the announcement date of the execution and commutation. All specifications include division and year fixed-effects and $\Delta$ Log Casualties and $\Delta$ Log Casualties 30 Days Ago. War Diaries analysis restricts to July 1916-June 1917, which is the time window for the surviving data. Standard errors in parentheses; $+\mathrm{p}<0.10, * \mathrm{p}<0.05, * * \mathrm{p}<0.01$ 
Appendix Table 5: Effects of Execution vs. Commutation on Elapsed Time Until Next Absence, Full Sample, Weak SUTVA

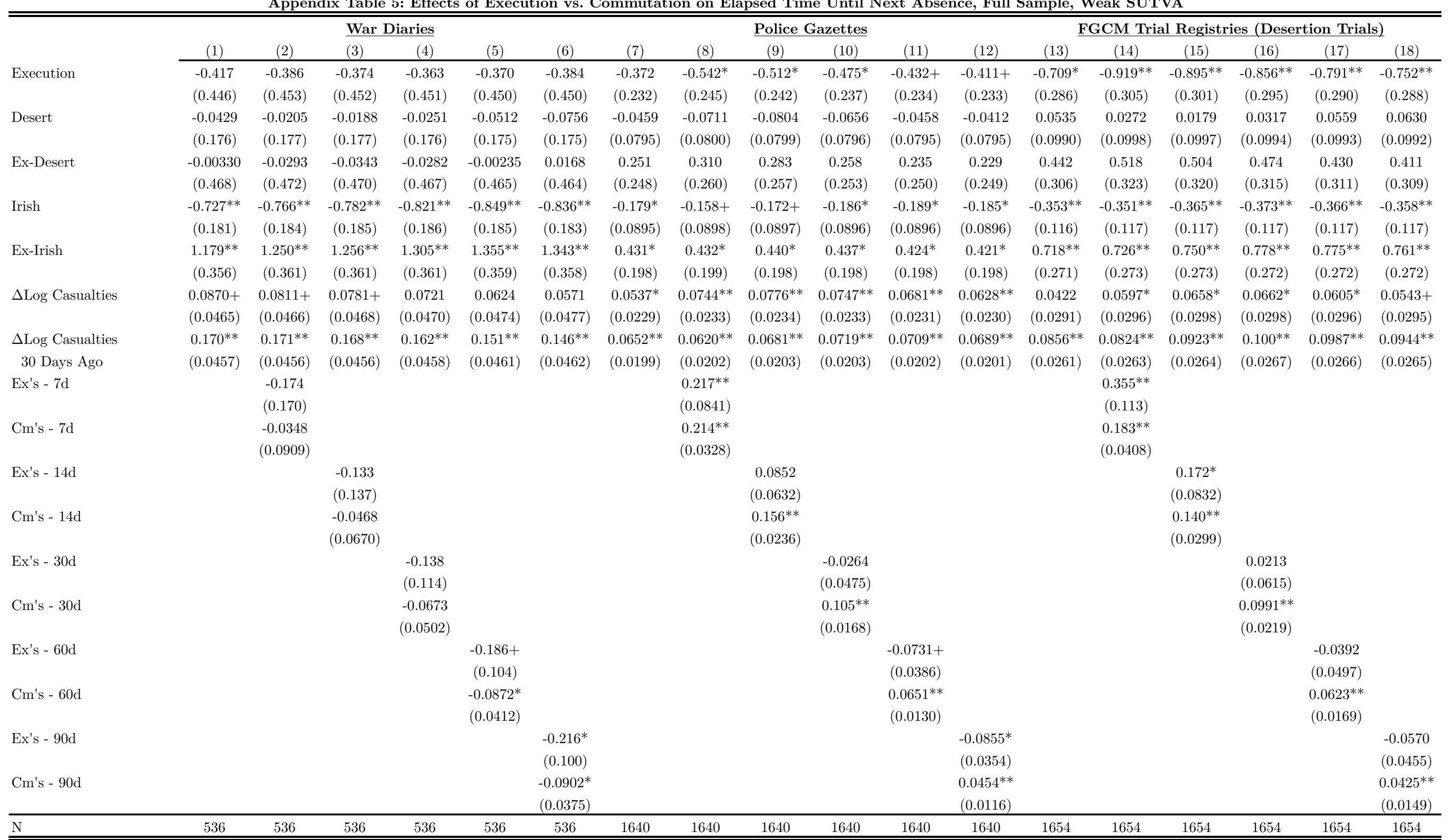

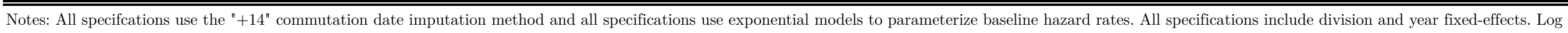

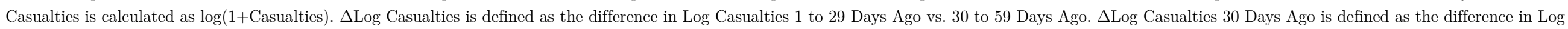

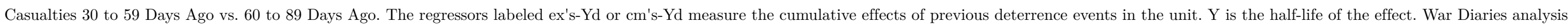
restricts to July 1916-June 1917, which is the time window for the surviving data. Standard errors in parentheses; $+\mathrm{p}<0.10,{ }^{*} \mathrm{p}<0.05,{ }^{* *} \mathrm{p}<0.01$ 
Appendix Table 6: Effects of Executions vs. Commutations on Elapsed Time Until Previous Absence Differing by whether Case was a Desertion Trial and whether Soldier was Irish

$\begin{array}{llllllll}(1) & (2) & (3) & (4) & (5) & (6) & (7) & (8)\end{array}$

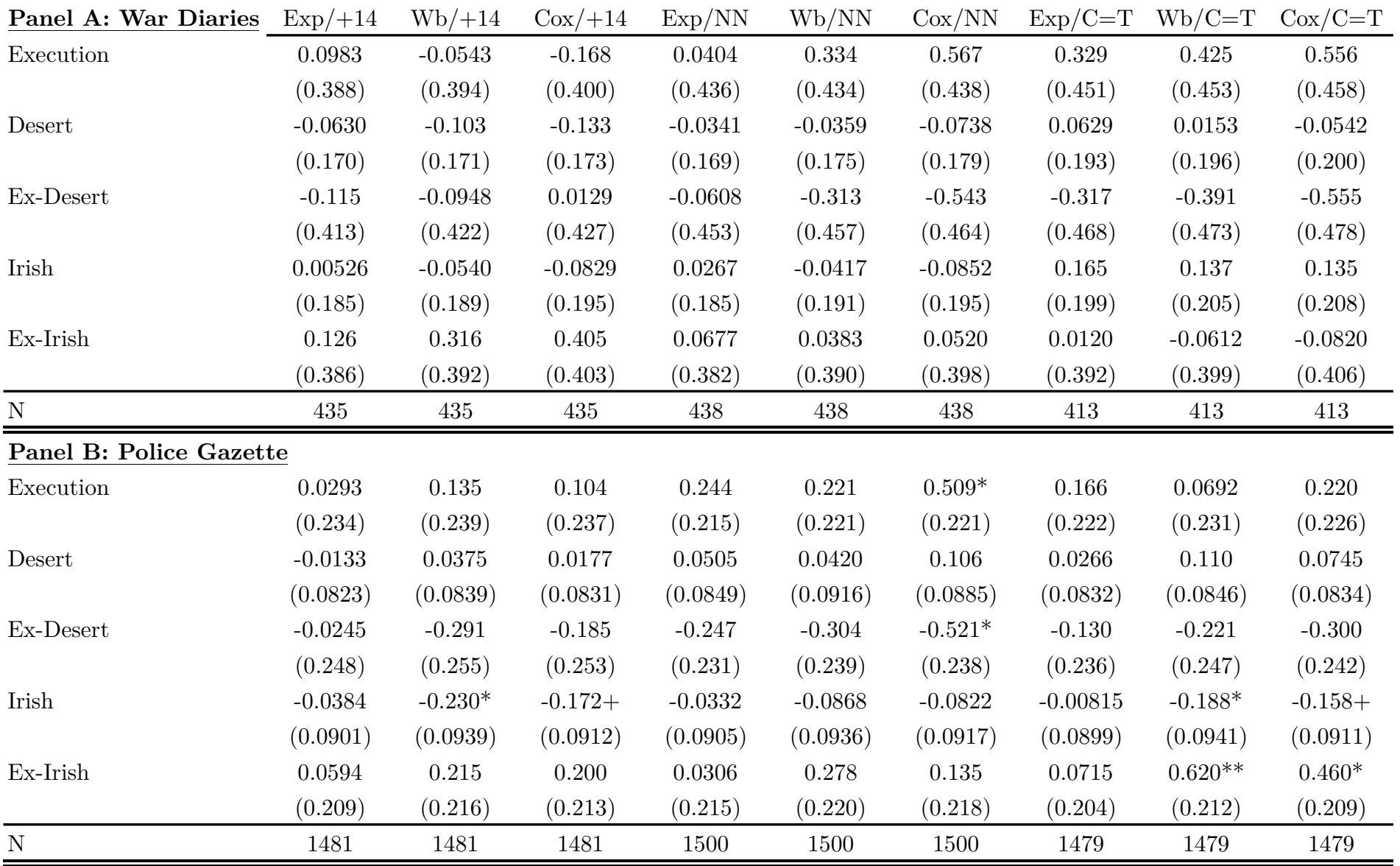

\begin{tabular}{|c|c|c|c|c|c|c|c|c|c|}
\hline \multicolumn{10}{|c|}{ Panel C: FGCM Trial Registries (Time Until Next Desertion Trial) } \\
\hline Execution & -0.177 & 0.0193 & -0.0555 & 0.335 & 0.303 & $0.517^{*}$ & -0.133 & 0.118 & 0.00467 \\
\hline & $(0.285)$ & $(0.293)$ & $(0.290)$ & $(0.235)$ & $(0.242)$ & $(0.240)$ & $(0.307)$ & $(0.316)$ & $(0.313)$ \\
\hline & $(0.0930)$ & $(0.0997)$ & $(0.0945)$ & $(0.0980)$ & $(0.100)$ & $(0.0986)$ & $(0.0989)$ & $(0.108)$ & $(0.102)$ \\
\hline Ex-Desert & 0.174 & 0.110 & 0.137 & $-0.463+$ & -0.427 & $-0.580^{*}$ & 0.0957 & -0.0744 & 0.00106 \\
\hline & $(0.108)$ & $(0.113)$ & $(0.110)$ & $(0.107)$ & $(0.112)$ & $(0.110)$ & $(0.112)$ & $(0.117)$ & $(0.114)$ \\
\hline \multirow[t]{2}{*}{ Ex-Irish } & -0.0397 & -0.125 & -0.119 & -0.00562 & 0.0560 & 0.0490 & 0.0572 & 0.0739 & 0.142 \\
\hline & $(0.260)$ & $(0.266)$ & $(0.263)$ & $(0.261)$ & $(0.271)$ & $(0.267)$ & $(0.266)$ & $(0.274)$ & $(0.270)$ \\
\hline $\mathrm{N}$ & 1648 & 1648 & 1648 & 1526 & 1526 & 1526 & 1642 & 1642 & 1642 \\
\hline
\end{tabular}

Notes: Outcome is elapsed time from death sentence resolution (execution or commutation) until previous absence at least 90 days before the death sentence. "Exp", "Wb" and "Cox" use the exponential, Weibull and Cox models respectively to parameterize the baseline hazard. In columns sub-titled " +14 ", the announcement of the commutation is assumed to occur 14 days after trial. In columns subtitled "NN" the nearest-neighbor method is used, which means the imputed announcement of the commutation is same as the most nearby execution announcement, while in columns labeled "C=T", the trial date is used as the announcement date of the execution and commutation. All specifications include division and year fixed-effects and $\Delta$ Log Casualties and $\Delta \log$ Casualties 30 Days Ago. War Diaries analysis restricts to July 1916-June 1917, which is the time window for the surviving data. Standard errors in parentheses; $+\mathrm{p}<0.10,{ }^{*} \mathrm{p}<0.05,{ }^{* *} \mathrm{p}<0.01$ 
Appendix Table 7: Effects of Execution vs. Commutation on Elapsed Time Until Previous Absence, Full Sample, Weak SUTVA

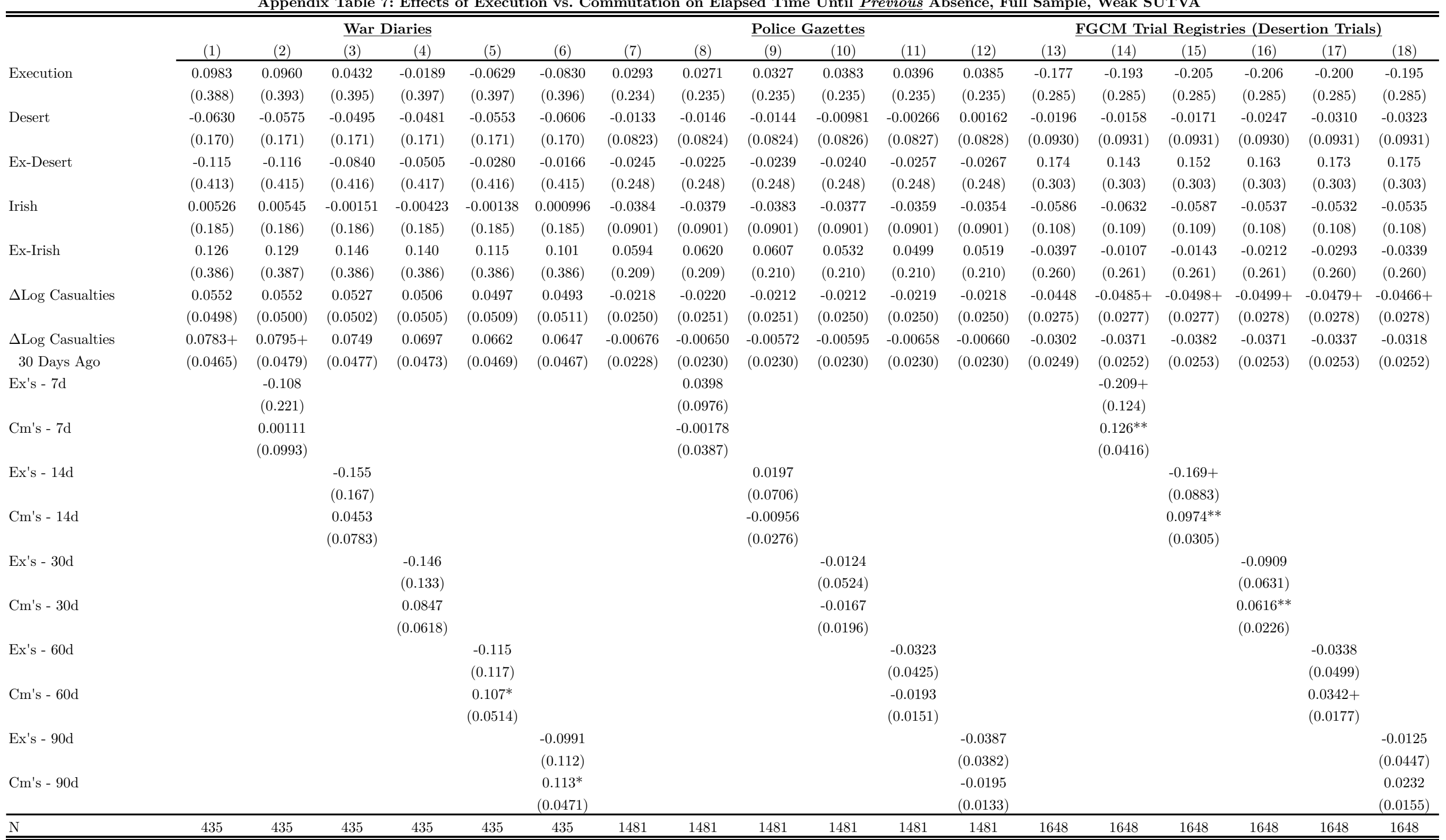

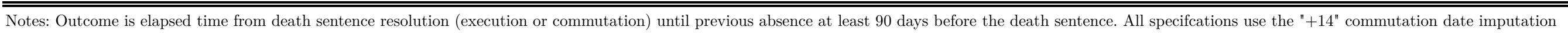

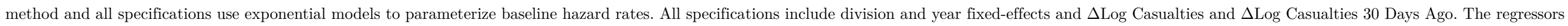

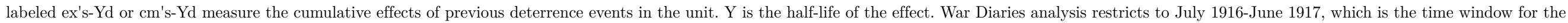
surviving data. Standard errors in parentheses; $+\mathrm{p}<0.10,{ }^{*} \mathrm{p}<0.05,{ }^{* *} \mathrm{p}<0.01$ 
Appendix Table 8: Day-by-Day Framework, Future Events and Previous Absences

\begin{tabular}{|c|c|c|c|c|c|}
\hline Panel A: War Diaries & $(1)$ & $(2)$ & $(3)$ & $(4)$ & $(5)$ \\
\hline Half-life & 1 week & $\underline{2 \text { weeks }}$ & 1 month & $\underline{2 \text { months }}$ & $\underline{3 \text { months }}$ \\
\hline \multirow[t]{2}{*}{ Execution } & 0.0171 & 0.0127 & 0.00897 & 0.00550 & 0.00318 \\
\hline & $(0.0218)$ & $(0.0156)$ & $(0.0118)$ & $(0.0102)$ & $(0.00921)$ \\
\hline \multirow[t]{2}{*}{ Death Sentence } & -0.0000876 & -0.000565 & -0.000739 & -0.000570 & -0.000497 \\
\hline & $(0.00143)$ & $(0.00127)$ & $(0.00111)$ & $(0.000977)$ & $(0.000942)$ \\
\hline \multirow[t]{2}{*}{ Ex-Irish } & 0.0127 & 0.0121 & 0.0124 & 0.0144 & 0.0158 \\
\hline & $(0.0137)$ & $(0.0102)$ & $(0.00928)$ & $(0.00953)$ & $(0.00958)$ \\
\hline \multirow[t]{2}{*}{ Irish } & $-0.0137^{*}$ & $-0.0123^{*}$ & $-0.00919+$ & -0.00765 & -0.00724 \\
\hline & $(0.00511)$ & -0.0049 & $(0.00465)$ & $(0.00457)$ & $(0.00440)$ \\
\hline \multirow[t]{2}{*}{ Ex-Desert } & -0.0190 & -0.0147 & -0.0122 & -0.0101 & -0.00839 \\
\hline & $(0.0197)$ & $(0.0147)$ & $(0.0117)$ & $(0.0101)$ & $(0.00893)$ \\
\hline \multirow[t]{2}{*}{ Desert } & 0.00204 & 0.00298 & 0.00279 & $0.00250+$ & $0.00239+$ \\
\hline & $(0.00196)$ & $(0.00196)$ & $(0.00181)$ & $(0.00144)$ & $(0.00130)$ \\
\hline $\mathrm{N}$ & 20750 & 20750 & 20750 & 20750 & 20750 \\
\hline \multicolumn{6}{|c|}{ Panel B: Police Gazettes } \\
\hline \multirow[t]{2}{*}{ Execution } & 0.00273 & -0.00634 & -0.00989 & -0.00994 & -0.00857 \\
\hline & $(0.0214)$ & $(0.0182)$ & $(0.0139)$ & $(0.0106)$ & $(0.00915)$ \\
\hline \multirow[t]{2}{*}{ Death Sentence } & 0.00741 & 0.00596 & 0.00414 & 0.00250 & 0.00167 \\
\hline & $(0.00452)$ & $(0.00414)$ & $(0.00312)$ & $(0.00207)$ & $(0.00160)$ \\
\hline \multirow[t]{2}{*}{ Ex-Irish } & 0.0124 & 0.00621 & -0.000201 & -0.00325 & -0.00353 \\
\hline & $(0.0161)$ & $(0.0125)$ & $(0.00906)$ & $(0.00699)$ & $(0.00599)$ \\
\hline \multirow[t]{2}{*}{ Irish } & -0.00154 & 0.00198 & 0.00371 & 0.00390 & 0.00352 \\
\hline & $(0.00586)$ & $(0.00506)$ & $(0.00443)$ & $(0.00382)$ & $(0.00333)$ \\
\hline \multirow[t]{2}{*}{ Ex-Desert } & -0.00454 & 0.00626 & 0.00954 & 0.00830 & 0.00629 \\
\hline & $(0.0206)$ & $(0.0169)$ & $(0.0128)$ & $(0.00949)$ & $(0.00818)$ \\
\hline \multirow[t]{2}{*}{ Desert } & -0.00729 & -0.00703 & -0.00569 & -0.00364 & -0.00237 \\
\hline & $(0.00454)$ & $(0.00419)$ & $(0.00341)$ & $(0.00256)$ & $(0.00215)$ \\
\hline $\mathrm{N}$ & 50465 & 50465 & 50465 & 50465 & 50465 \\
\hline \multicolumn{6}{|c|}{ Panel C: FGCM Desertion Trial Registries } \\
\hline \multirow[t]{2}{*}{ Execution } & $-0.0308^{*}$ & $-0.0245+$ & -0.0133 & -0.00607 & -0.00400 \\
\hline & $(0.0141)$ & $(0.0122)$ & $(0.0110)$ & $(0.00890)$ & $(0.00705)$ \\
\hline \multirow[t]{2}{*}{ Death Sentence } & 0.00367 & 0.00350 & $0.00288+$ & $0.00196+$ & $0.00144+$ \\
\hline & $(0.00313)$ & $(0.00233)$ & $(0.00167)$ & $(0.00111)$ & $(0.000793)$ \\
\hline \multirow[t]{2}{*}{ Ex-Irish } & -0.00701 & -0.00497 & -0.00283 & -0.000694 & 0.000834 \\
\hline & $(0.0167)$ & $(0.0134)$ & (0.00998) & $(0.00725)$ & $(0.00612)$ \\
\hline \multirow[t]{2}{*}{ Irish } & $0.0152^{*}$ & $0.0122^{* *}$ & $0.00857^{*}$ & $0.00532^{*}$ & $0.00366+$ \\
\hline & $(0.00611)$ & $(0.00456)$ & $(0.00345)$ & $(0.00249)$ & $(0.00199)$ \\
\hline \multirow[t]{2}{*}{ Ex-Desert } & 0.0231 & 0.0178 & 0.00644 & 0.000998 & 0.000752 \\
\hline & $(0.0143)$ & $(0.0124)$ & $(0.0118)$ & $(0.00979)$ & $(0.00785)$ \\
\hline \multirow[t]{2}{*}{ Desert } & 0.00102 & 0.000660 & 0.00261 & $0.00364^{*}$ & $0.00345^{*}$ \\
\hline & $(0.00468)$ & $(0.00322)$ & $(0.00227)$ & $(0.00168)$ & $(0.00136)$ \\
\hline $\mathrm{N}$ & 54855 & 54855 & 54855 & 54855 & 54855 \\
\hline
\end{tabular}

Notes: Outcome is whether there was any absence on that day and division. All specifcations use the "+14" commutation date imputation method and include division and year fixed-effects, $\Delta \log$ Casualties, and $\Delta \log$ Casualties 30 Days Ago. The half-life row indicates the assumed exponential half-life of the effect of future events beginning 90 days in the future. War Diaries analysis restricts to July 1916-June 1917, which is the time window for the surviving data. War Diaries analysis restricts to July 1916-June 1917, which is the time window for the surviving data. Standard errors clustered at the division level in parentheses; $+\mathrm{p}<0.10,{ }^{*} \mathrm{p}<0.05,{ }^{* *} \mathrm{p}<0.01$ 
Appendix Table 9: Day-by-Day Framework, Future Events and Previous Irish - non-Irish Absence

\begin{tabular}{|c|c|c|c|c|c|}
\hline Panel A: War Diaries & $(1)$ & $(2)$ & $(3)$ & $(4)$ & $(5)$ \\
\hline Half-life & 1 week & 2 weeks & 1 month & $\underline{2 \text { months }}$ & 3 months \\
\hline \multirow[t]{2}{*}{ Execution } & -0.00885 & -0.00633 & -0.00499 & -0.00447 & -0.00374 \\
\hline & $(0.0110)$ & $(0.00899)$ & $(0.00544)$ & $(0.00531)$ & $(0.00562)$ \\
\hline \multirow[t]{2}{*}{ Death Sentence } & 0.000503 & 0.000822 & 0.000949 & 0.000954 & 0.000943 \\
\hline & $(0.00153)$ & $(0.00119)$ & $(0.000903)$ & $(0.000834)$ & $(0.000819)$ \\
\hline \multirow[t]{2}{*}{ Ex-Irish } & 0.00699 & 0.00319 & 0.00103 & -0.00117 & -0.00298 \\
\hline & $(0.0145)$ & $(0.00875)$ & $(0.00680)$ & $(0.00696)$ & $(0.00706)$ \\
\hline \multirow[t]{2}{*}{ Irish } & 0.00239 & 0.00102 & -0.000630 & -0.000713 & -0.000241 \\
\hline & $(0.00447)$ & $(0.00279)$ & $(0.00254)$ & $(0.00278)$ & $(0.00273)$ \\
\hline \multirow[t]{2}{*}{ Ex-Desert } & 0.00150 & 0.00128 & 0.00256 & 0.00430 & 0.00474 \\
\hline & $(0.0130)$ & $(0.0105)$ & $(0.00544)$ & $(0.00435)$ & $(0.00468)$ \\
\hline \multirow[t]{2}{*}{ Desert } & 0.00167 & 0.000528 & -0.000378 & -0.00109 & -0.00135 \\
\hline & $(0.00281)$ & $(0.00218)$ & $(0.00151)$ & $(0.00116)$ & $(0.00106)$ \\
\hline $\mathrm{N}$ & 20750 & 20750 & 20750 & 20750 & 20750 \\
\hline \multicolumn{6}{|l|}{ Panel B: Police Gazettes } \\
\hline \multirow[t]{2}{*}{ Execution } & -0.0282 & -0.0199 & -0.0114 & -0.00543 & -0.00315 \\
\hline & $(0.0178)$ & $(0.0129)$ & $(0.00849)$ & $(0.00568)$ & $(0.00453)$ \\
\hline \multirow[t]{2}{*}{ Death Sentence } & 0.000329 & 0.000108 & -0.000266 & -0.000187 & -0.00000606 \\
\hline & $(0.00221)$ & $(0.00164)$ & $(0.00122)$ & $(0.000866)$ & $(0.000701)$ \\
\hline \multirow[t]{2}{*}{ Ex-Irish } & 0.00120 & 0.00495 & $0.00567+$ & $0.00449+$ & 0.00339 \\
\hline & $(0.0103)$ & $(0.00605)$ & $(0.00330)$ & $(0.00249)$ & $(0.00232)$ \\
\hline \multirow[t]{2}{*}{ Irish } & -0.000198 & -0.00167 & -0.00158 & -0.00139 & -0.00133 \\
\hline & $(0.00532)$ & $(0.00397)$ & $(0.00297)$ & $(0.00214)$ & $(0.00172)$ \\
\hline \multirow[t]{2}{*}{ Ex-Desert } & 0.0269 & 0.0187 & 0.0113 & 0.00639 & 0.00450 \\
\hline & $(0.0179)$ & $(0.0130)$ & $(0.00874)$ & $(0.00599)$ & $(0.00487)$ \\
\hline \multirow[t]{2}{*}{ Desert } & -0.00338 & -0.00169 & -0.000409 & -0.000265 & -0.000454 \\
\hline & $(0.00262)$ & $(0.00175)$ & $(0.00133)$ & $(0.00103)$ & $(0.000886)$ \\
\hline $\mathrm{N}$ & 50465 & 50465 & 50465 & 50465 & 50465 \\
\hline \multicolumn{6}{|c|}{ Panel C: FGCM Desertion Trial Registries } \\
\hline \multirow[t]{2}{*}{ Execution } & $0.0332^{* *}$ & $0.0259^{*}$ & 0.0148 & 0.00739 & 0.00475 \\
\hline & $(0.0121)$ & $(0.0109)$ & $(0.00949)$ & $(0.00725)$ & $(0.00563)$ \\
\hline \multirow[t]{2}{*}{ Death Sentence } & -0.00265 & -0.00240 & -0.00207 & -0.00157 & -0.00121 \\
\hline & $(0.00266)$ & $(0.00191)$ & $(0.00133)$ & $(0.000948)$ & $(0.000748)$ \\
\hline \multirow[t]{2}{*}{ Ex-Irish } & -0.00942 & -0.00784 & -0.00677 & -0.00461 & -0.00361 \\
\hline & $(0.0122)$ & $(0.00976)$ & $(0.00774)$ & $(0.00620)$ & $(0.00553)$ \\
\hline \multirow[t]{2}{*}{ Irish } & $-0.00851+$ & $-0.00807^{*}$ & -0.00398 & -0.000594 & 0.000457 \\
\hline & $(0.00441)$ & $(0.00338)$ & $(0.00263)$ & $(0.00218)$ & $(0.00192)$ \\
\hline \multirow[t]{2}{*}{ Ex-Desert } & $-0.0248^{*}$ & -0.0174 & -0.00559 & -0.000398 & 0.0000879 \\
\hline & $(0.0123)$ & $(0.0108)$ & $(0.00925)$ & $(0.00727)$ & $(0.00597)$ \\
\hline \multirow[t]{2}{*}{ Desert } & -0.00206 & -0.000792 & -0.00226 & $-0.00319^{*}$ & $-0.00308^{* *}$ \\
\hline & $(0.00333)$ & $(0.00218)$ & $(0.00155)$ & $(0.00122)$ & $(0.00104)$ \\
\hline $\mathrm{N}$ & 54855 & 54855 & 54855 & 54855 & 54855 \\
\hline
\end{tabular}

Notes: Outcome is whether there was any Irish absence on that day and division minus whether there was any non-Irish absence on that day and division. All specifcations use the " +14 " commutation date imputation method and include division and year fixed-effects, $\Delta$ Log Casualties, and $\Delta$ Log Casualties 30 Days Ago. The half-life row indicates the assumed exponential half-life of the effect of past events. War Diaries analysis restricts to July 1916-June 1917, which is the time window for the surviving data. War Diaries analysis restricts to July 1916-June 1917, which is the time window for the surviving data. Standard errors clustered at the division level in parentheses; $+\mathrm{p}<0.10,{ }^{*} \mathrm{p}<0.05,{ }^{* *} \mathrm{p}<0.01$ 
Appendix Table 10: Effects of Execution vs. Commutation on Elapsed Time Until Next Absence, Full Sample, Weak SUTVA

\begin{tabular}{|c|c|c|c|c|c|c|c|c|c|c|c|c|c|c|c|c|c|c|}
\hline & \multicolumn{6}{|c|}{ War Diaries } & \multicolumn{6}{|c|}{ Police Gazettes } & \multicolumn{6}{|c|}{ FGCM Trial Registries (Desertion Trials) } \\
\hline & \multicolumn{2}{|c|}{ Exp } & \multicolumn{2}{|c|}{ Weibull } & \multicolumn{2}{|c|}{ Cox } & \multicolumn{2}{|c|}{ Exp } & \multicolumn{2}{|c|}{ Weibull } & \multicolumn{2}{|c|}{ Cox } & \multicolumn{2}{|c|}{ Exp } & \multicolumn{2}{|c|}{ Weibull } & \multicolumn{2}{|c|}{ Cox } \\
\hline & $(1)$ & $(2)$ & (3) & (4) & $(5)$ & $(6)$ & $(7)$ & (8) & (9) & $(10)$ & $(11)$ & $(12)$ & $(13)$ & $(14)$ & $(15)$ & $(16)$ & $(17)$ & $(18)$ \\
\hline Execution & $\begin{array}{l}-0.368 \\
(0.742)\end{array}$ & $\begin{array}{l}-0.394 \\
(0.625)\end{array}$ & $\begin{array}{l}-0.359 \\
(0.694)\end{array}$ & $\begin{array}{l}-0.213 \\
(0.619)\end{array}$ & $\begin{array}{l}-0.278 \\
(0.682)\end{array}$ & $\begin{array}{l}-0.118 \\
(0.618)\end{array}$ & $\begin{array}{l}-0.475 \\
(0.447)\end{array}$ & $\begin{array}{l}-0.432 \\
(0.394)\end{array}$ & $\begin{array}{l}-0.457 \\
(0.427)\end{array}$ & & $\begin{array}{l}-0.434 \\
(0.387)\end{array}$ & $\begin{array}{l}-0.421 \\
(0.451)\end{array}$ & $\begin{array}{l}-0.855 \\
(0.622)\end{array}$ & $\begin{array}{l}-0.498 \\
(0.500)\end{array}$ & $\begin{array}{l}-0.779 \\
(0.559)\end{array}$ & $\begin{array}{l}-0.577 \\
(0.572)\end{array}$ & $\begin{array}{l}-0.688 \\
(0.483)\end{array}$ & $\begin{array}{l}-0.539 \\
(0.507)\end{array}$ \\
\hline Desert & $\begin{array}{l}-0.0253 \\
(0.300)\end{array}$ & $\begin{array}{l}-0.0511 \\
(0.308)\end{array}$ & $\begin{array}{l}-0.0103 \\
(0.269)\end{array}$ & $\begin{array}{l}-0.283 \\
(0.243)\end{array}$ & $\begin{array}{c}-0.00336 \\
(0.235)\end{array}$ & $\begin{array}{l}-0.245 \\
(0.231)\end{array}$ & $\begin{array}{l}-0.0656 \\
(0.0851)\end{array}$ & $\begin{array}{l}-0.0815 \\
(0.0855)\end{array}$ & $\begin{array}{l}-0.0608 \\
(0.0823)\end{array}$ & $\begin{array}{l}-0.0788 \\
(0.0998)\end{array}$ & $\begin{array}{l}-0.0514 \\
(0.0767)\end{array}$ & $\begin{array}{l}-0.0700 \\
(0.0925)\end{array}$ & $\begin{array}{l}0.0317 \\
(0.122)\end{array}$ & $\begin{array}{l}0.0299 \\
(0.126)\end{array}$ & $\begin{array}{l}0.0246 \\
(0.113)\end{array}$ & $\begin{array}{l}-0.0607 \\
(0.132)\end{array}$ & $\begin{array}{l}0.0118 \\
(0.103)\end{array}$ & $\begin{array}{l}-0.0489 \\
(0.123)\end{array}$ \\
\hline Ex-Desert & $\begin{array}{l}-0.0250 \\
(0.728)\end{array}$ & $\begin{array}{l}0.0408 \\
(0.619)\end{array}$ & $\begin{array}{l}0.0317 \\
(0.688)\end{array}$ & $\begin{array}{l}-0.0144 \\
(0.534)\end{array}$ & $\begin{array}{c}-0.0314 \\
(0.663)\end{array}$ & $\begin{array}{l}-0.0884 \\
(0.540)\end{array}$ & $\begin{array}{l}0.258 \\
(0.480)\end{array}$ & $\begin{array}{c}0.191 \\
(0.415)\end{array}$ & $\begin{array}{c}0.249 \\
(0.459)\end{array}$ & $\begin{array}{c}0.117 \\
(0.471)\end{array}$ & $\begin{array}{l}0.241 \\
(0.417)\end{array}$ & $\begin{array}{c}0.134 \\
(0.440)\end{array}$ & $\begin{array}{c}0.474 \\
(0.663)\end{array}$ & $\begin{array}{c}0.299 \\
(0.539)\end{array}$ & $\begin{array}{c}0.425 \\
(0.600)\end{array}$ & $\begin{array}{c}0.414 \\
(0.570)\end{array}$ & $\begin{array}{c}0.366 \\
(0.520)\end{array}$ & $\begin{array}{c}0.374 \\
(0.499)\end{array}$ \\
\hline Irish & $\begin{array}{c}-0.822^{* *} \\
(0.212)\end{array}$ & $\begin{array}{c}-0.702^{* *} \\
(0.219)\end{array}$ & $\begin{array}{c}-0.717^{* *} \\
(0.204)\end{array}$ & $\begin{array}{c}-0.755^{* *} \\
(0.229)\end{array}$ & $\begin{array}{c}-0.549^{* *} \\
(0.173)\end{array}$ & $\begin{array}{c}-0.573^{* *} \\
(0.196)\end{array}$ & $\begin{array}{c}-0.186+ \\
(0.107)\end{array}$ & $\begin{array}{l}-0.140 \\
(0.114)\end{array}$ & $\begin{array}{r}-0.180+ \\
(0.102)\end{array}$ & $\begin{array}{r}-0.211+ \\
(0.119)\end{array}$ & $\begin{array}{c}-0.174+ \\
(0.0951)\end{array}$ & $\begin{array}{c}-0.206+ \\
(0.112)\end{array}$ & $\begin{array}{c}-0.374^{* *} \\
(0.145)\end{array}$ & $\begin{array}{c}-0.349^{*} \\
(0.146)\end{array}$ & $\begin{array}{c}-0.346^{* *} \\
(0.133)\end{array}$ & $\begin{array}{l}-0.420^{*} \\
(0.166)\end{array}$ & $\begin{array}{c}-0.314^{* *} \\
(0.120)\end{array}$ & $\begin{array}{c}-0.391^{* *} \\
(0.146)\end{array}$ \\
\hline Ex-Irish & $\begin{array}{c}1.310^{* *} \\
(0.282)\end{array}$ & $\begin{array}{c}1.118^{* *} \\
(0.334)\end{array}$ & $\begin{array}{l}1.127^{* *} \\
(0.253)\end{array}$ & $\begin{array}{c}1.058^{* *} \\
(0.333)\end{array}$ & $\begin{array}{c}0.925^{* *} \\
(0.242)\end{array}$ & $\begin{array}{c}0.863^{* *} \\
(0.291)\end{array}$ & $\begin{array}{l}0.437^{*} \\
(0.196)\end{array}$ & $\begin{array}{l}0.445^{*} \\
(0.203)\end{array}$ & $\begin{array}{l}0.423^{*} \\
(0.186)\end{array}$ & $\begin{array}{l}0.554^{*} \\
(0.233)\end{array}$ & $\begin{array}{l}0.402^{*} \\
(0.167)\end{array}$ & $\begin{array}{l}0.536^{*} \\
(0.217)\end{array}$ & $\begin{array}{c}0.778^{* *} \\
(0.253)\end{array}$ & $\begin{array}{c}0.712^{* *} \\
(0.270)\end{array}$ & $\begin{array}{c}0.702^{* *} \\
(0.234)\end{array}$ & $\begin{array}{l}0.608+ \\
(0.328)\end{array}$ & $\begin{array}{c}0.612^{* *} \\
(0.214)\end{array}$ & $\begin{array}{l}0.566+ \\
(0.292)\end{array}$ \\
\hline Ex's - 30d & $\begin{array}{l}-0.147 \\
(0.130)\end{array}$ & $\begin{array}{c}-0.204+ \\
(0.112)\end{array}$ & $\begin{array}{l}-0.152 \\
(0.115)\end{array}$ & $\begin{array}{c}-0.299^{*} \\
(0.124)\end{array}$ & $\begin{array}{c}-0.176+ \\
(0.102)\end{array}$ & $\begin{array}{l}-0.302^{*} \\
(0.117)\end{array}$ & $\begin{array}{l}-0.0270 \\
(0.0703)\end{array}$ & $\begin{array}{l}-0.0674 \\
(0.0611)\end{array}$ & $\begin{array}{l}-0.0257 \\
(0.0678)\end{array}$ & $\begin{array}{l}-0.158^{*} \\
(0.0754)\end{array}$ & $\begin{array}{l}-0.0247 \\
(0.0634)\end{array}$ & $\begin{array}{l}-0.148^{*} \\
(0.0699)\end{array}$ & $\begin{array}{c}0.0227 \\
(0.0738)\end{array}$ & $\begin{array}{l}-0.0513 \\
(0.0663)\end{array}$ & $\begin{array}{c}0.0197 \\
(0.0687)\end{array}$ & $\begin{array}{l}-0.158 \\
(0.105)\end{array}$ & $\begin{array}{c}0.0203 \\
(0.0626)\end{array}$ & $\begin{array}{c}-0.145 \\
(0.0972)\end{array}$ \\
\hline Cm's - 30d & $\begin{array}{l}-0.0654 \\
(0.0722)\end{array}$ & $\begin{array}{l}-0.121+ \\
(0.0697)\end{array}$ & $\begin{array}{l}-0.0574 \\
(0.0646)\end{array}$ & $\begin{array}{l}-0.184^{*} \\
(0.0888)\end{array}$ & $\begin{array}{l}-0.0532 \\
(0.0562)\end{array}$ & $\begin{array}{l}-0.149+ \\
(0.0821)\end{array}$ & $\begin{array}{l}0.105^{* *} \\
(0.0267)\end{array}$ & $\begin{array}{l}0.0967^{* *} \\
(0.0355)\end{array}$ & $\begin{array}{l}0.101^{* *} \\
(0.0248)\end{array}$ & $\begin{array}{l}-0.0177 \\
(0.0470)\end{array}$ & $\begin{array}{c}0.0926^{* *} \\
(0.0234)\end{array}$ & $\begin{array}{l}-0.0170 \\
(0.0432)\end{array}$ & $\begin{array}{l}0.0988^{* *} \\
(0.0255)\end{array}$ & $\begin{array}{l}0.0877^{* *} \\
(0.0258)\end{array}$ & $\begin{array}{l}0.0898^{* *} \\
(0.0235)\end{array}$ & $\begin{array}{l}-0.0850^{*} \\
(0.0414)\end{array}$ & $\begin{array}{l}0.0775^{* *} \\
(0.0218)\end{array}$ & $\begin{array}{l}-0.0780^{*} \\
(0.0374)\end{array}$ \\
\hline$\Delta$ Log Casualties & $\begin{array}{c}0.0721 \\
(0.0595)\end{array}$ & $\begin{array}{c}0.0552 \\
(0.0596)\end{array}$ & $\begin{array}{c}0.0618 \\
(0.0539)\end{array}$ & $\begin{array}{c}0.0471 \\
(0.0663)\end{array}$ & $\begin{array}{c}0.0448 \\
(0.0501)\end{array}$ & $\begin{array}{c}0.0423 \\
(0.0597)\end{array}$ & $\begin{array}{l}0.0748^{*} \\
(0.0292)\end{array}$ & $\begin{array}{l}0.0829^{* *} \\
(0.0267)\end{array}$ & $\begin{array}{l}0.0726^{*} \\
(0.0284)\end{array}$ & $\begin{array}{l}0.113^{* *} \\
(0.0275)\end{array}$ & $\begin{array}{l}0.0689^{*} \\
(0.0268)\end{array}$ & $\begin{array}{l}0.108^{* *} \\
(0.0262)\end{array}$ & $\begin{array}{l}0.0663+ \\
(0.0388)\end{array}$ & $\begin{array}{l}0.0751^{*} \\
(0.0342)\end{array}$ & $\begin{array}{c}0.0574 \\
(0.0365)\end{array}$ & $\begin{array}{l}0.106^{* *} \\
(0.0362)\end{array}$ & $\begin{array}{c}0.0466 \\
(0.0334)\end{array}$ & $\begin{array}{l}0.0901^{* *} \\
(0.0344)\end{array}$ \\
\hline $\begin{array}{l}\Delta \text { Log Casualties } \\
30 \text { Days Ago }\end{array}$ & $\begin{array}{l}0.163^{* *} \\
(0.0613)\end{array}$ & $\begin{array}{c}0.148^{*} \\
(0.0602)\end{array}$ & $\begin{array}{l}0.150^{* *} \\
(0.0529)\end{array}$ & $\begin{array}{l}0.175^{* *} \\
(0.0566)\end{array}$ & $\begin{array}{c}0.113^{*} \\
(0.0472)\end{array}$ & $\begin{array}{l}0.142^{* *} \\
(0.0498)\end{array}$ & $\begin{array}{c}0.0719^{* *} \\
(0.0275)\end{array}$ & $\begin{array}{c}0.0739^{* *} \\
(0.0273)\end{array}$ & $\begin{array}{c}0.0704^{* *} \\
(0.0266)\end{array}$ & $\begin{array}{l}0.116^{* *} \\
(0.0292)\end{array}$ & $\begin{array}{c}0.0684^{* *} \\
(0.0248)\end{array}$ & $\begin{array}{l}0.114^{* *} \\
(0.0279)\end{array}$ & $\begin{array}{l}0.100^{* *} \\
(0.0344)\end{array}$ & $\begin{array}{l}0.108^{* *} \\
(0.0391)\end{array}$ & $\begin{array}{l}0.0934^{* *} \\
(0.0334)\end{array}$ & $\begin{array}{l}0.141^{* *} \\
(0.0439)\end{array}$ & $\begin{array}{c}0.0848^{* *} \\
(0.0321)\end{array}$ & $\begin{array}{l}0.128^{* *} \\
(0.0410)\end{array}$ \\
\hline Division and Year FE & Y & $\mathrm{Y}$ & Y & $\mathrm{Y}$ & Y & $\mathrm{Y}$ & Y & $\mathrm{Y}$ & Y & Y & $\mathrm{Y}$ & Y & $\mathrm{Y}$ & $\mathrm{Y}$ & Y & $\mathrm{Y}$ & Y & $\mathrm{Y}$ \\
\hline Additional Controls & $\mathrm{N}$ & $\mathrm{Y}$ & $\mathrm{N}$ & $\mathrm{Y}$ & $\mathrm{N}$ & $\mathrm{Y}$ & $\mathrm{N}$ & $\mathrm{Y}$ & $\mathrm{N}$ & $\mathrm{Y}$ & $\mathrm{N}$ & $\mathrm{Y}$ & $\mathrm{N}$ & $\mathrm{Y}$ & $\mathrm{N}$ & $\mathrm{Y}$ & $\mathrm{N}$ & $\mathrm{Y}$ \\
\hline $\mathrm{N}$ & 536 & 536 & 536 & 536 & 536 & 536 & 1640 & 1640 & 1640 & 1640 & 1640 & 1640 & 1654 & 1654 & 1654 & 1654 & 1654 & 1654 \\
\hline
\end{tabular}

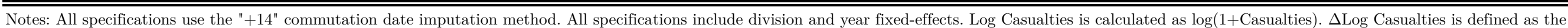

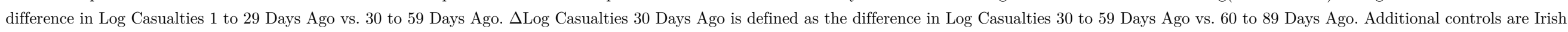

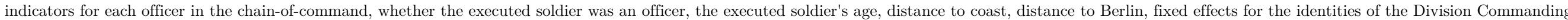

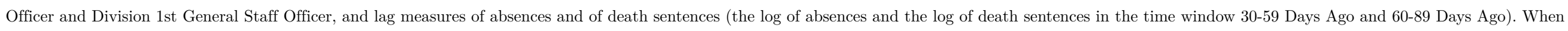

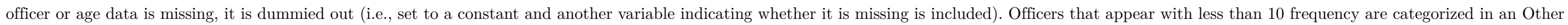

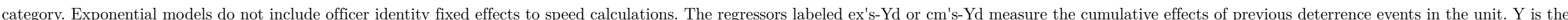

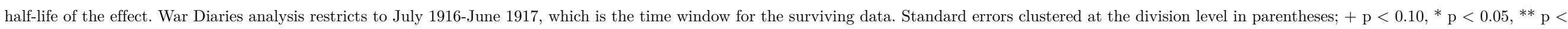
0.01 
Appendix Table 11: Effects of Execution vs. Commutation on Elapsed Time Until Next Absence, Full Sample, Weak SUTVA (Hazard coefficients)

\begin{tabular}{|c|c|c|c|c|c|c|c|c|c|c|c|c|c|c|c|c|c|c|}
\hline & \multicolumn{6}{|c|}{ War Diaries } & \multicolumn{6}{|c|}{ Police Gazettes } & \multicolumn{6}{|c|}{ FGCM Trial Registries (Desertion Trials) } \\
\hline & $(1)$ & $(2)$ & (3) & $(4)$ & $(5)$ & (6) & $(7)$ & $(8)$ & (9) & $(10)$ & $(11)$ & $(12)$ & $(13)$ & $(14)$ & $(15)$ & $(16)$ & $(17)$ & $(18)$ \\
\hline Execution & $\begin{array}{c}0.659 \\
(0.485)\end{array}$ & $\begin{array}{c}0.680 \\
(0.541)\end{array}$ & $\begin{array}{c}0.688 \\
(0.536)\end{array}$ & $\begin{array}{c}0.695 \\
(0.515)\end{array}$ & $\begin{array}{c}0.691 \\
(0.484)\end{array}$ & $\begin{array}{c}0.681 \\
(0.462)\end{array}$ & $\begin{array}{c}0.689 \\
(0.267)\end{array}$ & $\begin{array}{c}0.580 \\
(0.306)\end{array}$ & $\begin{array}{c}0.599 \\
(0.297)\end{array}$ & $\begin{array}{c}0.622 \\
(0.278)\end{array}$ & $\begin{array}{c}0.650 \\
(0.264)\end{array}$ & $\begin{array}{c}0.663 \\
(0.260)\end{array}$ & $\begin{array}{c}0.492 \\
(0.257)\end{array}$ & $\begin{array}{c}0.399 \\
(0.279)\end{array}$ & $\begin{array}{c}0.408 \\
(0.276)\end{array}$ & $\begin{array}{c}0.425 \\
(0.264)\end{array}$ & $\begin{array}{c}0.454 \\
(0.257)\end{array}$ & $\begin{array}{c}0.471 \\
(0.255)\end{array}$ \\
\hline Ex-Desert & $\begin{array}{c}0.997 \\
(0.743)\end{array}$ & $\begin{array}{c}0.971 \\
(0.757)\end{array}$ & $\begin{array}{c}0.966 \\
(0.735)\end{array}$ & $\begin{array}{c}0.972 \\
(0.708)\end{array}$ & $\begin{array}{c}0.998 \\
(0.695)\end{array}$ & $\begin{array}{c}1.017 \\
(0.695)\end{array}$ & $\begin{array}{c}1.285 \\
(0.543)\end{array}$ & $\begin{array}{c}1.366 \\
(0.767)\end{array}$ & $\begin{array}{c}1.329 \\
(0.703)\end{array}$ & $\begin{array}{c}1.294 \\
(0.621)\end{array}$ & $\begin{array}{c}1.264 \\
(0.557)\end{array}$ & $\begin{array}{c}1.257 \\
(0.535)\end{array}$ & $\begin{array}{c}1.556 \\
(0.864)\end{array}$ & $\begin{array}{l}1.679 \\
(1.245)\end{array}$ & $\begin{array}{c}1.655 \\
(1.184)\end{array}$ & $\begin{array}{c}1.607 \\
(1.065)\end{array}$ & $\begin{array}{c}1.537 \\
(0.933)\end{array}$ & $\begin{array}{l}1.508 \\
(0.874)\end{array}$ \\
\hline Irish & $\begin{array}{l}0.483^{* *} \\
(0.0867)\end{array}$ & $\begin{array}{l}0.465^{* *} \\
(0.0840)\end{array}$ & $\begin{array}{l}0.457^{* *} \\
(0.0867)\end{array}$ & $\begin{array}{l}0.440^{* *} \\
(0.0931)\end{array}$ & $\begin{array}{l}0.428^{* *} \\
(0.0964)\end{array}$ & $\begin{array}{l}0.434^{* *} \\
(0.0951)\end{array}$ & $\begin{array}{c}0.836 \\
(0.0910)\end{array}$ & $\begin{array}{c}0.854 \\
(0.0936)\end{array}$ & $\begin{array}{c}0.842 \\
(0.0914)\end{array}$ & $\begin{array}{c}0.830+ \\
(0.0886)\end{array}$ & $\begin{array}{c}0.828+ \\
(0.0890)\end{array}$ & $\begin{array}{c}0.831+ \\
(0.0901)\end{array}$ & $\begin{array}{c}0.702^{*} \\
(0.0992)\end{array}$ & $\begin{array}{l}0.704^{*} \\
(0.101)\end{array}$ & $\begin{array}{l}0.695^{*} \\
(0.100)\end{array}$ & $\begin{array}{l}0.688^{* *} \\
(0.0997)\end{array}$ & $\begin{array}{c}0.693^{*} \\
(0.0999)\end{array}$ & $\begin{array}{l}0.699^{*} \\
(0.100)\end{array}$ \\
\hline Ex-Irish & $\begin{array}{c}3.252^{* *} \\
(0.926)\end{array}$ & $\begin{array}{c}3.492^{* *} \\
(1.126)\end{array}$ & $\begin{array}{l}3.511^{* *} \\
(1.078)\end{array}$ & $\begin{array}{c}3.689^{* *} \\
(1.038)\end{array}$ & $\begin{array}{l}3.877^{* *} \\
(1.045)\end{array}$ & $\begin{array}{c}3.833^{* *} \\
(1.026)\end{array}$ & $\begin{array}{l}1.539^{*} \\
(0.302)\end{array}$ & $\begin{array}{l}1.541^{*} \\
(0.324)\end{array}$ & $\begin{array}{l}1.553^{*} \\
(0.313)\end{array}$ & $\begin{array}{l}1.548^{*} \\
(0.304)\end{array}$ & $\begin{array}{l}1.528^{*} \\
(0.299)\end{array}$ & $\begin{array}{l}1.522^{*} \\
(0.298)\end{array}$ & $\begin{array}{c}2.050^{* *} \\
(0.498)\end{array}$ & $\begin{array}{c}2.066^{* *} \\
(0.537)\end{array}$ & $\begin{array}{c}2.117^{* *} \\
(0.541)\end{array}$ & $\begin{array}{c}2.177^{* *} \\
(0.551)\end{array}$ & $\begin{array}{c}2.170^{* *} \\
(0.544)\end{array}$ & $\begin{array}{r}2.141^{* *} \\
(0.533)\end{array}$ \\
\hline$\Delta$ Log Casualties & $\begin{array}{c}1.091 \\
(0.0657)\end{array}$ & $\begin{array}{c}1.084 \\
(0.0653)\end{array}$ & $\begin{array}{c}1.081 \\
(0.0648)\end{array}$ & $\begin{array}{c}1.075 \\
(0.0639)\end{array}$ & $\begin{array}{c}1.064 \\
(0.0635)\end{array}$ & $\begin{array}{c}1.059 \\
(0.0638)\end{array}$ & $\begin{array}{l}1.055+ \\
(0.0318)\end{array}$ & $\begin{array}{l}1.077^{* *} \\
(0.0289)\end{array}$ & $\begin{array}{l}1.080^{* *} \\
(0.0303)\end{array}$ & $\begin{array}{c}1.078^{*} \\
(0.0315)\end{array}$ & $\begin{array}{c}1.071^{*} \\
(0.0315)\end{array}$ & $\begin{array}{c}1.065^{*} \\
(0.0312)\end{array}$ & $\begin{array}{c}1.043 \\
(0.0431)\end{array}$ & $\begin{array}{c}1.062 \\
(0.0394)\end{array}$ & $\begin{array}{l}1.068+ \\
(0.0406)\end{array}$ & $\begin{array}{c}1.068+ \\
(0.0416)\end{array}$ & $\begin{array}{c}1.062 \\
(0.0418)\end{array}$ & $\begin{array}{c}1.056 \\
(0.0420)\end{array}$ \\
\hline $\begin{array}{c}\Delta \text { Log Casualties } \\
30 \text { Days Ago }\end{array}$ & $\begin{array}{l}1.185^{* *} \\
(0.0675)\end{array}$ & $\begin{array}{l}1.187^{* *} \\
(0.0697)\end{array}$ & $\begin{array}{l}1.184^{* *} \\
(0.0702)\end{array}$ & $\begin{array}{l}1.176^{* *} \\
(0.0717)\end{array}$ & $\begin{array}{c}1.164^{*} \\
(0.0735)\end{array}$ & $\begin{array}{l}1.157^{*} \\
(0.0740)\end{array}$ & $\begin{array}{l}1.067^{*} \\
(0.0305)\end{array}$ & $\begin{array}{l}1.064^{*} \\
(0.0293)\end{array}$ & $\begin{array}{c}1.070^{*} \\
(0.0291)\end{array}$ & $\begin{array}{l}1.075^{* *} \\
(0.0295)\end{array}$ & $\begin{array}{l}1.073^{* *} \\
(0.0295)\end{array}$ & $\begin{array}{l}1.071^{*} \\
(0.0294)\end{array}$ & $\begin{array}{l}1.089^{*} \\
(0.0403)\end{array}$ & $\begin{array}{c}1.086^{*} \\
(0.0388)\end{array}$ & $\begin{array}{l}1.097^{* *} \\
(0.0384)\end{array}$ & $\begin{array}{l}1.106^{* *} \\
(0.0381)\end{array}$ & $\begin{array}{l}1.104^{* *} \\
(0.0378)\end{array}$ & $\begin{array}{l}1.099^{* *} \\
(0.0377)\end{array}$ \\
\hline Ex's $-7 d$ & & $\begin{array}{c}0.840 \\
(0.177)\end{array}$ & & & & & & $\begin{array}{l}1.239^{*} \\
(0.116)\end{array}$ & & & & & & $\begin{array}{l}1.428^{* *} \\
(0.166)\end{array}$ & & & & \\
\hline Ex's - 14d & & & $\begin{array}{c}0.876 \\
(0.134)\end{array}$ & & & & & & $\begin{array}{c}1.088 \\
(0.0857)\end{array}$ & & & & & & $\begin{array}{l}1.188+ \\
(0.107)\end{array}$ & & & \\
\hline Cm's - 14d & & & $\begin{array}{c}0.954 \\
(0.102)\end{array}$ & & & & & & $\begin{array}{l}1.169^{* *} \\
(0.0448)\end{array}$ & & & & & & $\begin{array}{l}1.150^{* *} \\
(0.0378)\end{array}$ & & & \\
\hline Ex's - 30d & & & & $\begin{array}{c}0.871 \\
(0.112)\end{array}$ & & & & & & $\begin{array}{c}0.973 \\
(0.0685)\end{array}$ & & & & & & $\begin{array}{c}1.022 \\
(0.0755)\end{array}$ & & \\
\hline Cm's - 30d & & & & $\begin{array}{c}0.935 \\
(0.0672)\end{array}$ & & & & & & $\begin{array}{l}1.111^{* *} \\
(0.0296)\end{array}$ & & & & & & $\begin{array}{l}1.104^{* *} \\
(0.0282)\end{array}$ & & \\
\hline Ex's - 60d & & & & & $\begin{array}{c}0.830 \\
(0.109)\end{array}$ & & & & & & $\begin{array}{c}0.929 \\
(0.0597)\end{array}$ & & & & & & $\begin{array}{c}0.962 \\
(0.0642)\end{array}$ & \\
\hline Cm's - 60d & & & & & $\begin{array}{c}0.917 \\
(0.0499)\end{array}$ & & & & & & $\begin{array}{l}1.067^{* *} \\
(0.0225)\end{array}$ & & & & & & $\begin{array}{l}1.064^{* *} \\
(0.0219)\end{array}$ & \\
\hline Ex's - 90d & & & & & & $\begin{array}{c}0.806 \\
(0.106)\end{array}$ & & & & & & $\begin{array}{c}0.918 \\
(0.0573)\end{array}$ & & & & & & $\begin{array}{c}0.945 \\
(0.0615)\end{array}$ \\
\hline Cm's - 90d & & & & & & $\begin{array}{c}0.914+ \\
(0.0437) \\
\end{array}$ & & & & & & $\begin{array}{l}1.047^{*} \\
(0.0199) \\
\end{array}$ & & & & & & $\begin{array}{c}1.043^{*} \\
(0.0189) \\
\end{array}$ \\
\hline
\end{tabular}

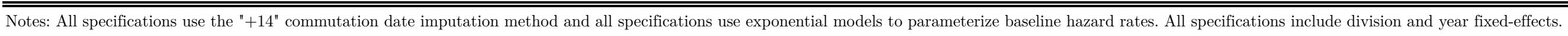

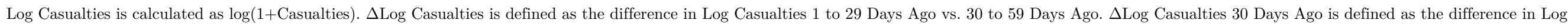

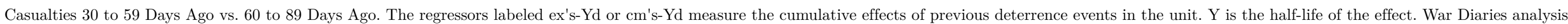
restricts to July 1916-June 1917, which is the time window for the surviving data. Standard errors clustered at the division level in parentheses; $+\mathrm{p}<0.10, * \mathrm{p}<0.05,{ }^{* *} \mathrm{p}<0.01$ 
Appendix Table 12: Effects of Executions vs. Commutations on Elapsed Time Until Next Absence Differing by Individual or Environmental Characteristics

\begin{tabular}{|c|c|c|c|c|c|c|c|c|c|c|c|c|c|c|c|c|c|c|c|c|c|}
\hline & \multicolumn{7}{|c|}{ War Diaries } & \multicolumn{7}{|c|}{ Police Gazette } & \multicolumn{7}{|c|}{ FGCM Trial Registries (Desertion Trials) } \\
\hline & $(1)$ & $(2)$ & (3) & $(4)$ & (5) & (6) & $(7)$ & (8) & (9) & $(10)$ & $(11)$ & $(12)$ & $(13)$ & $(14)$ & $(15)$ & $(16)$ & $(17)$ & $(18)$ & $(19)$ & $(20)$ & $(21)$ \\
\hline Execution & $\begin{array}{c}0.109 \\
(0.260)\end{array}$ & $\begin{array}{c}0.240 \\
(0.222)\end{array}$ & $\begin{array}{c}0.261 \\
(0.214)\end{array}$ & $\begin{array}{l}-1.040 \\
(0.778)\end{array}$ & $\begin{array}{l}13.53+ \\
(7.019)\end{array}$ & $\begin{array}{l}-27.20 \\
(21.87)\end{array}$ & & $\begin{array}{l}0.0463 \\
(0.156)\end{array}$ & $\begin{array}{l}-0.357 \\
(0.239)\end{array}$ & $\begin{array}{l}-0.448 \\
(0.385)\end{array}$ & $\begin{array}{l}-0.454 \\
(0.605)\end{array}$ & $\begin{array}{c}2.367 \\
(1.506)\end{array}$ & $\begin{array}{l}-4.031 \\
(2.908)\end{array}$ & & $\begin{array}{l}-0.200 \\
(0.295)\end{array}$ & $\begin{array}{l}-0.321 \\
(0.309)\end{array}$ & $\begin{array}{l}-0.483 \\
(0.506)\end{array}$ & $\begin{array}{r}-2.128+ \\
(1.096)\end{array}$ & $\begin{array}{l}1.870^{*} \\
(0.743)\end{array}$ & $\begin{array}{l}4.112 \\
(4.648)\end{array}$ & \\
\hline Ex-Casualties & $\begin{array}{l}-0.0629 \\
(0.0672)\end{array}$ & & & & & & & $\begin{array}{l}-0.0493 \\
(0.0464)\end{array}$ & & & & & & & $\begin{array}{l}-0.0204 \\
(0.0638)\end{array}$ & & & & & & \\
\hline Ex-Distance to Coast & & $\begin{array}{l}-0.00492 \\
(0.00312)\end{array}$ & & & & & & & $\begin{array}{c}0.00287 \\
(0.00298)\end{array}$ & & & & & & & $\begin{array}{c}0.000282 \\
(0.00424)\end{array}$ & & & & & \\
\hline Ex-Distance to Berlin & & ? & $\begin{array}{l}0.000654- \\
0.000390\end{array}$ & & & & & & & $\begin{array}{l}0.000414 \\
0.000519\end{array}$ & & & & & & & $\begin{array}{l}0.000255 \\
0.000703\end{array}$ & & & & \\
\hline Ex-Private & & & & $\begin{array}{c}0.990 \\
(0.760)\end{array}$ & & & & & & & $\begin{array}{c}0.302 \\
(0.623)\end{array}$ & & & & & & & $\begin{array}{l}1.919+ \\
(1.121)\end{array}$ & & & \\
\hline Ex-Age & & & & & $\begin{array}{c}-0.620^{*} \\
(0.279)\end{array}$ & & & & & & & $\begin{array}{l}-0.0913 \\
(0.0558)\end{array}$ & & & & & & & $\begin{array}{r}-0.0506+ \\
(0.0260)\end{array}$ & & \\
\hline Ex-Time & & & & & & $\begin{array}{l}-0.00172 \\
(0.00139)\end{array}$ & & & & & & & $\begin{array}{l}-0.000244 \\
0.000184\end{array}$ & & & & & & & $\begin{array}{l}0.000281 \\
0.000294\end{array}$ & \\
\hline Ex-Regular Army & & & & & & & $\begin{array}{l}0.441^{*} \\
(0.192)\end{array}$ & & & & & & & $\begin{array}{c}-0.0889 \\
(0.188)\end{array}$ & & & & & & & $\begin{array}{l}-0.202 \\
(0.181)\end{array}$ \\
\hline Ex-Territorial Army & & & & & & & $\begin{array}{l}0.0560 \\
(0.350) \\
\end{array}$ & & & & & & & $\begin{array}{r}-0.232+ \\
(0.127) \\
\end{array}$ & & & & & & & $\begin{array}{r}-0.0432 \\
(0.222) \\
\end{array}$ \\
\hline $\mathrm{N}$ & 536 & 536 & 536 & 536 & 536 & 536 & 536 & 1640 & 1640 & 1640 & 1640 & 1640 & 1640 & 1640 & 1654 & 1654 & 1654 & 1654 & 1654 & 1654 & 1654 \\
\hline
\end{tabular}

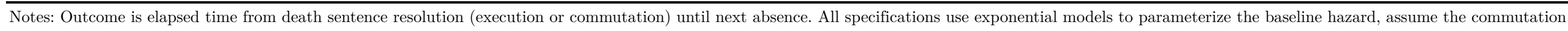

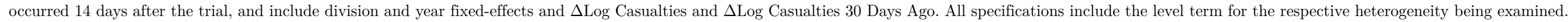

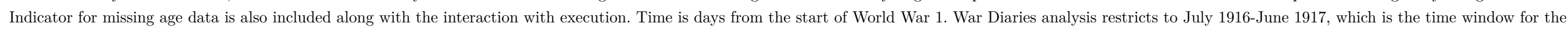
surviving data. Standard errors clustered at the division level in parentheses; $+\mathrm{p}<0.10,{ }^{*} \mathrm{p}<0.05,{ }^{* *} \mathrm{p}<0.01$ 


\% of Next Desertion Trial Resulting in a Death Sentence

\section{Panel A: +14 Imputation}

\section{All Death Sentences}

Irish Execution

Non-Irish Execution

Irish Commutation

Non-Irish Commutation

\section{All Desertion Trials}

$13.8 \%$

$18.3 \%$

$22.5 \%$

$22.9 \%$
Irish Desertion Trials

$19.6 \%$

$20.1 \%$

$22.0 \%$

$18.7 \%$

\section{Desertion Death Sentences}

Irish Execution

Non-Irish Execution

Irish Commutation

Non-Irish Commutation

Panel B: NN Imputation

\section{All Death Sentences}

Irish Execution

$\begin{array}{ll}12.1 \% & 16.1 \% \\ 17.4 \% & 19.1 \% \\ 21.6 \% & 19.6 \% \\ 22.0 \% & 17.0 \%\end{array}$

Non-Irish Execution

$9.1 \%$

Irish Commutation

$17.0 \%$

Non-Irish Commutation

\section{Desertion Death Sentences}

Irish Execution

Non-Irish Execution

Irish Commutation

Non-Irish Commutation

$\begin{array}{ll}12.5 \% & 14.9 \% \\ 18.3 \% & 19.7 \% \\ 21.8 \% & 19.8 \% \\ 20.6 \% & 15.4 \%\end{array}$

\section{All Death Sentences}

Irish Execution

$13.8 \%$

$23.3 \%$

$19.5 \%$

$19.9 \%$

$\begin{array}{ll}14.6 \% & 12.8 \% \\ 23.0 \% & 18.4 \% \\ 18.0 \% & 22.6 \% \\ 19.5 \% & 15.3 \%\end{array}$

$14.3 \%$

$18.0 \%$

$21.2 \%$

$16.6 \%$
$15.3 \%$

Non-Irish Commutation

Desertion Death Sentences

Irish Execution

Non-Irish Execution

$\begin{array}{llr}\text { Irish Commutation } & 18.0 \% & 22.6 \% \\ \text { Non-Irish Commutation } & 19.5 \% & 15.3 \%\end{array}$

Notes: In panels sub-titled "+14", the announcement of the commutation is assumed to occur 14 days after trial. In panels subtitled "NN" the nearest-neighbor method is used, which means the imputed announcement of the commutation is same as the most nearby execution announcement, while in panels labeled " $\mathrm{C}=\mathrm{T}$ ", the trial date is used as the announcement date of the execution and commutation. 
Appendix Table 14: Effects of Executions vs. Commutations on Elapsed Time Until Next Absence Differing by whether Case was a Desertion Trial and whether Soldier was Irish

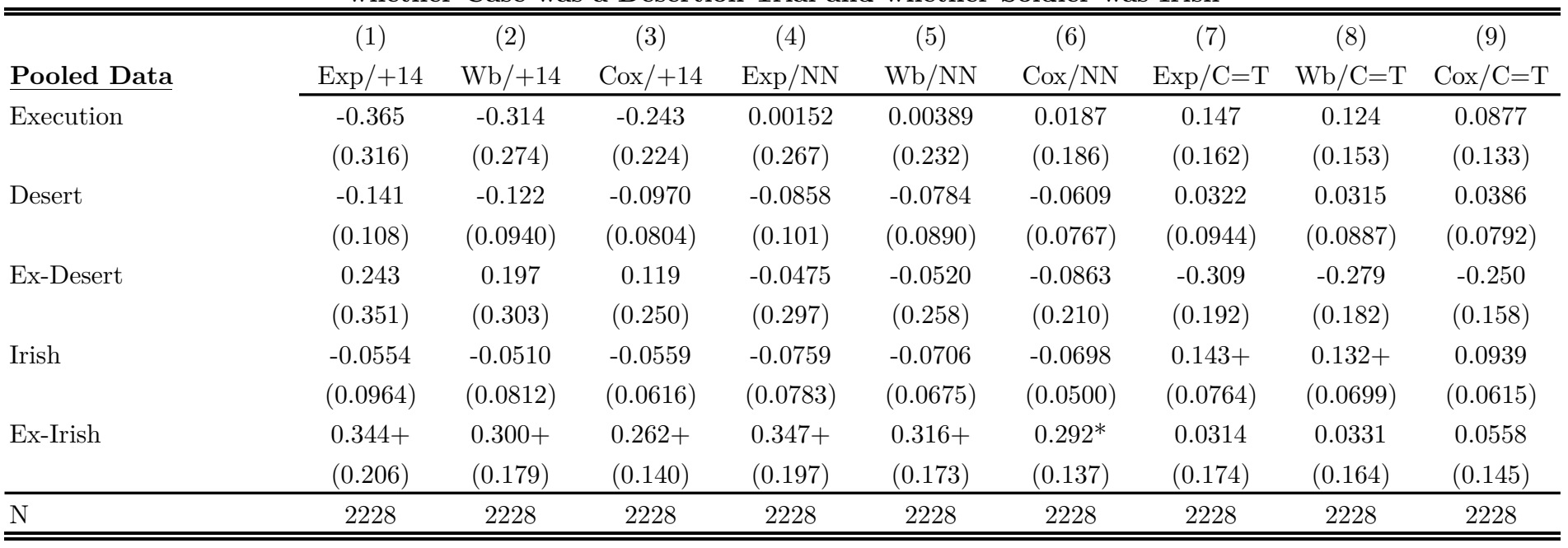

Notes: Outcome is elapsed time from death sentence resolution (execution or commutation) until next absence. "Exp", "Wb" and "Cox" use the exponential, Weibull and Cox models respectively to parameterize the baseline hazard. In columns sub-titled "+14", the announcement of the commutation is assumed to occur 14 days after trial. In columns subtitled "NN" the nearest-neighbor method is used, which means the imputed announcement of the commutation is same as the most nearby execution announcement, while in columns labeled " $\mathrm{C}=\mathrm{T}$ ", the trial date is used as the announcement date of the execution and commutation. All specifications include division and year fixed-effects and $\Delta$ Log Casualties and $\Delta$ Log Casualties 30 Days Ago. Death sentences that precede another death sentence instead of an absence and death sentences that precede the end of the war are treated as censored events. Standard errors clustered at the division level in parentheses; $+\mathrm{p}<0.10,{ }^{*} \mathrm{p}<0.05,{ }^{*} * \mathrm{p}<0.01$ 


\begin{tabular}{|c|c|c|c|c|c|c|c|c|c|c|}
\hline & (1) & (2) & $(3)$ & (4) & (5) & (6) & (7) & (8) & (9) & (10) \\
\hline \multirow[t]{2}{*}{ Private } & -0.0989 & & & & & & & & & 0.0100 \\
\hline & $(0.0742)$ & & & & & & & & & $(0.0576)$ \\
\hline \multirow[t]{2}{*}{ Age } & & -0.00746 & & & & & & & & 0.00201 \\
\hline & & $(0.00631)$ & & & & & & & & $(0.00726)$ \\
\hline \multirow[t]{2}{*}{ New Army } & & & & & & & 0.0585 & & & \\
\hline & & & & & & & $(0.0535)$ & & & \\
\hline \multirow[t]{2}{*}{ Territorial Army } & & & & & & & 0.0252 & & & \\
\hline & & & & & & & $(0.0538)$ & & & \\
\hline \multirow[t]{2}{*}{ Desert } & & & & & & & & 0.247 & & 0.116 \\
\hline & & & & & & & & $(0.165)$ & & $(0.114)$ \\
\hline \multirow[t]{2}{*}{ Coward } & & & & & & & & 0.103 & & 0.0158 \\
\hline & & & & & & & & $(0.174)$ & & $(0.119)$ \\
\hline \multirow[t]{2}{*}{ Disobedience } & & & & & & & & 0.0226 & & -0.0116 \\
\hline & & & & & & & & $(0.195)$ & & $(0.133)$ \\
\hline \multirow[t]{2}{*}{ Murder } & & & & & & & & $1.096^{* *}$ & & $0.561^{* *}$ \\
\hline & & & & & & & & $(0.235)$ & & $(0.163)$ \\
\hline \multirow[t]{2}{*}{ Mutiny } & & & & & & & & 0.131 & & 0.0181 \\
\hline & & & & & & & & $(0.238)$ & & $(0.164)$ \\
\hline \multirow[t]{2}{*}{ Quit } & & & & & & & & 0.125 & & 0.00325 \\
\hline & & & & & & & & $(0.204)$ & & $(0.141)$ \\
\hline \multirow[t]{2}{*}{ Sleep } & & & & & & & & 0.0551 & & 0.0602 \\
\hline & & & & & & & & $(0.171)$ & & $(0.118)$ \\
\hline \multirow[t]{2}{*}{ Striking } & & & & & & & & 0.229 & & 0.178 \\
\hline & & & & & & & & $(0.211)$ & & $(0.144)$ \\
\hline \multirow[t]{2}{*}{ Rape } & & & & & & & & 0.0123 & & 0.0275 \\
\hline & & & & & & & & $(0.216)$ & & $(0.149)$ \\
\hline \multirow[t]{2}{*}{$\Delta$ Log Casualties } & & & & & & & & & $0.0332^{*}$ & 0.0136 \\
\hline & & & & & & & & & $(0.0141)$ & $(0.00950)$ \\
\hline \multirow{2}{*}{$\begin{array}{l}\Delta \text { Log Casualties } \\
30 \text { Days Ago }\end{array}$} & & & & & & & & & 0.0121 & 0.00114 \\
\hline & & & & & & & & & $(0.0133)$ & $(0.00898)$ \\
\hline \multirow[t]{2}{*}{ Distance to Coast } & & & & & & & & & & -0.130 \\
\hline & & & & & & & & & & $(0.501)$ \\
\hline \multirow[t]{2}{*}{ Distance to Berlin } & & & & & & & & & & 0.848 \\
\hline & & & & & & & & & & $(0.874)$ \\
\hline Year Fixed Effects & $\mathrm{N}$ & $\mathrm{N}$ & $\mathrm{Y}$ & $\mathrm{N}$ & $\mathrm{N}$ & $\mathrm{N}$ & $\mathrm{N}$ & $\mathrm{Y}$ & $\mathrm{Y}$ & $\mathrm{Y}$ \\
\hline Month Fixed Effects & $\mathrm{N}$ & $\mathrm{N}$ & $\mathrm{N}$ & $\mathrm{Y}$ & $\mathrm{N}$ & $\mathrm{N}$ & $\mathrm{N}$ & $\mathrm{N}$ & $\mathrm{N}$ & $\mathrm{N}$ \\
\hline Day Fixed Effects & $\mathrm{N}$ & $\mathrm{N}$ & $\mathrm{N}$ & $\mathrm{N}$ & $\mathrm{Y}$ & $\mathrm{N}$ & $\mathrm{N}$ & $\mathrm{N}$ & $\mathrm{N}$ & $\mathrm{N}$ \\
\hline Division Fixed Effects & $\mathrm{N}$ & $\mathrm{N}$ & $\mathrm{N}$ & $\mathrm{N}$ & $\mathrm{N}$ & $\mathrm{Y}$ & $\mathrm{N}$ & $\mathrm{Y}$ & $\mathrm{Y}$ & $\mathrm{Y}$ \\
\hline Joint Test of Fixed Effects & & & 0.399 & 0.731 & 0.0428 & 0.624 & 0.462 & & & \\
\hline Joint Test of Casualties & & & & & & & & & 0.0638 & \\
\hline Joint Test of Distance & & & & & & & & & & 0.221 \\
\hline \multirow[t]{2}{*}{ Constant } & $0.227^{* *}$ & $1.083^{* *}$ & 0.133 & $0.161^{* *}$ & $0.174^{* *}$ & $0.333+$ & $0.0962^{*}$ & 0.302 & $0.383+$ & 0.217 \\
\hline & $(0.0724)$ & $(0.167)$ & $(0.0878)$ & $(0.0613)$ & $(0.0497)$ & $(0.197)$ & $(0.0472)$ & $(0.267)$ & $(0.230)$ & $(0.684)$ \\
\hline$\overline{\mathrm{N}}$ & 466 & 466 & 466 & 466 & 466 & 466 & 406 & 466 & 466 & 466 \\
\hline R-sq & 0.004 & 0.531 & 0.009 & 0.017 & 0.028 & 0.130 & 0.004 & 0.219 & 0.148 & 0.650 \\
\hline
\end{tabular}

Notes: All regressions use ordinary least squares on death sentences occurring in France \& Flanders before the end of World War I. Death sentences recorded without Divisions or from the Labour Corps were removed. Log Casualties is calculated as $\log (1+$ Casualties $)$. $\Delta$ Log Casualties is defined as the difference in Log Casualties 1 to 29 Days Ago vs. 30 to 59 Days Ago. $\Delta$ Log Casualties 30 Days Ago is defined as the difference in Log Casualties 30 to 59 Days Ago vs. 60 to 89 Days Ago. Distances are calculated based on the soldier's unit's participation in battles and are interpolated between battles. Distances are set to missing before the first battle and after the last battle. Territorial/New/Regular Army status is not assigned for Indian, Australian, Canadian, or New Zealand Divisions. Regressions including age also dummy out age when it is missing (i.e., assign a constant and include an indicator for age being missing). Standard errors in parentheses; $+\mathrm{p}<0.10,{ }^{*} \mathrm{p}<0.05,{ }^{* *} \mathrm{p}<0.01$. Results are similar with Logit or Probit. 
Panel A:

Brigade Unit

Corp Unit

Army Unit

Brigade Commanding Officer

Division Commanding Officer

Division 1st General Staff Officer

Corp Commanding Officer

Corp 1st General Staff Officer

Army Commanding Officer

Army 1st General Staff Officer

GHQ Commanding Officer

GHQ 1st General Staff Officer

Irish Soldier x Irish Officer FE

Military Indiscipline 30-59 \& 60-89 days ago

Death Sentences 30-59 \& 60-89 days ago

Execution Rate 30-59 \& 60-89 days ago

\section{Panel B:}

Aggregation level

Division

Brigade

Corp

Army

Army Type

Joint Test of Significance

0.426

0.628

0.143

0.542

0.897

0.843

0.654

0.690

0.784

0.366

0.194

0.209

0.112

0.990

0.0409

0.132

Correlation with Lag Decision
$-0.110+$

$(0.0636)$

$-0.172+$

(0.0930)

0.0257

(0.0601)

0.0168

$(0.0555)$

$-0.0985+$

(0.0547)

0.0445

$(0.0577)$

Notes: Data is restricted to Irish death sentences occurring in France \& Flanders before the end of World War I. Death sentences recorded without Divisions or from the Labour Corps were removed. In Panel A, each row reports a separate ordinary least squares regression and tests of joint significance of the fixed effects or measures of the recent battle environment. Military indiscipline and death sentences are calculated as $\log (1+$ number $)$. Military indiscipline is the average of absentees and trials measured from the War Diaries, Police Gazettes, and FGCM trial registries. Lag execution rates is a set of controls comprising the numbers of executions and commutations within each time window. Units or officers that appeared with less than 10 frequency were categorized in a separate "other" category. All regression models include year, division, and Irish fixed effects. In Panel B, each row reports a separate ordinary least squares stacked autocorrelation regression. The strings of events within each unit were stacked and the first event within each unit was excluded as a dependent variable. If more than one event occurred on a day within a unit, the average outcome was calculated for that day. All regression models include year fixed effects and the leave-one-out mean execution rate of the unit. Standard errors in parentheses; $+\mathrm{p}<0.10,{ }^{*} \mathrm{p}<0.05,{ }^{* *} \mathrm{p}<0.01$. Results are similar with Logit or Probit. 